\title{
KNOWLEDGE-CAPITAL MEETS NEW ECONOMIC GEOGRAPHY
}

\author{
PETER EGGER \\ STEFAN GRUBER \\ MARIO LARCH \\ MICHAEL PFAFFERMAYR
}

CESIFO WORKING PAPER NO. 1432

CATEGORY 7: TRADE POLICY

MARCH 2005

\footnotetext{
An electronic version of the paper may be downloaded

- from the SSRN website: http://SSRN.com/abstract $=700641$

- from the CESifo website: www.CESifo.de
} 


\title{
KNOWLEDGE-CAPITAL MEETS NEW ECONOMIC GEOGRAPHY
}

\begin{abstract}
We incorporate the now standard knowledge-capital model of multinational firms in a new economic geography setting. The theoretical predictions of our model suggest that unskilled labor mobility leads to less concentration of production than skilled labor mobility does. This is in line with empirical evidence that agglomeration of production among European nations is less pronounced than among US regions. Our model shows that the different patterns in labor mobility can explain actual differences in the spreading of industries. According to our welfare analysis, trade liberalization is likely Pareto-improving for a larger (smaller) country with mobile unskilled (skilled) labor.

In the supplement, we investigate the sensitivity of our results in several respects. In the first section, we provide the figures of real factor rewards for the trade liberalization scenarios discussed in and underlying Figures 7 and 8 of the paper. Second, in Figures 3(n) - 5(v) (6(n) - $6 \mathrm{~b}(\mathrm{v}))$ we infer the existence, or non-existence, of each firm type separately in the $\tau-\lambda_{L}$ space ( $\tau-\lambda_{S}$-space) for country $i$ firms and all four scenarios of firm regimes. Third, we illustrate how changes in the parameters $\mu, \rho$ and $\sigma$ affect the outcome. Finally, we analyze how the asymmetric endowment with the immobile factor influences the core-periphery patterns.
\end{abstract}

JEL Code: F12, F23, R12, R13.

Keywords: knowledge-capital model, new economic geography, unskilled labor mobility, skilled labor mobility.

\author{
Peter Egger \\ Ifo Institute for Economic Research at \\ the University of Munich \\ Poschingerstr. 5 \\ 81679 Munich \\ Germany \\ egger@ifo.de \\ Mario Larch \\ Ifo Institute for Economic Research at \\ the University of Munich \\ Poschingerstr. 5 \\ 81679 Munich \\ Germany \\ larch@ifo.de
}

\author{
Stefan Gruber \\ University of Innsbruck \\ Faculty of Economics and Statistics \\ Universitaetsstr. 15 \\ 6020 Innsbruck \\ Austria \\ Stefan.Gruber@uibk.ac.at \\ Michael Pfaffermayr \\ University of Innsbruck \\ Faculty of Economics and Statistics \\ Universitaetsstr. 15 \\ 6020 Innsbruck \\ Austria \\ Michael.Pfaffermayr@uibk.ac.at
}




\section{Introduction $^{1}$}

"European nations are less specialized than US regions" (Krugman, 1991a, p. 76).

This stylized fact was recently confirmed by the study of Midelfart-Knarvik et al. (2000). Although also European agglomeration tends to increase, especially after the ratification of the Maastricht Treaty that facilitates the mobility of production factors between the EU member states (Haaland et al., 1999, Overman et al., 2001), a gap is still left between concentration in Europe and the US. This gap may be explained by multinational activity.

Since the early stages of new trade theory, the consideration of multinationals may be seen as one of the major innovations in the last two decades' economic research (Helpman, 1984, Helpman and Krugman, 1985, Markusen, 1984). From its beginning, this literature distinguishes firms by the scope of activities carried out: (i) national single plant firms engaging in trade, (ii) horizontal (two-plant) multinationals serving both the home and the foreign market locally (Markusen and Venables, 1998, 2000), and (iii) vertical multinationals with production only in the low-wage country and headquarters in the high-wage economy (Helpman, 1984). Both the horizontal and vertical model characterize multinationals by intangible assets (knowledge-capital). Only in the knowledge-capital model of multinationals and trade, all these types of firms arise endogenously and may co-exist (for an overview see Markusen, 2002), which seems well in line with the stylized facts (Carr et al. 2001, Markusen and Maskus, 2002, Egger and Pfaffermayr, 2004).

Only recently, the links between multinational production and agglomeration came into the limelight of research. Gao (1999) concentrates on vertical multinational enterprises (MNEs), which exploit international/interregional factor cost differences. There are no relative factor endowment differences between the two countries. In order to produce the differentiated good, labor and the manu-

\footnotetext{
${ }^{1}$ We are grateful to Nadia Almaraz de Neuzil, Peter Huber, Gianmarco Ottaviano and participants at research seminars at the Universities of Bologna, Ferrara and Innsbruck for useful and constructive comments.
} 
facturing composite has to be used to produce the headquarter services. The manufacturing output is furthermore used for consumption and plant set-up. He finds that agglomeration may break down with economic integration (i.e., a reduction in trade costs) or economic growth. There is no agglomeration at very low transport costs, because unskilled labor-cost differentials become more important than the agglomeration forces in shaping production structure. Concerning the introduction of vertical MNEs, he concludes that they speed up the spreading of industries and thus the process of industrialization of the periphery.

Raybaudi-Massilia (2000) concentrates on specific constellations of one- and twoplant firms. She introduces two factors, a specific one, land, and a mobile one, labor. Firms may defect from their location choice by setting up an additional plant, closing one of the two plants, or moving a plant from one region to the other. As a result, the evolution of MNEs makes agglomeration of production in only a single country/region less likely.

Ekholm and Forslid (2001) look at vertical and horizontal MNEs separately and (i) confirm Raybaudi-Massilia's (2000) finding that rising trade costs and the associated surge of horizontal MNEs lead to less agglomeration, and (ii) find that with vertical MNEs agglomeration of headquarters becomes more likely. They introduce footloose multi-region firms which are not headquartered in a specific country. This strong assumption leads to a unique symmetric equilibrium. A reallocation of unskilled labor forces firms in the receiving region to produce at a higher scale and, therefore, at lower prices. Furthermore, the smaller region engages proportionally more in headquarter services, as fixed costs are equally borne by both regions. Accordingly, real (unskilled) labor rewards are lower in the larger region.

Our approach differs from the available work in several ways. First, it incorporates the now standard model of multinationals and trade, namely the knowledgecapital model, in a new economic geography setting. Therefore, exporting enterprises (NEs) and horizontal as well as vertical MNEs may arise endogenously, ${ }^{2}$

\footnotetext{
${ }^{2}$ For instance, Ekholm and Forslid (2001) look at horizontal and vertical multi-region firm regimes, separately.
} 
which allows for a richer firm and core-periphery structure. Similar to Markusen and Venables (2000), MNEs are not footloose, but they are headquartered in one specific country where fixed costs are paid.

Second, we are interested in the dependence of agglomeration patterns on transport costs, allowing either skilled or unskilled labor to be mobile as a response to differentials in real factor rewards. ${ }^{3}$ Despite the conceptual differences to Raybaudi-Massilia (2000), horizontal MNEs make agglomeration less likely also in our framework.

In line with recent empirical evidence, we argue that the US are characterized by skilled rather than unskilled labor mobility. The results in Kennan and Walker (2003) point in this direction. For instance, they find that unfavorable local income conditions stimulate US interstate migration of skilled male workers. ${ }^{4}$

In contrast, there are mainly unskilled immigrants in Europe (see Sapir, 2000, Coppel et al., 2001). ${ }^{5}$ For instance, Constant and Massey (2003) argue that German immigrants mainly take unskilled and semi-skilled jobs shunned by natives. This is supported by the large sample study of De New and Zimmermann (1994), pointing out that immigration in Germany negatively affects the average worker's wages, leaving experienced German workers unchanged. Geddes (2003, p. 156) mentions that "migrants and their descendants in the UK are more likely found in lower-income and lower-status occupations, ...". According to Rygiel (2001), similar conclusions can be drawn for France.

Associating skilled labor mobility with the US case and unskilled labor mobility with the European case, our model provides a possible explanation for the different agglomeration patterns observed in Europe and the US. Our analysis suggests that unskilled labor mobility leads to a relatively more dispersed struc-

\footnotetext{
${ }^{3}$ In our model, agglomeration is driven by factor mobility rather than product market linkages as, e.g., in Gao (1999).

${ }^{4}$ Even at the level of international immigration, Adams (2003) reports that about two thirds of the US immigrants have at least secondary education levels.

${ }^{5}$ However, it should be noted that migration rates in Europe are generally lower than in the US (see Bentivogli and Pagano, 1999). This seems mainly due to the more rigid labor markets and the different institutional framework in Europe (see Adsera and Boix, 2000, Sapir, 2000, Puga, 2002).
} 
ture than skilled labor mobility. This fits nicely with the empirical stylized facts of both the different agglomeration patterns and the skill-specific characteristics of the mobility of workers in Europe and the US. Hence, we might conclude that these different types of factor mobility together with the activity of multinational firms are one of the driving forces behind the different agglomeration patterns observed.

Finally, we investigate the welfare consequences of trade liberalization. This is important, since, in the long run, trade costs are not necessarily fixed, but they are affected by country politics (e.g., infrastructure investments). Hence, countries may choose to liberalize trade, depending on its impact on factor migration. For the larger country, the welfare analysis suggests that trade liberalization is likely to raise both, skilled and unskilled labor wages. For low values of trade costs, both countries gain individually from further liberalizing trade, irrespective of which factor is mobile.

The paper is organized as follows. The next section introduces the model, Section 3 looks at the core-periphery patterns. The welfare effects of trade liberalization are analyzed in Section 4. In Section 5, we assess the robustness of our results with respect to changes of several decisive parameters. The last section concludes.

\section{The Model}

\subsection{Households}

There are two countries, referred to as country 1 and 2 , and indexed as $\{i, j\}=$ $\{1,2\}$. Both countries produce two tradable goods, $Z$ and $X$. $Z$ is a homogeneous good produced at constant returns to scale by a competitive industry. $X$-goods are differentiated in the usual Dixit and Stiglitz (1977) fashion. We consider the following firm types: national enterprises (NEs) sell on the local market and export to the other country, where the number of national enterprises of country $i$ is denoted by $n_{i}$; horizontal multinational enterprises (MNEs) are running production plants in both countries, where $h_{i}$ denotes the number of horizontal MNEs 
headquartered in $i$; vertical MNEs are able to unbundle the headquarter and the production plant, where $v_{i}$ is the number of vertical MNEs with headquarters in $i$ and production plants only in $j$. In contrast to horizontal MNEs, vertical ones engage in goods trade. Quantities are indexed as follows: the first subscript indicates the country where the headquarter is based, the second subscript denotes the country where the variety is sold and the superscript refers to the firm type. Therefore, $X_{i j}^{n}$ are the exports of country $i$-based NEs to country $j$ and $X_{i j}^{h}$ are sales of country $i$-based horizontal MNEs in country $j .{ }^{6}$ Similar definitions apply for the other firm types. $X_{i c}$ denotes the consumption of $X$ in country $i$, being a CES aggregate of the individual varieties. Consumer preferences are assumed to be a nest of the homogeneous $Z$-good and the differentiated $X$-good. The symmetry of varieties within a group of goods allows to formulate the utility of country $i\left(U_{i}\right)$ as follows:

$$
\begin{aligned}
U_{i} & =X_{i c}^{\mu}\left(Z_{i i}+Z_{j i}\right)^{1-\mu} \\
X_{i c} & \equiv\left[n_{i}\left(X_{i i}^{n}\right)^{\frac{\sigma-1}{\sigma}}+n_{j}\left(\frac{X_{j i}^{n}}{1+\tau}\right)^{\frac{\sigma-1}{\sigma}}+h_{i}\left(X_{i i}^{h}\right)^{\frac{\sigma-1}{\sigma}}+h_{j}\left(X_{j i}^{h}\right)^{\frac{\sigma-1}{\sigma}}\right. \\
& \left.+v_{i}\left(\frac{X_{i i}^{v}}{1+\tau}\right)^{\frac{\sigma-1}{\sigma}}+v_{j}\left(X_{j i}^{v}\right)^{\frac{\sigma-1}{\sigma}}\right]^{\frac{\sigma}{\sigma-1}},
\end{aligned}
$$

where $\mu$ denotes the Cobb-Douglas expenditure share for differentiated products, and $\sigma>1$ is the elasticity of substitution between varieties.

We assume that $Z$-goods are costlessly tradable across countries, whereas $X$ goods trade incurs iceberg transport $\operatorname{costs}(\tau)$, which are symmetric for either direction of shipment. In terms of quantity, one unit of consumption of an $X$ variety in country $j$ requires a firm in $i$ to send $(1+\tau)$ units. For convenience, quantities of $X$ are defined as (both of NEs and vertical MNEs) firm-specific productions for the respective foreign market.

As usual, the consumer's maximization problem can be solved in two steps. In the first step, each variety $X_{i j}^{k}, k \in\{n, h, v\}$, needs to be chosen such that it minimizes the cost of attaining $X_{i c}$, whatever the consumption of $X_{i c}$ is. In the second step, consumers allocate income between the $Z$-good and the composite

\footnotetext{
${ }^{6}$ Whenever we use $i$ and $j$ from the set $\{1,2\}$, this implies that $i \neq j$.
} 
$X$-good. Let $p_{j i}^{k}$ be the price of an $X$ variety in country $i$ produced by a type- $k$ firm headquartered in country $j$. The price for the homogeneous good, $q_{i}$, is indexed once, since all (indigenous and foreign) homogeneous goods consumed at a single location $i$ must face the same price $q_{i}$. We take $q_{1}$ as the numéraire. Further, $P_{i}$ denotes the price aggregator, defined as the minimum cost of buying one unit of $X_{i c}$ at prices $p_{j i}^{k}$ of an individual variety:

$$
P_{i}=\min _{X_{j i}^{k}} \sum_{i, j, k} p_{j i}^{k} X_{j i}^{k} \quad \text { s.t. } \quad X_{i c}=1 .
$$

The first-stage budgeting problem leads to:

$$
X_{j i}^{k}=\left(p_{j i}^{k}\right)^{-\sigma} P_{i}^{\sigma-1} \mu Y_{i} \quad \forall \quad i, j \in\{1,2\} \quad \wedge \quad \forall \quad k \in\{n, h, v\}
$$

where $Y_{i}$ denotes total expenditures of consumers in country $i$. Identical price elasticities of demand and identical marginal costs (technologies) within a country ensure that the price of a locally produced good is equal to the mill price for exports. Moreover, all firms producing in the same country face the same marginal costs. Hence, prices of all goods produced in one country are equal in equilibrium. $p_{i}$ denotes the price of all goods produced in country $i$. With these assumptions, the price aggregator $P_{i}$ of differentiated goods consumed in country $i$ can be written as

$$
P_{i}=\left[\left(n_{i}+h_{i}+h_{j}+v_{j}\right) p_{i}^{1-\sigma}+\left(n_{j}+v_{i}\right)\left((1+\tau) p_{j}\right)^{1-\sigma}\right]^{\frac{1}{1-\sigma}}
$$

The second-stage budgeting yields the division of expenditures between the two sectors:

$$
\begin{aligned}
X_{i c} & =\frac{\mu Y_{i}}{P_{i}} \\
Z_{i i}+Z_{j i} & =\frac{1-\mu}{q_{i}} Y_{i},
\end{aligned}
$$

\subsection{Factor Markets, Production and Income}

Let $w_{S i}$ and $w_{L i}$ denote the factor rewards for skilled and unskilled labor in country $i$, respectively. Assuming that $Z$-production only uses unskilled labor 
$(L)$, variable unit costs (i.e., marginal costs) $c_{Z i}$ satisfy

$$
c_{z i} \geq w_{L i} \quad \perp \quad Z_{i i} \geq 0
$$

where $\perp$ indicates that at least one of the adjacent conditions has to hold with equality. This implies

$$
c_{z i} \geq q_{j} \quad \perp \quad Z_{i j} \geq 0
$$

There is monopolistic competition in the $X$-sector, and each firm produces under a CES technology, using both factors (where ' $a$ ' is the coefficient for skilled labor and ' $1-a$ ' for unskilled labor), with an elasticity of substitution of $1 /(1-\rho)$ $(-\infty<\rho<1)$. As all firms face the same factor prices and the CES technology is homothetic, all firm types in a country face the same unit input coefficients. The country specific unit input coefficient for the two factors of $X$-production can be derived by cost minimization subject to this CES technology:

$$
\begin{aligned}
& a_{L x i}=w_{L i}^{\frac{1}{\rho-1}}(1-a)^{\frac{-1}{\rho-1}}\left(a^{\frac{-1}{\rho-1}} w_{S i}^{\frac{\rho}{\rho-1}}+(1-a)^{\frac{-1}{\rho-1}} w_{L i}^{\frac{\rho}{\rho-1}}\right)^{\frac{-1}{\rho}} . \\
& a_{S x i}=w_{S i}^{\frac{1}{\rho-1}} a^{\frac{-1}{\rho-1}}\left(a^{\frac{-1}{\rho-1}} w_{S i}^{\frac{\rho}{\rho-1}}+(1-a)^{\frac{-1}{\rho-1}} w_{L i}^{\frac{\rho}{\rho-1}}\right)^{\frac{-1}{\rho}} .
\end{aligned}
$$

Additionally, national enterprises and horizontal and vertical MNEs require skilled labor to set up plants $\left(a_{S n i}, a_{S h i}, a_{S v i}\right)$, and they employ unskilled labor to organize the multinational network $\left(a_{L n i}, a_{L h i}, a_{L v i}\right)$. In line with the literature (see for example Markusen, 2002), we assume that firm specific fixed costs are highest for horizontal MNEs, slightly lower for vertical ones, and lowest for exporters: $a_{S n i} w_{S i}+a_{L n i} w_{L i}<a_{S v i} w_{s i}+a_{L v i} w_{L i}<a_{S h i} w_{S i}+a_{L h i} w_{L i}$, and, specifically, $a_{\text {Sni }}=a_{L n i}=1, a_{S v i}=a_{S h i}=1+\delta, a_{L v i}=1+\gamma$, and $a_{L h i}=2+\gamma$, without loss of generality. $\delta$ is the additional skilled labor requirement to organize a multinational network, and $1+\gamma$ are the fixed costs in terms of unskilled labor country $i$ 's MNEs have to incur to set up a foreign plant in $j$. As mentioned above, horizontal MNEs also run local production plants, which is reflected by $a_{S h i}>a_{S v i}$.

Factor market clearing in country $i$ for skilled labor $S_{i}$ and unskilled labor $L_{i}$ requires

$$
S_{i} \geq a_{S x i}\left(n_{i} X_{i i}^{n}+n_{i} X_{i j}^{n}+h_{i} X_{i i}^{h}+h_{j} X_{j i}^{h}+v_{j} X_{j i}^{v}+v_{j} X_{j j}^{v}\right)
$$




$$
\begin{aligned}
& +a_{S n i} n_{i}+a_{S h i} h_{i}+a_{S v i} v_{i} \quad \perp \quad w_{S i} \geq 0, \\
L_{i} \geq & a_{L x i}\left(n_{i} X_{i i}^{n}+n_{i} X_{i j}^{n}+h_{i} X_{i i}^{h}+h_{j} X_{j i}^{h}+v_{j} X_{j i}^{v}+v_{j} X_{j j}^{v}\right)+Z_{i i} \\
& +Z_{i j}+a_{L n i} n_{i}+a_{L h i} h_{i}+a_{L v i} v_{i} \perp \quad w_{L i} \geq 0 .
\end{aligned}
$$

Variable unit costs of producing an $X$-variety in country $i$ are given by $c_{X i}=$ $a_{S x i} w_{S i}+a_{L x i} w_{L i}$. There is a fixed markup over variable costs, which is determined by the elasticity of substitution between varieties. Given that under CES-utility demand for all varieties is positive, we may write

$$
p_{i}=c_{X i} \frac{\sigma}{\sigma-1} \text {. }
$$

Free entry implies that firms earn zero profits, since operating profits are used to cover fixed costs. The corresponding zero-profit conditions determine the numbers of firms.

National enterprises in $i$ have to bear fixed costs of $F C_{n i}=a_{S n i} w_{S i}+a_{L n i} w_{L i}$. The zero profit condition for NEs, therefore, implies

$$
F C_{n i} \geq \frac{p_{i}\left(X_{i i}^{n}+X_{i j}^{n}\right)}{\sigma} \quad \perp \quad n_{i} \geq 0
$$

Vertical and horizontal MNEs are able to cover their fixed costs $\left(F C_{v i}=a_{S v i} w_{S i}+\right.$ $\left.a_{L v i} w_{L i}, F C_{h i}=a_{S h i} w_{S i}+a_{L h i} w_{L i}\right)$ via operating profits of both the local and the remote activities. The conditions for the number of MNEs are thus given by

$$
\begin{array}{cll}
F C_{v i} \geq \frac{p_{j}\left(X_{i j}^{v}+X_{i i}^{v}\right)}{\sigma} \quad \perp \quad v_{i} \geq 0, \\
F C_{h i} \geq \frac{p_{i} X_{i i}^{h}+p_{j} X_{i j}^{h}}{\sigma} \quad \perp \quad h_{i} \geq 0 .
\end{array}
$$

All factors are owned by the households, so that consumer income (i.e., GNP) in country $i$ is given by

$$
Y_{i}=w_{S i} S_{i}+w_{L i} L_{i}
$$

The equivalence of total factor income $\left(Y_{i}, Y_{j}\right)$ and demand in each country implicitly balances payments between countries.

Real factor rewards $(\omega)$ are normalized by country-specific costs of living $\left(P_{i}^{\mu} q_{i}^{1-\mu}\right)$, and are thus given by:

$$
\omega_{L i}=w_{L i} P_{i}^{-\mu} q_{i}^{\mu-1} .
$$




$$
\omega_{S i}=w_{S i} P_{i}^{-\mu} q_{i}^{\mu-1}
$$

\section{Core-Periphery-Patterns}

In contrast to the standard new economic geography models à la Krugman (1991b), production of the manufacturing good uses two input factors ( $S$ and $L)$. In the standard new economic geography models it is straightforward to assume that the factor used in the manufacturing sector is mobile across countries. In our setting, both factors are immobile in the short run. In the long run, we investigate situations where either unskilled labor $L$ (intensively used in homogeneous goods production and plant set-up) or skilled labor $S$ (intensively used in differentiated goods production and in research) is mobile. ${ }^{7}$ For both types of labor mobility we look at the effects of the firm regimes and, therefore, at the importance of the three types of firms that may endogenously arise in our model: exporting firms, horizontal MNEs, and vertical MNEs. By simulating scenarios where either horizontal FDI, vertical FDI or both are restricted for some exogenous reason, we find that the possible coexistence of all three types of firms changes the core-periphery structure significantly.

\subsection{Unskilled Labor Mobility}

Figure 1 depicts the agglomeration pattern at constant transport costs $(\tau=0.2)$ if unskilled labor is mobile, where $\lambda_{L}\left(\lambda_{S}\right)$ denotes country $i$ 's share of world endowment of unskilled (skilled) labor. A long run equilibrium is defined similar to Krugman (1991b) by real wage equalization across countries $\left(\omega_{L i}=\omega_{L j}\right.$ if unskilled labor is mobile and $\omega_{S i}=\omega_{S j}$ if skilled labor is mobile).

We find seven interior equilibria, four stable and three unstable ones. The stability of a long run equilibrium can be verified by exogenously shifting one unit of unskilled labor to the other country, and deriving the new short run equilibrium.

\footnotetext{
${ }^{7}$ We have chosen the following parameter values for our simulations: $\delta=0.01, \gamma=0.05$, $\sigma=4, \mu=0.8, \rho=-1, a=0.8, \tau=0.2$ if constant, $L=L_{1}+L_{2}=100, S=S_{1}+S_{2}=50$. As mentioned by Baldwin et al. (2003), if both factors were mobile, one country would become "extinct", due to the incentive to avoid trade costs by agglomerating in one country.
} 


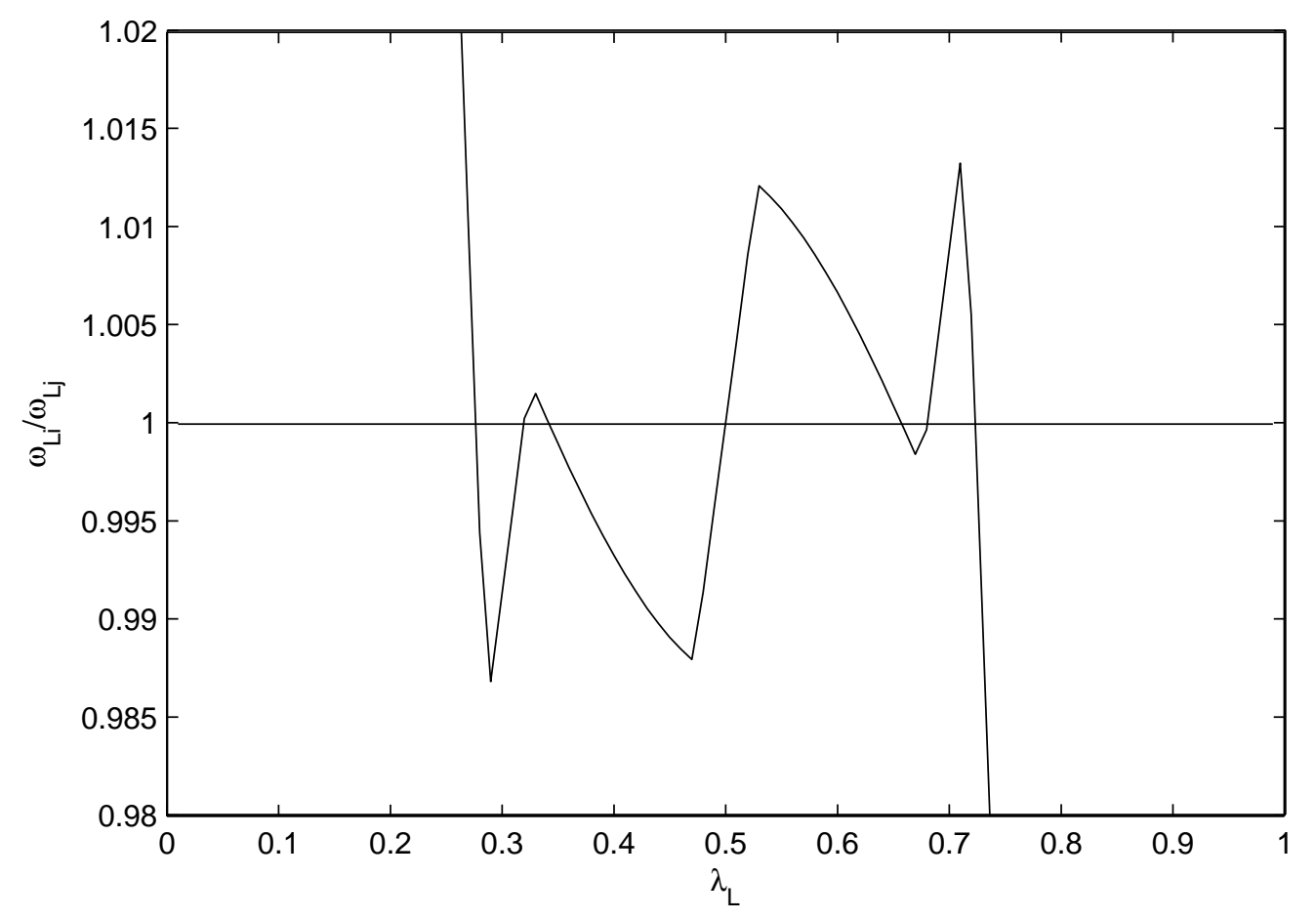

Figure 1: Core-periphery pattern with mobile unskilled labor and $\lambda_{S}=0.5$, $\tau=0.2$.

Then, firms are allowed to enter and exit to avoid losses and exploit profits. If this reallocation of production factors results in a decline of real wages in the receiving country, the initial equilibrium can be considered as stable. Otherwise, the initial equilibrium is unstable, because even more workers have an incentive to relocate.

Only partially agglomerated equilibria are stable in the long run, whereas the symmetric equilibrium is unstable. Note that in Figure 1 points left to $\lambda_{L i}=0.5$ are the inverse of those to the right. Looking at the left part of the figure (i.e., when country $i$ is small in terms of $L$ ), there are two different partially agglomerated equilibria for the same value of transport costs. In the equilibrium with a high level of agglomeration (at $\lambda_{L i} \approx 0.25$ ) vertical MNEs are important (see also Figure 2). ${ }^{8}$ Also NEs and horizontal MNEs are present in this equilibrium.

Coexistence of all three firm types based in one country is possible if the following

\footnotetext{
${ }^{8}$ Follow the vertical solid lines in Figure 2 to see which types of firms exist in each of the long run stable equilibria of Figure 1.
} 


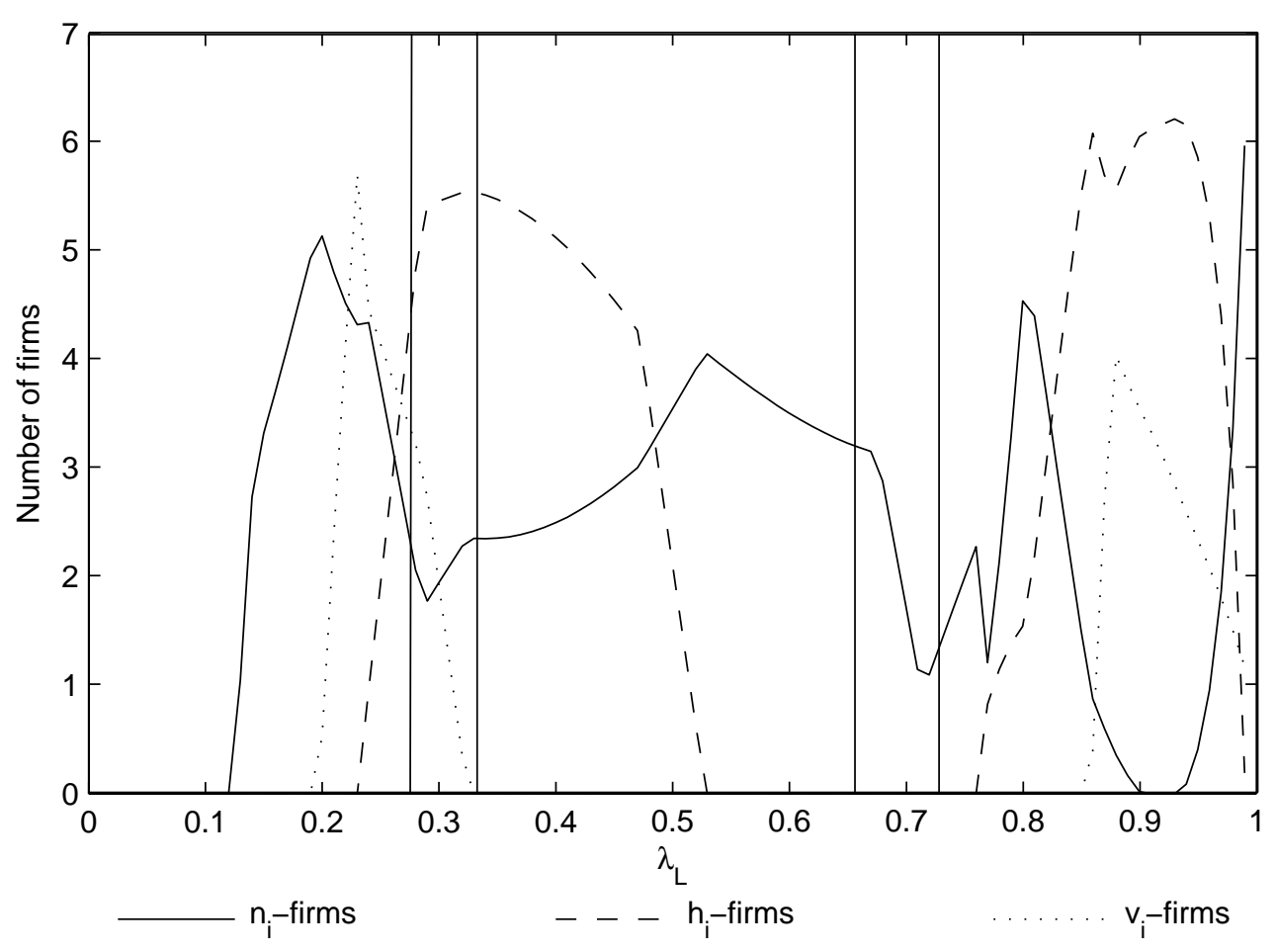

Figure 2: Firm structure corresponding to Figure 1.

generalized proximity-concentration trade-off holds (the derivation is relegated to the Appendix):

$$
\frac{F C_{n i}}{c_{X i}}=\frac{F C_{h i}-F C_{v i}}{c_{X i}-\left(\frac{c_{X i}}{c_{X j}}\right)^{\sigma}(1+\tau)^{1-\sigma} c_{X j}}+\frac{(1+\tau)^{1-\sigma}\left(\frac{c_{X j}}{c_{X i}}\right)^{\sigma}\left(F C_{h i}-F C_{n i}\right)}{c_{X j}-\left(\frac{c_{X j}}{c_{X i}}\right)^{\sigma}(1+\tau)^{1-\sigma} c_{X i}}
$$

The left-hand side is the ratio of fixed to variable costs of a national firm. The first term on the right-hand side gives the ratio of the fixed cost difference of horizontal and vertical MNEs to the difference of their respective revenues for serving the home market. ${ }^{9}$ The second term gives the ratio of the fixed cost difference of horizontal MNEs and national firms to the difference of their respective marginal revenues for serving the foreign market. The two terms are scaled by the relative importance of the foreign and home market for total sales of a national firm. The coexistence between horizontal MNEs and vertical MNEs is mainly determined by the revenues in the home market, whereas the decision to set up a plant abroad or to serve the foreign market via export is driven by the market

\footnotetext{
${ }^{9}$ For convenience, we have already divided all expressions by the constant markup and the identical quantities. Accordingly, the revenue difference is represented by the expressions in Equation 20. See the Appendix for further details.
} 
conditions abroad. This condition is more likely fulfilled if the labor abundant country specializes in homogeneous goods production and the labor scarce one in running headquarter services. Alternatively, the condition more likely holds if an extremely labor abundant country specializes in both, homogeneous goods production and headquarter services, whereas the other country specializes in differentiated goods production.

If the endowment differences with unskilled labor between countries are small, a stable agglomerated equilibrium is dominated by horizontal MNEs headquartered in the smaller country (such as the equilibrium at $\lambda_{L i} \approx 0.33$ ). This outcome seems to be somewhat surprising, as one would expect agglomeration to take place in the larger country. However, the firm structure per se is not informative with respect to production volumes. In our setting, the smaller country is relatively skilled labor abundant (since $\lambda_{L}<\lambda_{S}$ by assumption) and, therefore, exhibits a comparative advantage in running MNEs, since setting up the multinational network requires additional skilled labor input. ${ }^{10}$ Country $i$ could be considered as a developed one, specializing in the provision of headquarter services and skilled labor-intensive goods. ${ }^{11}$ In contrast, the larger country $j$ is unskilled labor-abundant, specialized in the production of homogeneous goods rather than research and brand proliferation.

Concerning the firm regimes, we find that horizontal MNEs exist in one of two cases. First, if unskilled labor endowments are very different between the countries. This implies strong relative factor endowment differences, where the unskilled labor abundant country specializes in homogeneous products and headquarter services. As skilled labor is scarce, factor prices and hence incomes are high, so that the market size justifies to run two plants in order to avoid transport costs. Second, for similarly endowed countries, the respective foreign market is large enough to invest in a plant in order to save transport costs. If a country

\footnotetext{
${ }^{10}$ Note that we assume that firms use only skilled labor from the home country to provide headquarter services. Allowing firms to split their firm- and/or plant-specific fixed costs would add an additional vertical dimension to all MNEs, making it harder to study the different effects of horizontal and vertical FDI on the agglomeration patterns.

${ }^{11}$ Since there are variable input coefficients, production of $X$-goods in country $i$ is more skilled labor-intensive than in country $j$.
} 
becomes unskilled labor abundant, skilled labor is essential for producing manufactured goods and, therefore, not used for setting up a multinational network. ${ }^{12}$ This is the case in the long run stable equilibria at $\lambda_{L i} \approx 0.66$ and $\lambda_{L i} \approx 0.72$.

So far, we have analyzed the core-periphery pattern and the firm structure at a specific value of transport costs. Now, we investigate at which levels of transport costs agglomeration is a possible outcome (the sustain point as in Fujita et al., 1999), and at which it is a necessary one (the break point).

Let transport costs $(\tau)$ vary between 0.005 and 0.495 in order to capture them in their empirically relevant range, as pointed out by Hummels (1999) or Baier and Bergstrand (2001). Figure 3 shows the resulting core-periphery bifurcation. ${ }^{13}$

If transport costs are very high, only horizontal MNEs exist due to the proximityconcentration trade-off. At the left bound of the equilibrium area, equilibria with horizontal MNEs only (within the shaded area) and other plant configurations (to the left of the shaded area) meet. At symmetry $\left(\lambda_{L}=0.5\right)$, NEs and MNEs will only co-exist at the bound of the equilibrium area. We can make use of the zero-profit conditions (14) and (16) to characterize the condition of co-existence for this case formally by:

$$
\frac{F C_{h i}}{F C_{n i}}=\frac{2}{1+(1+\tau)^{1-\sigma}}
$$

(21) represents the well-known proximity-concentration trade-off. It states that horizontal MNEs and NEs will only co-exist if high plant-setup costs are matched by sufficiently high transport costs. If trade costs are too high in relation to fixed plant set-up costs, only horizontal MNEs can survive (at $\lambda_{L}=0.5$ within the shaded equilibrium area). If trade costs are too low, it does not pay off to run foreign plants (at $\lambda_{L}=0.5$ to the left of the shaded equilibrium area).

If only horizontal MNEs are present, the price indices in both countries are the same $\left(P_{i}=P_{j}\right.$, which follows from Equation 4 after taking into account that $p_{i}=$

\footnotetext{
${ }^{12}$ Note that a very high ratio of unskilled to skilled labor leads to a specialization in homogeneous goods production and leads again to headquarters in the respective country.

${ }^{13}$ In all bifurcation diagrams, long run stable equilibria are depicted by solid lines, areas of long run stable equilibria are cross-hatched and bordered by dashed lines, and unstable equilibria are indicated by dotted lines.
} 


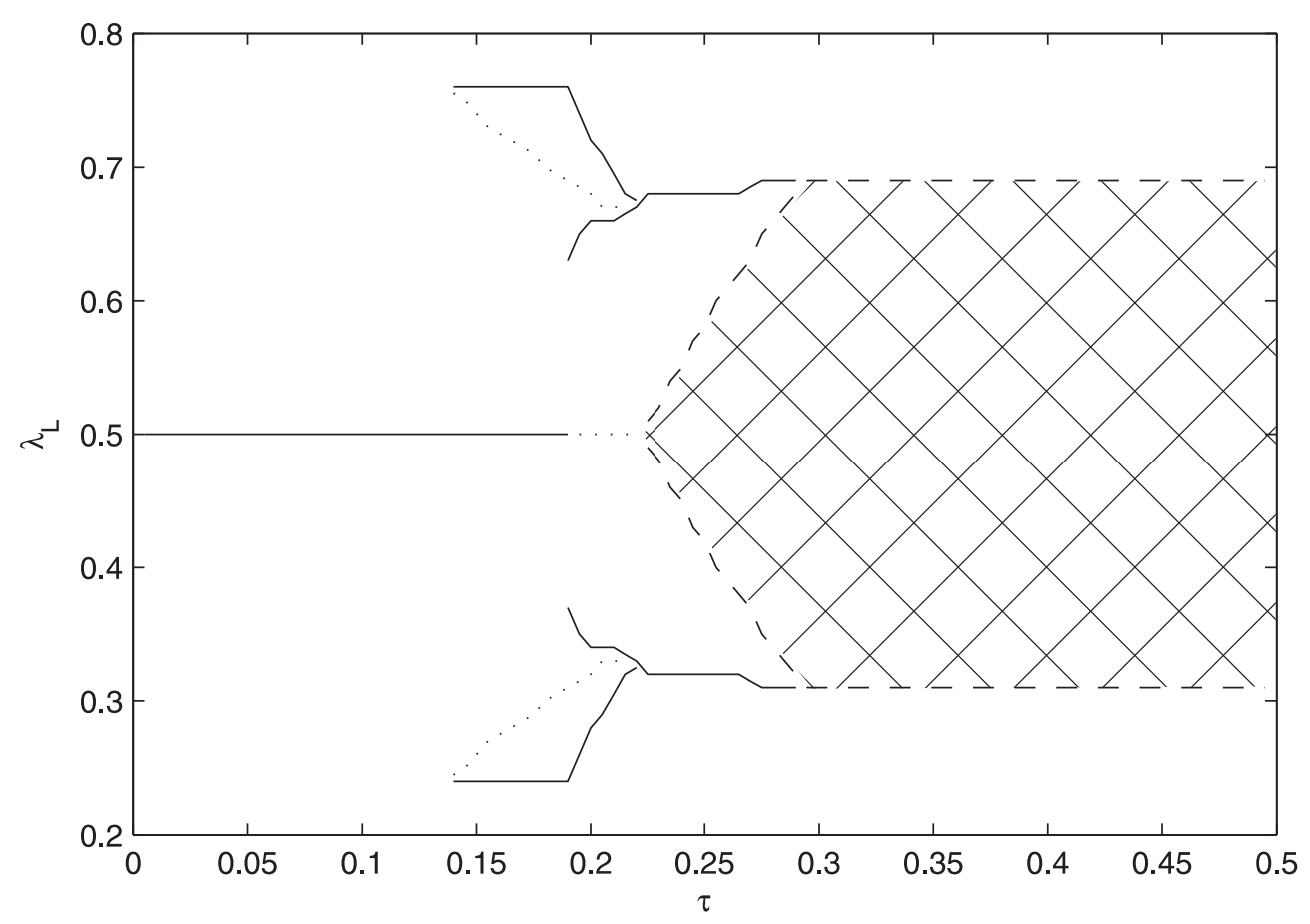

Figure 3: Bifurcation diagram with mobile unskilled labor and $\lambda_{S}=0.5$, all firm types.

$p_{j}$ in the exclusive presence of horizontal MNEs). Together with the possibility of free trade of agricultural goods and shifting of factor intensities in production, this leads to an equilibrium area where both real wages for unskilled as well as skilled labor are equalized, if only horizontal MNEs exist and production patterns are diversified. Hence, shifts of unskilled labor supply in a specific range do not alter the firm structure and, therefore, a long run equilibrium exists (ensured by $\left.\frac{\partial \omega_{L i}}{\partial \lambda}=0\right)$, even at $\lambda_{L} \neq 0.5$. This is in contrast to Ekholm and Forslid (2001) who find a unique stable symmetric equilibrium if only horizontal MNEs exist, due to their assumption of footloose MNEs that are forced to cover their fixed costs in both countries in equal proportions.

At low transport costs, only the symmetric equilibrium is stable in the long run, because it does not pay off to run horizontal MNEs. In this case, even vertical MNEs do not exist since factor price differences are too small to render unbundling profitable.

In Figure 3, there are two break points. Moving from the left towards the right, 
a symmetric equilibrium remains stable until $\tau \approx 0.19$. Then, this equilibrium breaks and we may end up in either one of the two different long run stable partially agglomerated equilibria. Starting from high transport costs (i.e., moving from the right to the left), we obtain another break point at $\tau \approx 0.22$. There, the long run stable equilibrium area collapses and a core-periphery pattern necessarily emerges.

If we are initially in a partially agglomerated equilibrium (for historical reasons or by incidence), we find a rather wide sustain range at $0.14 \lesssim \tau \lesssim 0.3$. The reason for this is our rich model structure which enables firms to exploit real wage differentials. This equalizes real factor rewards so that there is no incentive for migration. This is in line with the empirical observation that wage differentials of the unskilled diminish, despite unskilled labor being still quite immobile (see for instance Barba Navaretti et al., 2002; Puga, 2002). Our outcome suggests that unskilled labor mobility is not necessary to obtain equalization of real unskilled labor rewards, and that an unequal division of unskilled labor between countries can be a long run stable equilibrium for a wide range of transport costs. Within the two different partially agglomerated equilibria, the firm regimes vary considerably. As indicated above, in the more agglomerated equilibrium (at $0.14 \lesssim \tau \lesssim 0.22$ ) factor price differences are big enough to render disentangling of headquarter services and production worthwhile so that vertical MNEs exist. In contrast, the other partially agglomerated equilibrium (at $0.19 \lesssim \tau \lesssim 0.3$ ) is dominated by horizontal MNEs, since higher transport costs increase the incentives to set up two plants in order to serve each market locally.

Now we turn to investigate the importance of the different types of firms for the development of the core-periphery pattern. This is done by looking at three different scenarios: (i) the case of NEs only (MNEs are not allowed to come into existence although it might be optimal), (ii) NEs and horizontal MNEs, and (iii) NEs and vertical MNEs.

Figures 4 and 5 show the resulting bifurcation diagrams for these scenarios. With exporting firms only, the symmetric equilibrium is stable for all values of transport 


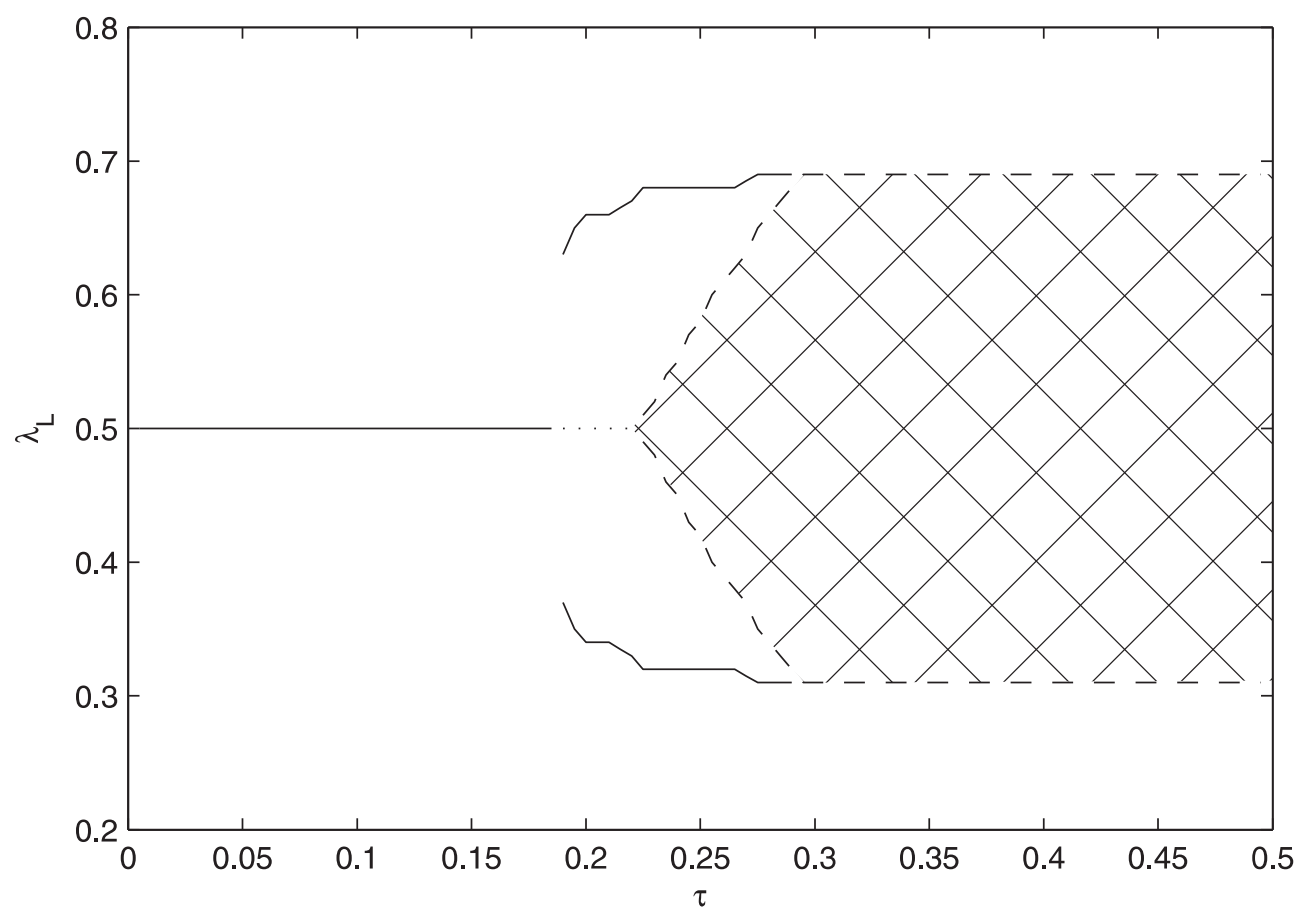

Figure 4: Bifurcation diagram with mobile unskilled labor and $\lambda_{S}=0.5$, NEs and horizontal MNEs

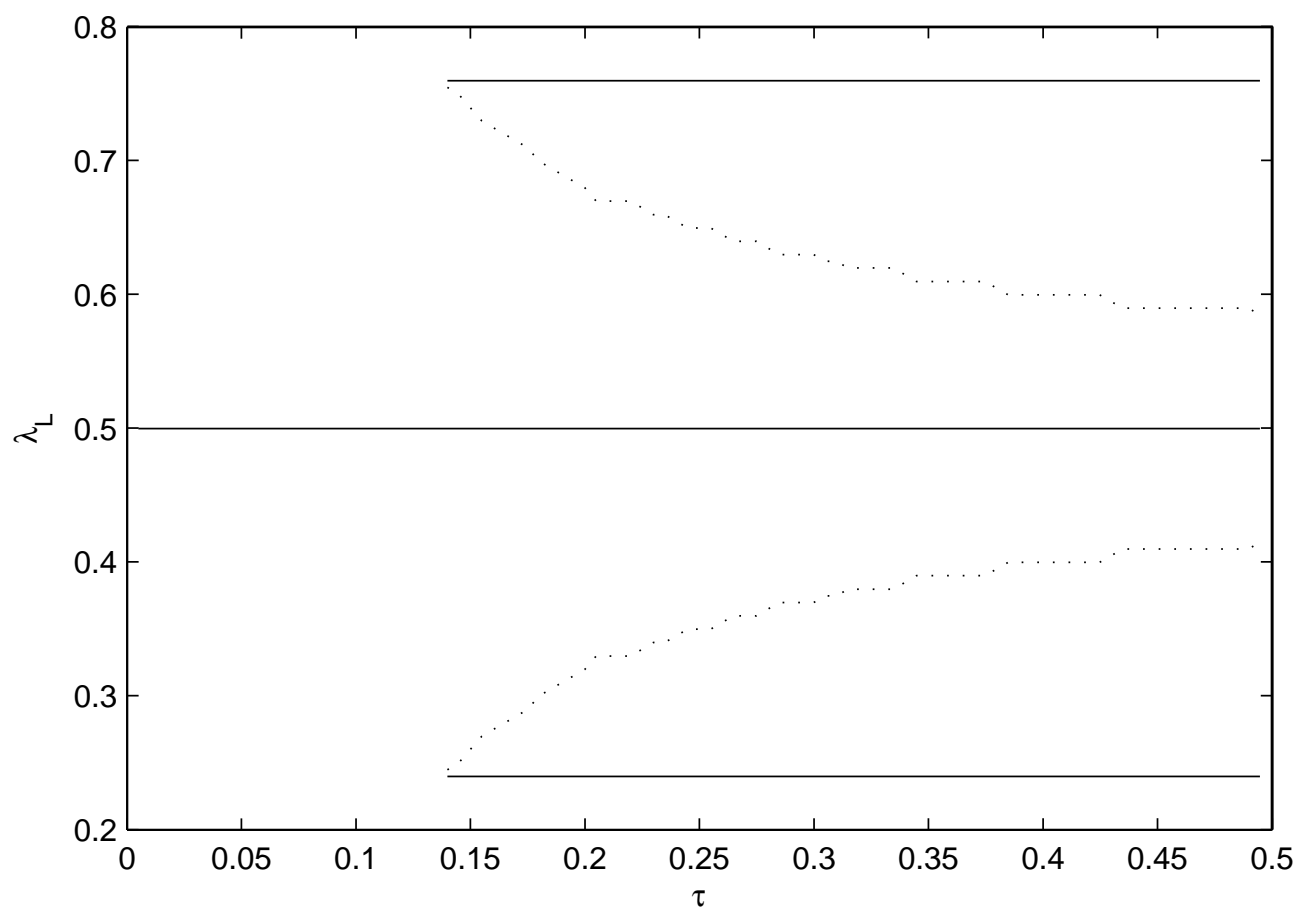

Figure 5: Bifurcation diagram with mobile unskilled labor and $\lambda_{S}=0.5$, NEs and vertical MNEs 
costs. ${ }^{14}$ The reason is that a one unit shift of unskilled labor leads to concentration of firms in the larger country (this is the well known home market effect). In turn, this leads to both higher skilled labor rewards and prices, thereby lowering real unskilled labor rewards. Accordingly, the symmetric equilibrium is stable.

Whereas all types of firms are allowed to coexist in Figure 3, vertical MNEs may not arise in Figure 4. A comparison identifies the importance of vertical MNEs for partial agglomeration to arise at moderate levels of trade costs. Without the possibility of unbundling of headquarter services and production through vertical MNEs, an extremely unequal unskilled labor distribution between countries can not be sustained as a long-run stable equilibrium. Hence, similar to and even beyond migration, vertical MNE activity is a source of real factor price equalization (see Helpman, 1984).

Consider a third scenario with NEs and vertical MNEs, where horizontal MNEs are not allowed to exist (Figure 5) and compare this scenario with the original one where all firm types may arise endogenously (Figure 3). It turns out that the partially agglomerated equilibrium (represented by values of $0.14 \lesssim \tau \lesssim 0.18$ and $\lambda \approx 0.25)$ in Figure 3 remains stable stable even for a large range of transport costs in Figure 5, where horizontal MNEs may not exist. In this country, factor price differences of skilled labor are large enough so that even for high transport costs it pays to unbundle headquarter services and production. If horizontal MNEs may not arise endogenously, there is no way for firms to avoid transport costs for serving the second market, where production does not take place. Hence, focussing on NEs and vertical MNEs only can lead to misleading results. The reason is that vertical MNEs come into existence at high trade costs. This would not happen, if also horizontal MNEs could endogenously arise.

\subsection{Skilled Labor Mobility}

If skilled labor is mobile and unskilled labor equally allocated $\left(\lambda_{L}=0.5\right)$, there is no interior stable equilibrium other than the equilibrium area with horizon-

\footnotetext{
${ }^{14}$ The bifurcation diagrams with NEs only are provided in the supplementary material to this paper.
} 
tal MNEs only. In contrast to the case of mobile unskilled labor, the symmetric equilibrium is unstable, and full agglomeration is stable for all values of transport costs. In the country where all the skilled labor is agglomerated, only exporting firms exist. Since both headquarter services and differentiated goods production use skilled and unskilled labor, the skilled labor scarce country is forced to specialize in homogeneous goods production. Homogeneous goods are exported in exchange for differentiated products. Note that this is fully in line with the standard new economic geography models, which also predict full agglomeration if trade costs are low. In our case such as in the standard new economic geography model, full agglomeration is no longer sustainable if trade costs are very high (at $\tau \approx 1.7$ in our simulation scenario), leading to the well known tomahawkbifurcation.

The bifurcation diagram with mobile skilled labor (Figure 6) shows an equilibrium area with horizontal MNEs at transport costs of $\tau \geq 0.23$. As in the case of unskilled labor mobility, there is equalization of both real wages for skilled and unskilled labor within the equilibrium area. ${ }^{15}$ At low values of transport costs, only full agglomeration of skilled labor in either country satisfies our long run equilibrium conditions. The reason is that the centrifugal forces are too strong for a symmetric equilibrium to be stable.

In Figure 6 , there is one break point at $\tau \approx 0.23$ when moving from the right to the left, but there is no sustain point. In other words, we find a quite large range $(0.495 \geq \tau \gtrsim 0.23)$ where long run equilibria can arise at different values of $\lambda_{S}\left(0.32 \lesssim \lambda_{S} \lesssim 0.68\right)$, when starting from very high transport costs. In contrast, at $\tau \lesssim 0.23$ full agglomeration is the only stable equilibrium, which remains sustainable for all values of transport costs, when starting from either low or high transport costs. With skilled labor mobility, a long run symmetric equilibrium can only be reached, if transport costs are sufficiently high (i.e., higher than the break point). At lower transport costs, the centrifugal forces are strong

\footnotetext{
${ }^{15}$ Note, that the equilibrium areas for the bifurcation diagrams with unskilled and skilled labor are quite similar. They start at the same value of transport costs and reach from about $\lambda=0.32$ to $\lambda=0.68$.
} 


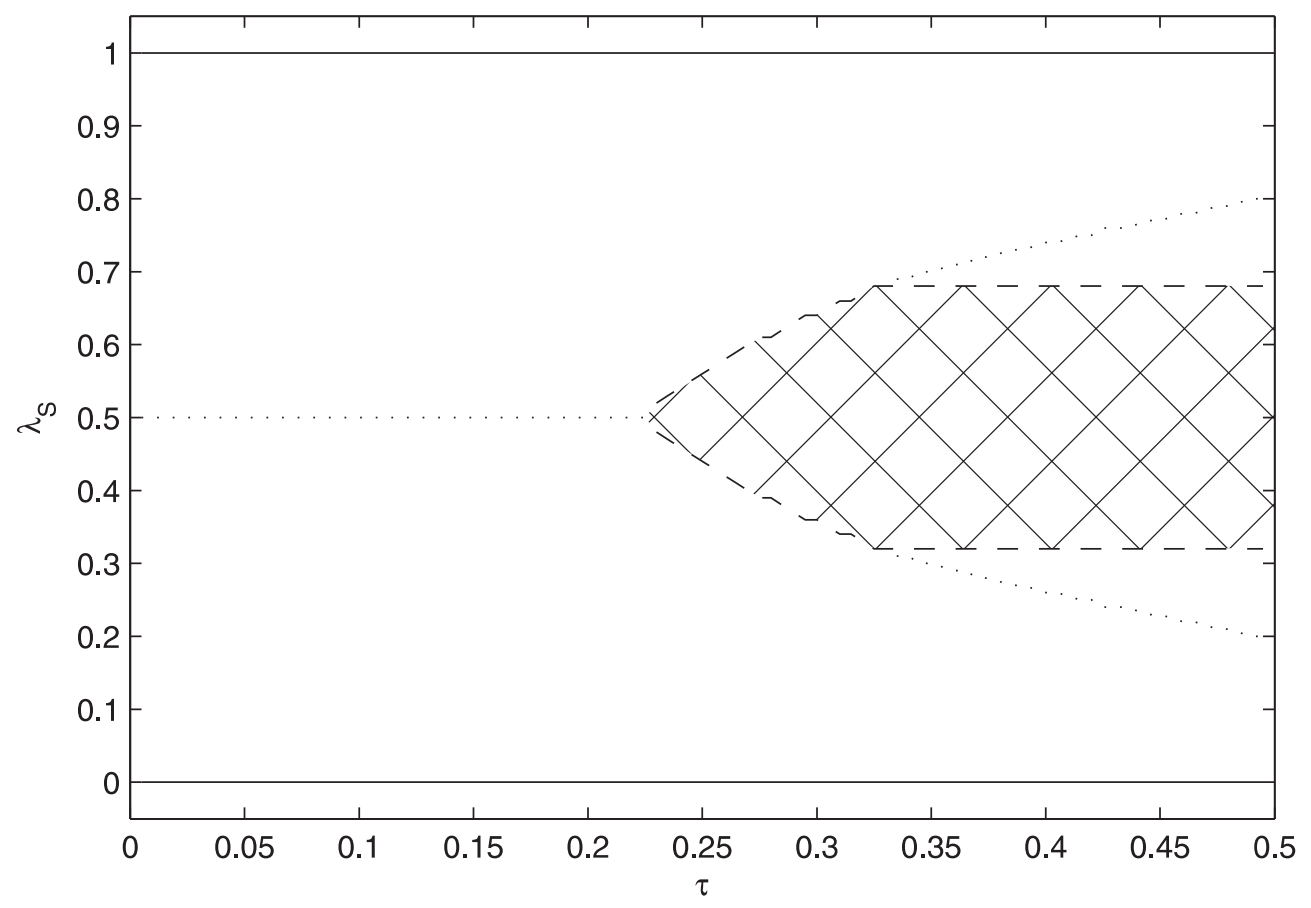

Figure 6: Bifurcation diagram with mobile skilled labor and $\lambda_{L}=0.5$, all firm types.

enough to motivate agglomeration. Since most products incur transport costs lower than 33\% (see Hummels, 1999; Baier and Bergstrand, 2001), our model can cope with the observed agglomeration tendency of skilled labor.

Let us now discuss each firm type's importance for the development of the coreperiphery patterns in the case of skilled labor mobility. In the scenario with NEs only, we can replicate the tomahawk bifurcation. For the range of transport costs plotted, only the full agglomeration equilibria are long-run stable ones. Hence, with MNEs it is possible to sustain a dispersed equilibrium at sufficiently high transport costs. This does not contradict Gao's (1999) result that vertical MNEs speed up the spread of industries. The reason is that, with skilled labor mobility and no forward-backward linkages through intermediate products, horizontal MNEs become much more important than vertical ones. With skilled labor mobility real factor price equalization for both factors is stimulated, since the factor price differential for unskilled labor is restricted by costless homogeneous goods trade (recall that homogeneous goods only require unskilled labor in production). 
In this case, unbundling of headquarter services and production by vertical MNEs is not profitable in equilibrium. However, horizontal MNEs arise even in the absence of factor price differences, since they come into existence whenever it pays to economize on transport costs.

The importance of horizontal MNEs is reflected by looking at the bifurcation diagram with NEs and horizontal MNEs. Here, the core-periphery pattern is exactly the same as if all three types of firms were allowed to coexist. Vertical MNEs do not influence the core-periphery patterns in the case of skilled labor mobility, since the agglomeration structure in the scenario with both NEs and vertical MNEs is the same as for that one with NEs only. Note that vertical MNEs do exist in this scenario, but they are not important enough to have an impact on the core-periphery pattern.

Comparing the agglomeration patterns in the cases of skilled and unskilled labor mobility, we see that overall the concentration tends to be higher when skilled labor is mobile. This is true for all long-run stable equilibria for lower values of trade costs $(\tau \lesssim 0.23)$. When trade costs are higher than $\tau \approx 0.23$, there is an equilibrium area when unskilled labor is mobile. Besides the equilibrium area, full agglomeration is a possible equilibrium in case of skilled labor mobility. Hence, the result for high transport costs can be the same with either factor mobility or is more concentrated with skilled labor mobility. As far as the effects of different firm regimes are concerned, unskilled labor mobility is compatible with a richer firm structure in the long-run stable equilibria. This is due to the fact that vertical MNEs headquartered in the unskilled labor scarce (and thus relatively skilled labor abundant) country can exploit factor price differentials of skilled labor, and set up their production plant in the country where skilled labor is relatively cheap. With skilled labor mobility, migration an disentangling of production processes have the same effect, which is manifested in the same agglomeration patterns in the long run. 


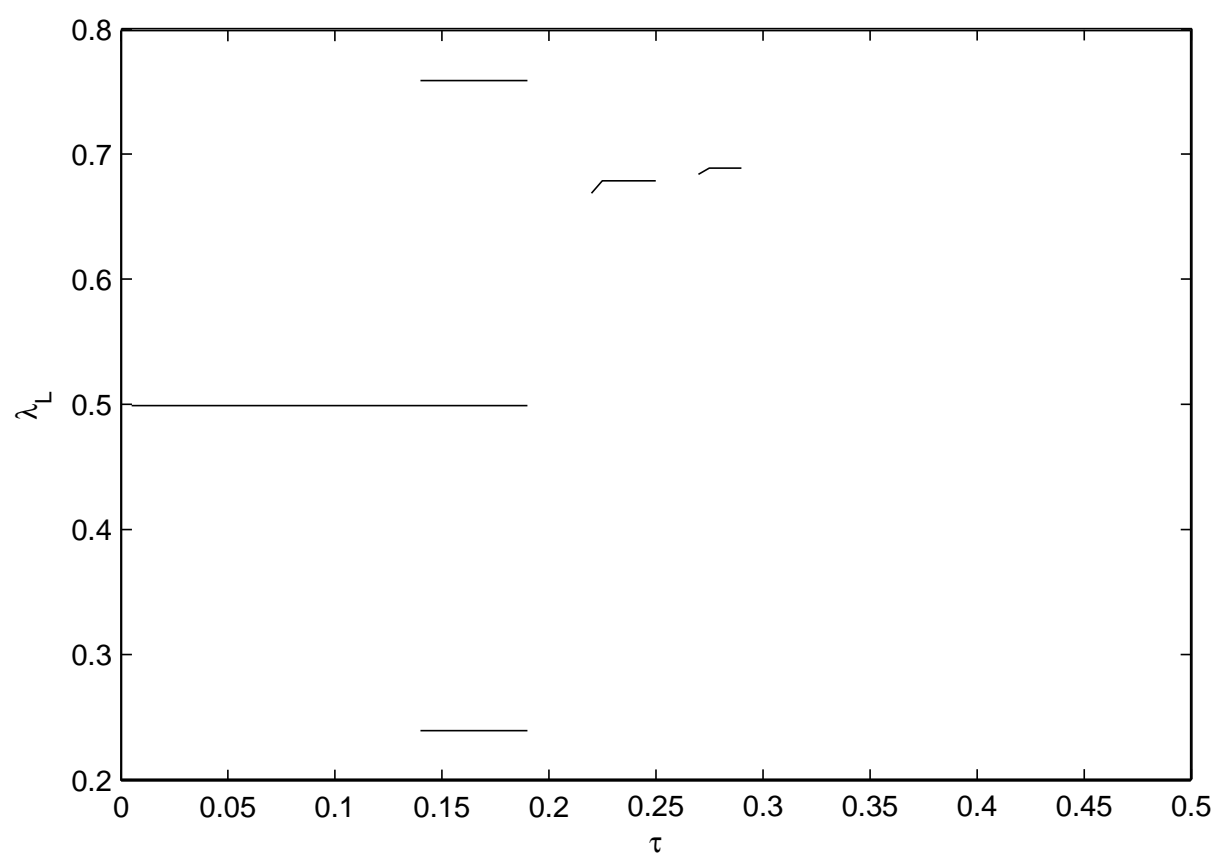

Figure 7: Regions of the bifurcation diagram with mobile unskilled labor where Pareto-improvements are possible.

\section{Effects of Trade Liberalization on Real Factor Rewards}

In order to determine a country's attitude towards trade liberalization, we look at the real factor rewards in each of the previously introduced bifurcation diagrams. Again, we compare the outcome with the counterfactual models where only NEs, only Nes and horizontal MNEs, or oonly NEs and vertical MNEs may endogenously arise. We only consider long run stable equilibria and denote in the case of partially agglomerated equilibria country $i$ as the mobile factor scarce one $(\lambda<0.5)$ and country $j$ as the mobile factor abundant one $(\lambda>0.5)$. Following Wong (2001), we speak of a Pareto-improving change in trade costs for a country, if at least one factor price in that country increases in real terms and none decreases after liberalization. ${ }^{16}$

Figures 4 depicts only those long run stable equilibria with mobile unskilled labor where Pareto-improvements due to trade liberalization are possible according to

\footnotetext{
${ }^{16}$ The underlying graphs of real factor rewards can be found in the supplementary material to this paper.
} 
the previously introduced criterion. This figure displays a sub-set of the equilibria illustrated in Figure 3.

For example, for $\tau=0.1$ we obtain three long run stable equilibria in the bifurcation diagram with unskilled labor mobility (Figure 3). From Figure 4 we see that if trade costs are lower than $\tau \approx 0.18$, further liberalizing trade is Paretoimproving for both countries, irrespective of whether we are in the long-run stable symmetric equilibrium or in the partially agglomerated equilibria. If trade costs are between $0.22 \lesssim \tau \lesssim 0.26$, only one of the partially agglomerated equilibria is stable. In this case, trade liberalization is Pareto-improving for the larger country but not for the smaller one. The reason is that the smaller country mainly headquarters horizontal MNEs which do not profit from trade liberalization. In contrast, NEs dominate the firm structure in the larger country. Actually, the larger country is in favor of trade liberalization in the symmetric equilibrium and in both partially agglomerated equilibria.

How do these results conmpare with other models characterized by more restrictive plant configurations, namely only NEs, only NEs and vertical MNEs, and only NEs and horizontal MNEs? If either only NEs or both NEs and vertical MNEs are allowed to exist, trade liberalization is beneficial in both countries at all values of transport costs. If only NEs and horizontal MNEs may exist, the range of trade costs where trade liberalization is Pareto-improving, is similar to Figure 4 where all firm types may arise endogenously. However, if vertical MNEs may exist as well, trade liberalization is Pareto-improving even in the partially agglomerated equilibrium at trade costs of $0.14 \lesssim \tau \lesssim 0.18$ in Figure 4 .

In case of skilled labor mobility, trade liberalization is never Pareto-improving for the larger country but always for the smaller one. This result holds true for our model as well as the more restricted ones that do not allow all firm types to arise endogenously. Put differently, in the fully agglomerated equilibrium, the country ending up without any skilled labor prefers to liberalize trade. However, the country ending up with all the available skilled labor would never adopt such a policy. The skilled labor abundant country runs NEs, whereas the smaller 
country specializes in homogeneous goods trade. Reducing trade costs for the differentiated product leads to a gain for the smaller country, since more differentiated goods are affordable for every unit of the homogeneous good exported. Within the equilibrium area where horizontal MNEs are present, trade liberalization is not Pareto-improving for the smaller country either, since real (and nominal) factor prices are equalized and do not change after a reduction of trade costs.

Summing up, trade liberalization is likely Pareto-improving for the larger country, if unskilled labor is mobile. By way of contrast, if skilled labor is mobile, the smaller country is in favor of adopting a trade liberalizing policy, whereas the larger country is never better off.

\section{Robustness of the Findings}

To investigate the robustness of our results, we discuss variations of the parameters $\mu, \rho$ and $\sigma$. For every new parameter value, we analyze the effects with respect to our two reference cases for unskilled as well as skilled labor mobility, where the respective immobile factor is equally allocated between the two countries.

So far, consumers are assumed to spend $80 \%(\mu=0.8)$ of their income on manufactured goods (this is well supported by empirical evidence). We lower this value to (i) $\mu=0.7$, (ii) $\mu=0.5$, and (iii) $\mu=0.3$, where the latter is the value frequently used in new economic geography models, for instance in Krugman (1991b) or Ekholm and Forslid (2001). We find that for lower values of $\mu$, MNEs become less important, because for a too low income spent on manufactures it does not pay to incur high fixed costs associated with foreign affiliates.

We continue by analyzing the effects of reducing the substitutability between skilled and unskilled labor, $\rho$, to -5 (corresponding to a TRS of $1 / 6$ ) and -20 (TRS $=1 / 21)$, respectively. As skilled labor is not only needed in manufacturing goods production but also essential for covering plant set-up costs, a lower sub- 
stitutability between the two types of labor in the production of manufactures causes the skilled labor reward to rise. Thus, setting up MNEs becomes less attractive and, therefore, the equilibrium area with only horizontal MNEs gets smaller and only exists for high transport costs. Moreover, we find that the long run stable, partially agglomerated equilibria are present over the whole range of transport costs, and that the agglomeration itself is more pronounced. Making factors in production of manufactured goods more substitutive (changing $\rho$ from -1 to 0.5 (implying a TRS of 2 ) and $5 / 6(\mathrm{TRS}=6)$, respectively), leads the partially agglomerated equilibria to be more pronounced, and the equilibrium area with only horizontal MNEs appears for a larger range of transport costs. Overall, lower (higher) values of $\rho$ shift the bifurcation diagrams to the right (left).

A lower elasticity of substitution between varieties of the manufactured good (additionally to $\sigma=4$, we run experiments for $\sigma=2$ and $\sigma=6$ ) implies that the equilibrium area with only horizontal MNEs becomes smaller or even vanishes. On the other hand, the ranges of the long run stable symmetric equilibrium as well as the partially agglomerated equilibria rise as $\sigma$ gets lower. In contrast, running vertical MNEs becomes more attractive. The reason is that the demand for manufactures is less sensitive to price changes at a lower values of $\sigma$. This renders multi-plant production by horizontal MNEs less attractive, since the avoidance of transport costs becomes less important.

By and large, the main agglomeration patterns prove to be robust with respect to moderate changes in $\mu, \rho$ and $\sigma$. We mainly observe leftward or rightward shifts of the bifurcations, which can be explained by the changing underlying firm structure (proximity-concentration trade-off).

\section{Conclusions}

Empirical evidence suggests that European nations are less concentrated than US countries. To the best of our knowledge, new economic geography models with multinational firms do not deal explicitly with these differences in the agglomeration patterns so far. 
We incorporate the now standard knowledge-capital model of multinationals in a new economic geography setting to account for the growing importance of foreign direct investment in the last decades. Accordingly, exporting firms and both horizontal and vertical multinational firms may endogenously arise. There are two sectors, a homogeneous one producing with unskilled labor only, and a differentiated one, which uses both skilled and unskilled labor in production. We find that the existence of multinationals leads to more pronounced core periphery patterns.

Recent empirical studies point to an important difference between Europe and the US, namely that in Europe unskilled labor is more mobile than skilled labor and that the reverse is true for the US. Accordingly, we analyze the agglomeration patterns for both unskilled and skilled labor mobility, arguing that the former represents the European case and the latter one the US case.

The theoretical predictions of the agglomeration patterns in our model suggest that unskilled labor mobility leads to lower concentration than skilled labor mobility. The different modes of factor mobility between Europe and the US could therefore be important to explain the observed differences in the spreading of industries.

According to our welfare analysis, trade liberalization is likely Pareto-improving for the larger country if unskilled labor is mobile. At skilled labor is mobility, the smaller country likely gains from trade liberalization. By and large, these results prove robust with respect to moderate changes in the parametrization of the model. 


\section{References}

Adams, R.H. (2003), International Migration, Remittances and the Brain Drain: A Study of 24 Labor-Exporting Countries, World Bank Policy Research Working Paper No. 3069.

Adsera, A., Boix, C. (2000), Must we choose? European Unemployment, American Inequality, and the Impact of Education and Labor Market Institutions, European Journal of Political Economy 16, pp. 611-38.

Baier, S.L., Bergstrand, J.H. (2001), The Growth of World Trade: Tariffs, Transport Costs, and Income Similarity, Journal of International Economics 53(1), pp. $1-27$.

Baldwin, R.E., Forslid, R., Martin, P., Ottaviano, G.I.P., Robert-Nicoud, F. (2003), Economic Geography and Public Policy, Princeton University Press, Princeton.

Barba Navaretti, G., Checchi, D., Turrini, A. (2003), Adjusting Labour Demand: Multinational vs. National Firms A Cross-European Analysis, Journal of the European Economic Association 1(2-3) pp. 708-19.

Bentivogli, C., Pagano, P. (1999), Regional Disparities and Labour Mobility: The Euro-11 versus the USA, Labour 13, pp. 737-60.

Boeri, T., Bruecker, H. (2003), Eastern Enlargement and EU-Labour-Markets: Perceptions, Challenges and Opportunities, World Economics, March 2001.

Carr, D.L., Markusen, J.R., Maskus, K.E. (2001), Estimating the KnowledgeCapital Model of the Multinational Enterprise, American Economic Review 91(3), pp. 693-708.

Coppel, J., Dumont, J-C., Visco, I. (2001), Trends in Immigration and Economic Consequences, OECD Economics Department Working Papers No. 284. 
Constant, A., Massey, D.S. (2003), Labor Market Segmentation and the Earnings of German Guestworkers, IZA (Institute for the Study of Labor) Discussion Paper No. 774 .

Dixit, A.K., Stiglitz, J.E. (1977), Monopolistic Competition and Optimum Product Diversity, American Economic Review 67(3), pp. 297-308.

De New, J.P., Zimmermann K.F. (1994), Blue Collar Labor Vulnerability: Wage Impact on Migrations, in: Steinmann G., Ulrich R., The Economic Consequences of Immigration to Germany, Physica Verlag, Heidelberg, pp. 81-99.

Egger, P., Pfaffermayr, M. (2004), Distance, Trade and FDI: A SUR HausmanTaylor Approach, Journal of Applied Econometrics 19(2), pp. 227-246.

Ekholm, K., Forslid, R. (2001), Trade and Location with Horizontal and Vertical Multi-Region-Firms, Scandinavian Journal of Economics 103(1), pp. 101-18.

Fujita, M., Krugman, P., Venables, A.J. (1999), The Spatial Economy - Cities, Regions, and International Trade, The MIT Press, Cambridge, Massachusetts.

Gao, T. (1999), Economic Geography and the Department of Vertical Multinational Production, Journal of International Economics 48, pp. 301-20.

Geddes, A. (2003), Migration and the Welfare State in Europe, The Political Quarterly 74(1), pp. 150-162.

Haaland, J.I., Kind, H.J., Midelfart-Knarvik, K.H., Torstensson, J. (1999), What Determines the Economic Geography of Europe?, CEPR Discussion Paper Nr. 2072.

Helpman, E. (1984), A Simple Theory of International Trade with Multinational Corporations, Journal of Political Economy 32(3), pp. 451-71.

Helpman, E., Krugman, P.R. (1985), Market Structure and Foreign Trade - Increasing Returns, Imperfect Competition and the International Economy, The MIT Press, Cambridge, Massachusetts. 
Hummels, D. (1999), Toward a Geography of Trade Costs, mimeo.

Kennan, J., Walker, J.R. (2003), The Effect of Expected Income on Individual Migration Decisions, NBER Working Paper No. 9585, March 2003.

Krugman, P. (1991a), Geography and Trade, Leuven University Press and MIT Press, Leuven, Belgium and Cambridge, Massachusetts.

Krugman, P. (1991b), Increasing Returns and Economic Geography, Journal of Political Economy 99(31), pp. 483-99.

Krugman, P., Venables, A.J. (1995), Globalization and the Inequality of Nations, Quarterly Journal of Economics 110(4), pp. 857-80.

Markusen, J.R. (1984), Multinationals, Multi-Plant Economies, and the Gains from Trade, Journal of International Economics 16, pp. 205-26.

Markusen, J.R. (2002), Multinational Firms and the Theory of International Trade, The MIT Press, Cambridge, Massachusetts.

Markusen, J.R., Maskus, K.E. (2002), Discriminating Among Alternative Theories of the Multinational Enterprise, Review of International Economics 10(4), pp. 694-707.

Markusen, J.R., Venables, A.J. (1998), Multinational Firms and the New Trade Theory, Journal of International Economics 46, pp. 183-203.

Markusen, J.R., Venables, A.J. (2000), The Theory of Endowment, Intra-industry and Multi-national Trade, Journal of International Economics 52, pp. 209-34.

Midelfart-Knarvik, K.H., Overman, H.G., Redding, S.J., Venables, A.J. (2000), The Location of European Industry, Report prepared for the Directorate General for Economic and Financial Affairs, European Commission.

Overman, H.G., Redding, S., Venables, A.J. (2001), The Economic Geography of Trade, Production, and Income: A Survery of Empirics, Centre of Economic Performance, London School of Economics. 
Porter, R.B., Sauvé, P., Subramanian, A., Zampetti, A.B. (eds., 2001), Efficiency, Equity, and Legitimacy: The Multilateral Trading System at the Millennium, Harvard University and Brookings Institution Press.

Puga, D. (2002), European Regional Policies in Light of Recent Location Theory, Journal of Economic Geography 2(4), pp. 372-406.

Raybaudi-Massilia, M. (2000), Economic Geography and Multinational Enterprise, Review of International Economics 8(1), pp. 1-19.

Rygiel, P. (2001), Destins immigrés: Cher, 1920-1980, Trajectoires d'Immigrés d'Europe, Annales littéraires de l'Université de Franche Comté, Besançon.

Sapir, A. (2000), Who is Afraid of Globalization? The Challenge of Domestic Adjustment in Europe and America, in: Porter, R.B., Sauvé, P., Subramanian, A., Zampetti, A.B. (eds., 2001), Efficiency, Equity, and Legitimacy: The Multilateral Trading System at the Millennium, Harvard University and Brookings Institution Press.

Wong, Kar-yiu (2001), Direct Investment Liberalization, Commodity Trade, and Income Distribution: What Can the WTO Do?, Pacific Economic Review 7(2), pp. 377-400. 


\section{A Appendix}

\section{Derivation of equation 20:}

As firms are symmetric and varieties from different firms enter the utility function symmetrically, production quantities of different firms in one country are equal, hence $X_{i i}^{n}=X_{i i}^{h}=X_{j i}^{v}=X_{j i}^{h}=\tilde{X}_{i} \quad \forall \quad i, j \in\{1,2\} \quad \wedge \quad i \neq j$. Furthermore, we use the pricing equation 13 and the relationships $X_{i j}^{n}=(1+\tau)^{1-\sigma}\left(\frac{p_{i}}{p_{j}}\right)^{-\sigma} X_{j j}^{n}$ and $X_{i i}^{v}=(1+\tau)^{1-\sigma}\left(\frac{p_{j}}{p_{i}}\right)^{-\sigma} X_{j i}^{v}$. With these assumptions the zero-profit conditions can be written as:

$$
\begin{aligned}
F C_{n i} & =\frac{c_{X i} \widetilde{X}_{i}+\left(\frac{c_{X i}}{c_{X j}}\right)^{-\sigma}(1+\tau)^{1-\sigma} c_{X i} \widetilde{X}_{j}}{\sigma-1}, \\
F C_{v i} & =\frac{c_{X j} \widetilde{X}_{j}+\left(\frac{c_{X j}}{c_{X i}}\right)^{-\sigma}(1+\tau)^{1-\sigma} c_{X j} \widetilde{X}_{i}}{\sigma-1}, \\
F C_{h i} & =\frac{c_{X i} \widetilde{X}_{i}+c_{X j} \widetilde{X}_{j}}{\sigma-1} .
\end{aligned}
$$

Taking the difference between $F C_{h i}$ and $F C_{v i}$, we can solve for $\widetilde{X}_{i}$ :

$$
\widetilde{X}_{i}=\frac{\left(F C_{h i}-F C_{v i}\right)(\sigma-1)}{c_{X i}-c_{X j}(1+\tau)^{1-\sigma}\left(\frac{c_{X j}}{c_{X i}}\right)^{-\sigma}} .
$$

Similar, by taking the difference between $F C_{h i}$ and $F C_{n i}$ we can solve for $\widetilde{X}_{j}$ :

$$
\widetilde{X}_{j}=\frac{\left(F C_{h i}-F C_{n i}\right)(\sigma-1)}{c_{X j}-c_{X i}(1+\tau)^{1-\sigma}\left(\frac{c_{X i}}{c_{X j}}\right)^{-\sigma}} .
$$

Note that in equations A2 and A3 the nominator is always positive. As quantities are restricted to be positive, the following two conditions have to hold: $(1+\tau)^{1-\sigma}\left(\frac{c_{X i}}{c_{X j}}\right)^{\sigma-1}<1$ and $(1+\tau)^{1-\sigma}\left(\frac{c_{X j}}{c_{X i}}\right)^{\sigma-1}<1$.

Combining leads to:

$$
\frac{1}{1+\tau}<\frac{c_{X j}}{c_{X i}}<1+\tau
$$

This condition implies that differences in variable costs are restricted to be within a range whose boundaries depend on the transport costs $\tau$ in order to render coexistence of all three firm types possible. Outside this range, one of the firms 
does no longer exist. Note that condition (A4) is necessary for coexistence but not sufficient.

Plugging the expressions for $\widetilde{X}_{i}$ and $\widetilde{X}_{j}$ (i.e., using equations A2 and A3) in the zero-profit condition for $n_{i}$, we can write:

$$
\frac{F C_{n i}}{c_{X i}}=\frac{F C_{h i}-F C_{v i}}{c_{X i}-\left(\frac{c_{X i}}{c_{X j}}\right)^{\sigma}(1+\tau)^{1-\sigma} c_{X j}}+\frac{(1+\tau)^{1-\sigma}\left(\frac{c_{X j}}{c_{X i}}\right)^{\sigma}\left(F C_{h i}-F C_{n i}\right)}{c_{X j}-\left(\frac{c_{X j}}{c_{X i}}\right)^{\sigma}(1+\tau)^{1-\sigma} c_{X i}} .
$$




\section{S1 Figures of Real Factor Rewards}

Figures 9-15 display the real factor rewards in the long-run stable equilibria of the bifurcation diagrams with mobile skilled and unskilled labor. From these figures, we learn for which values of trade costs trade liberalization is Pareto-improving. These regions are depicted in Figure 6 in the paper.

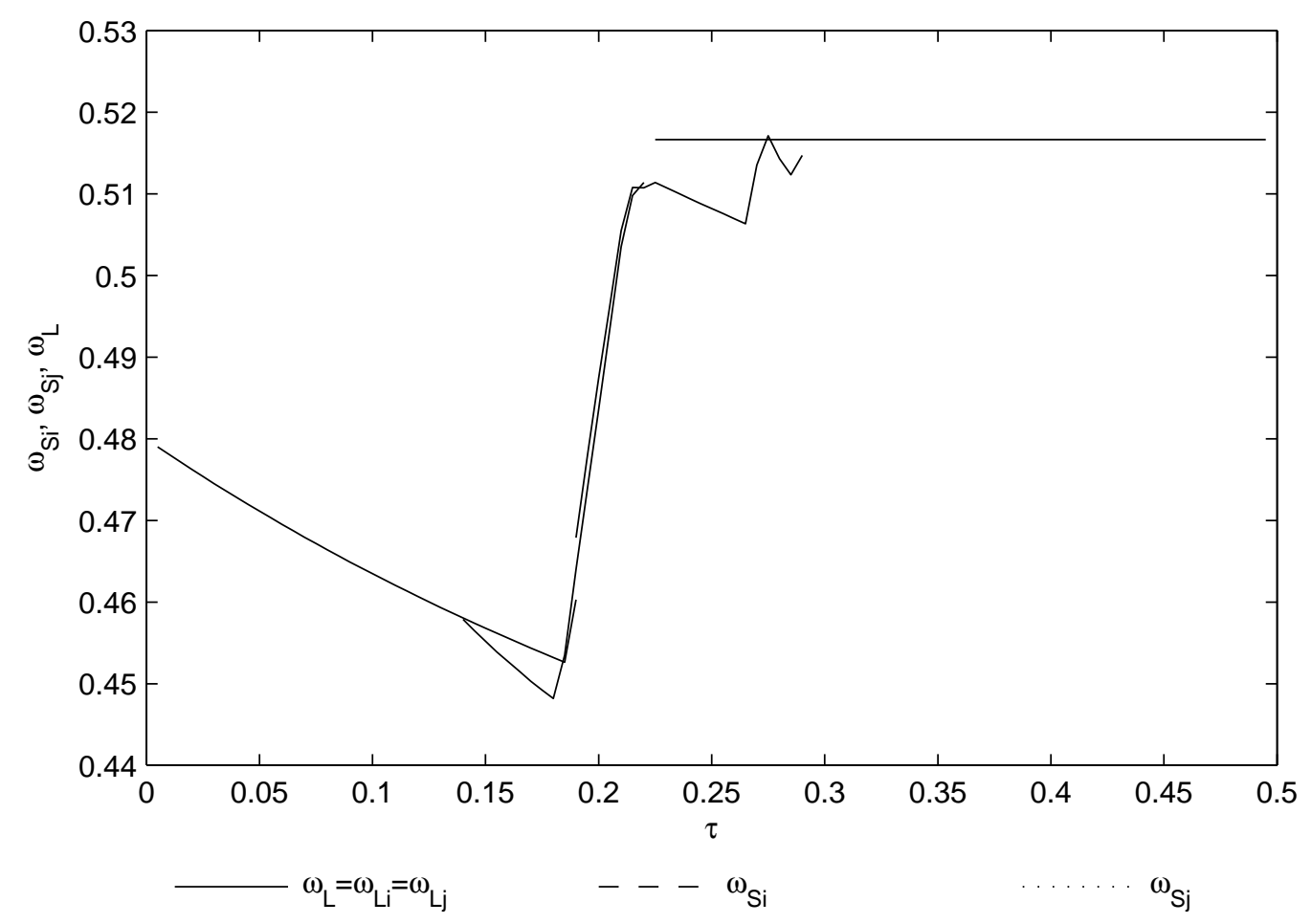

Figure 9: Real factor rewards of unskilled labor in the stable equilibria of the bifurcation with mobile unskilled labor. 


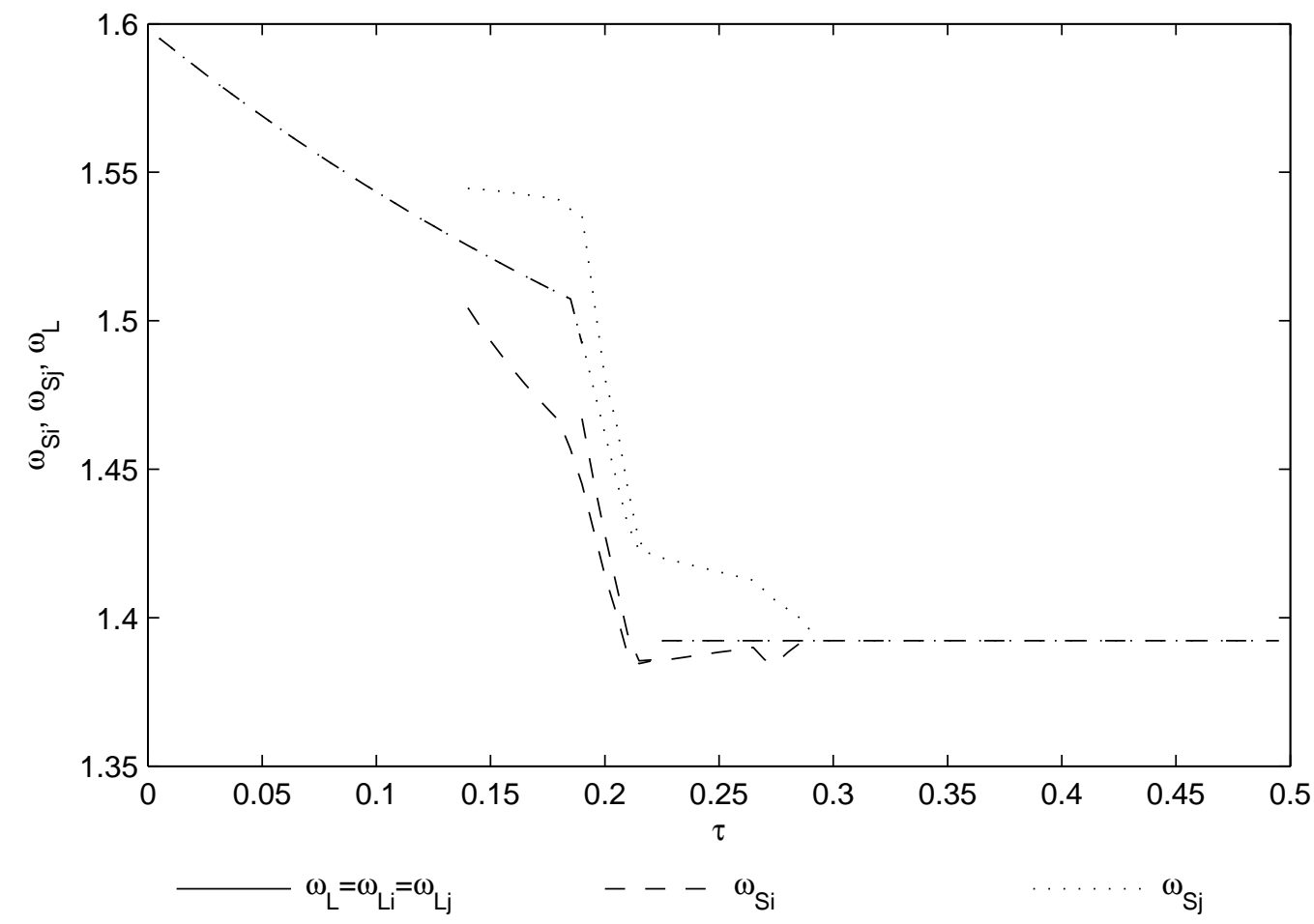

Figure 10: Real factor rewards of skilled labor in the stable equilibria of the bifurcation with mobile unskilled labor.

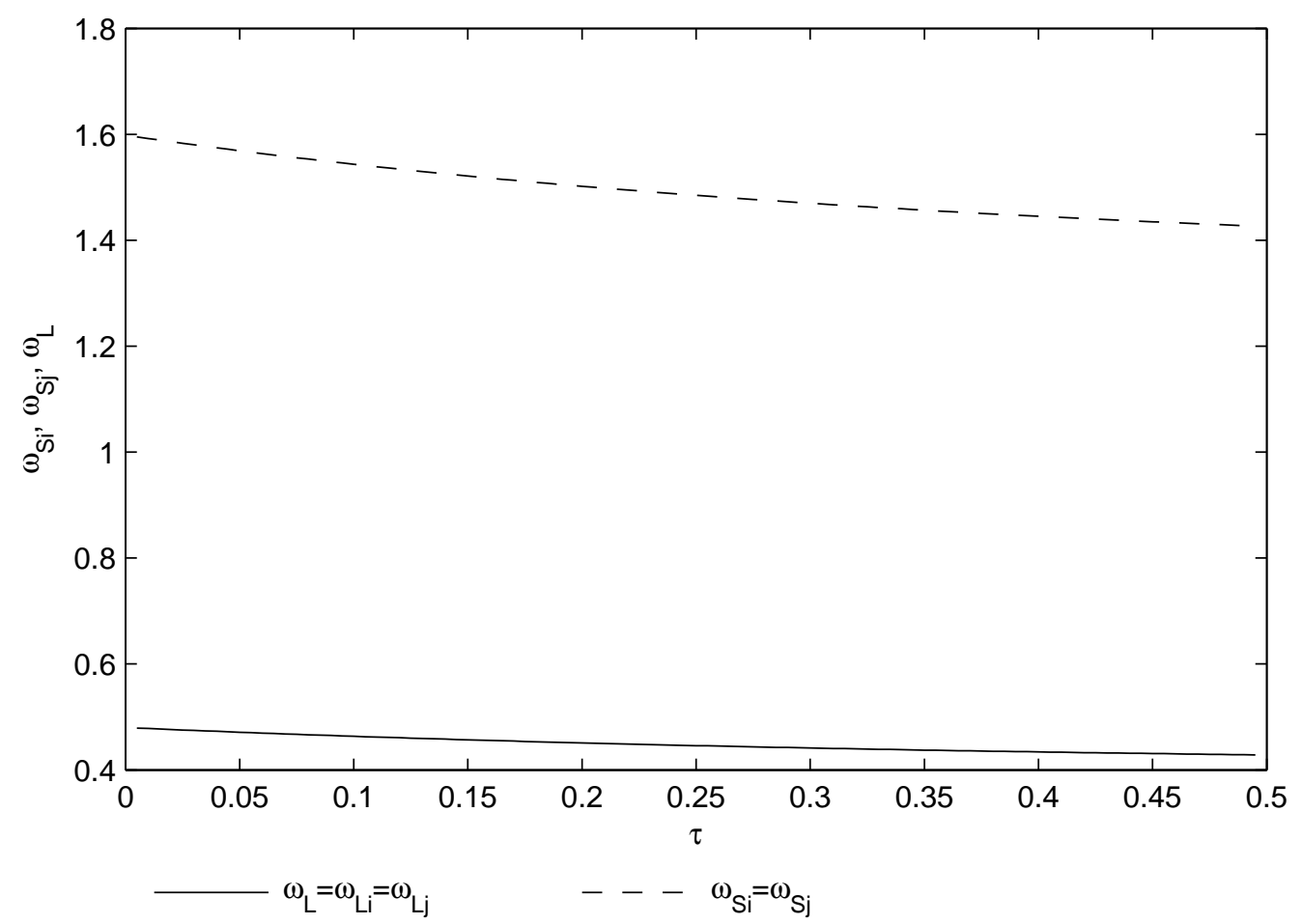

Figure 11: Real factor rewards in the stable equilibria of the bifurcation with mobile unskilled labor, NEs only. 


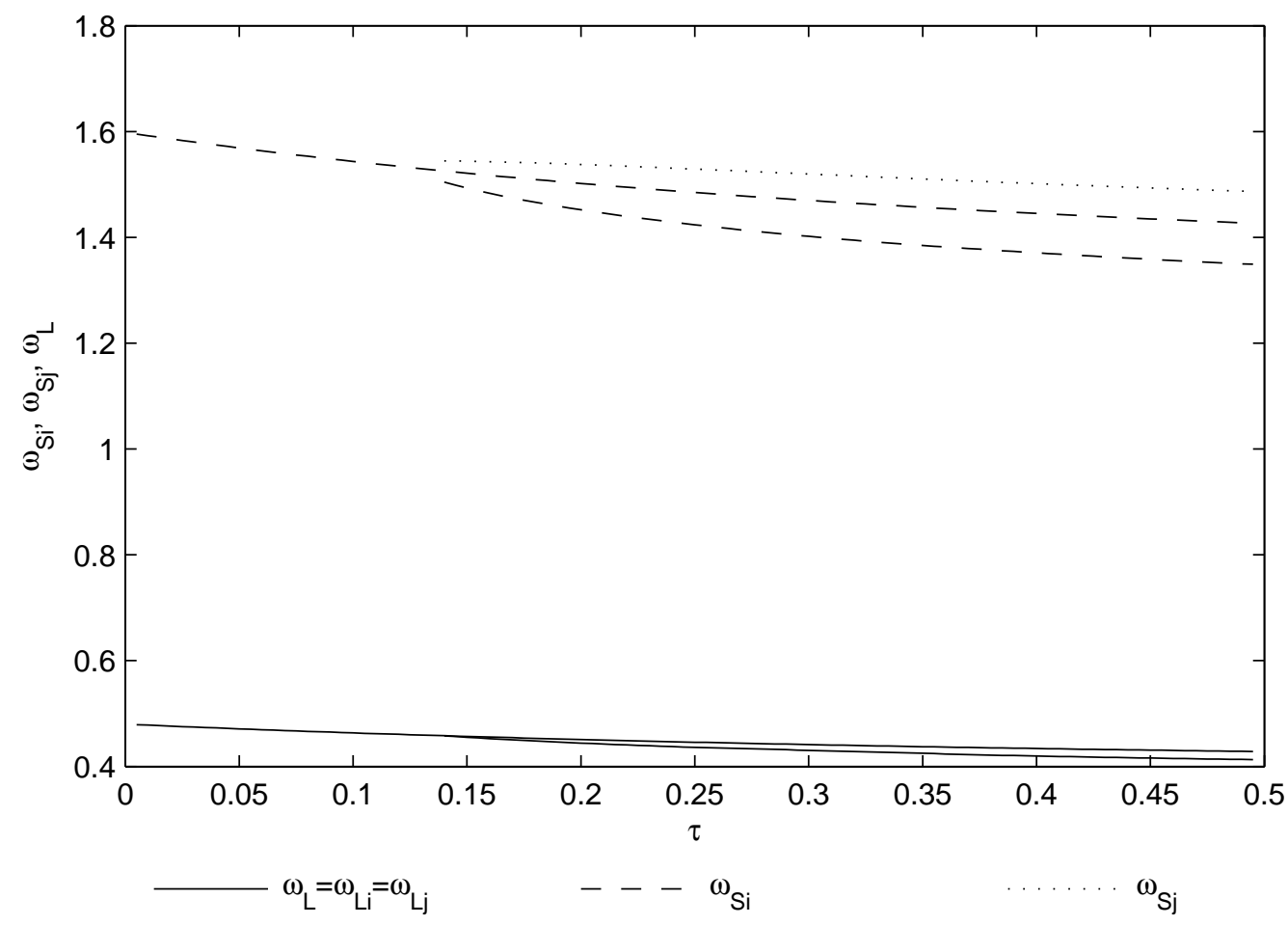

Figure 12: Real factor rewards in the stable equilibria of the bifurcation with mobile unskilled labor, NEs and vertical MNEs only.

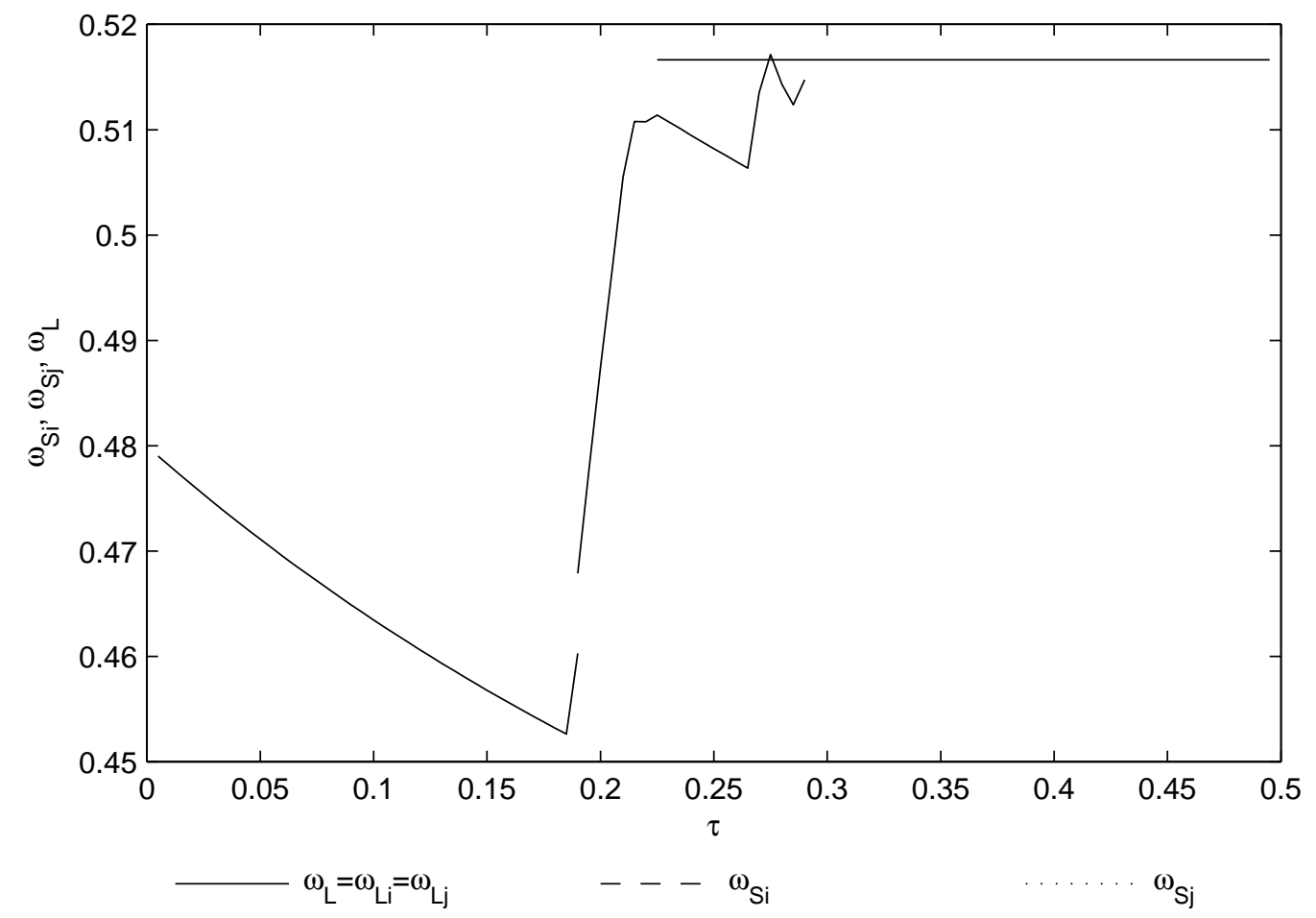

Figure 13: Real factor rewards in the stable equilibria of the bifurcation with mobile unskilled labor, NEs and horizontal MNEs only. 


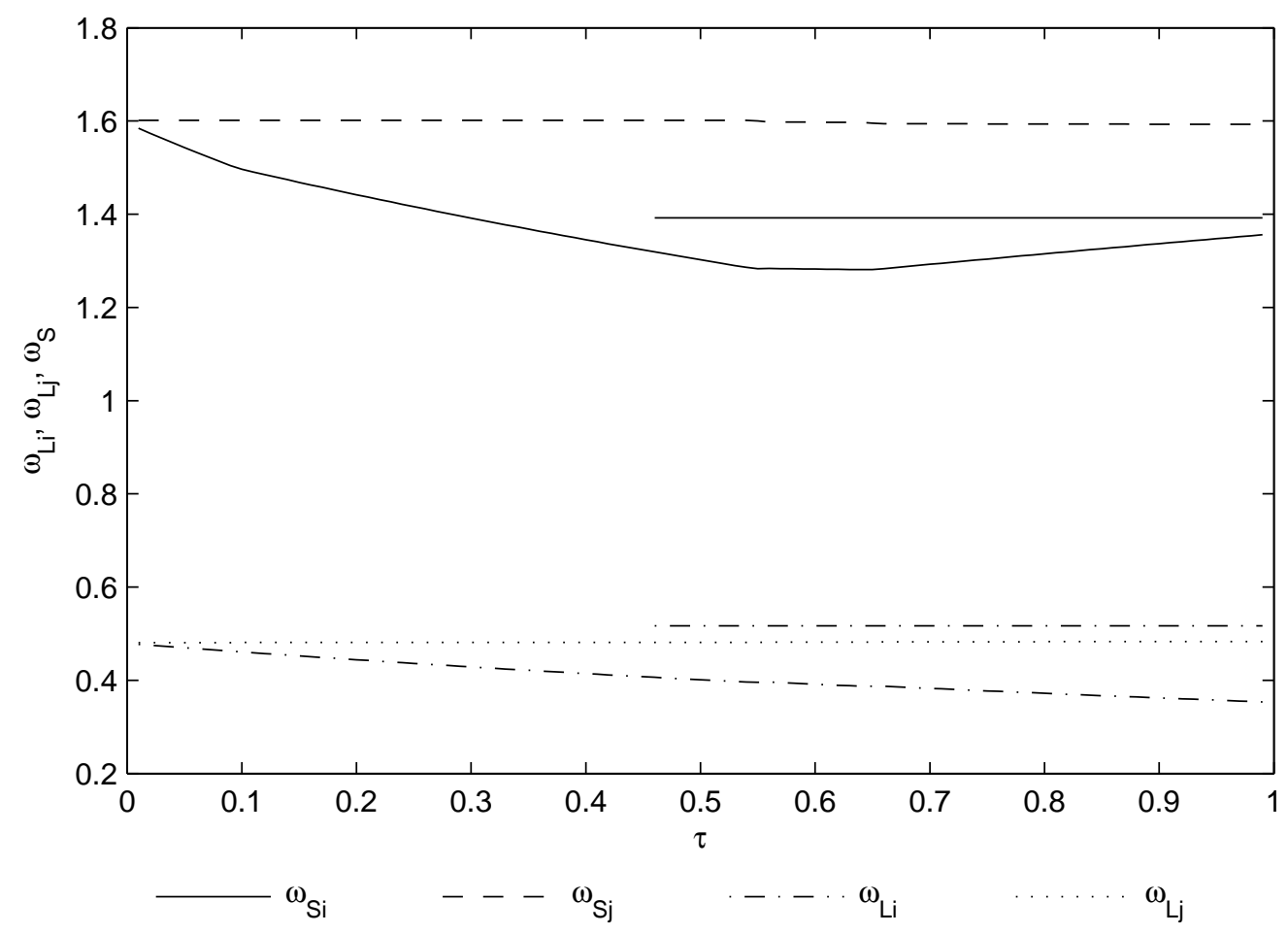

Figure 14: Real factor rewards in the stable equilibria of the bifurcation with mobile skilled labor, all firms allowed, and NEs and horizontal MNEs only.

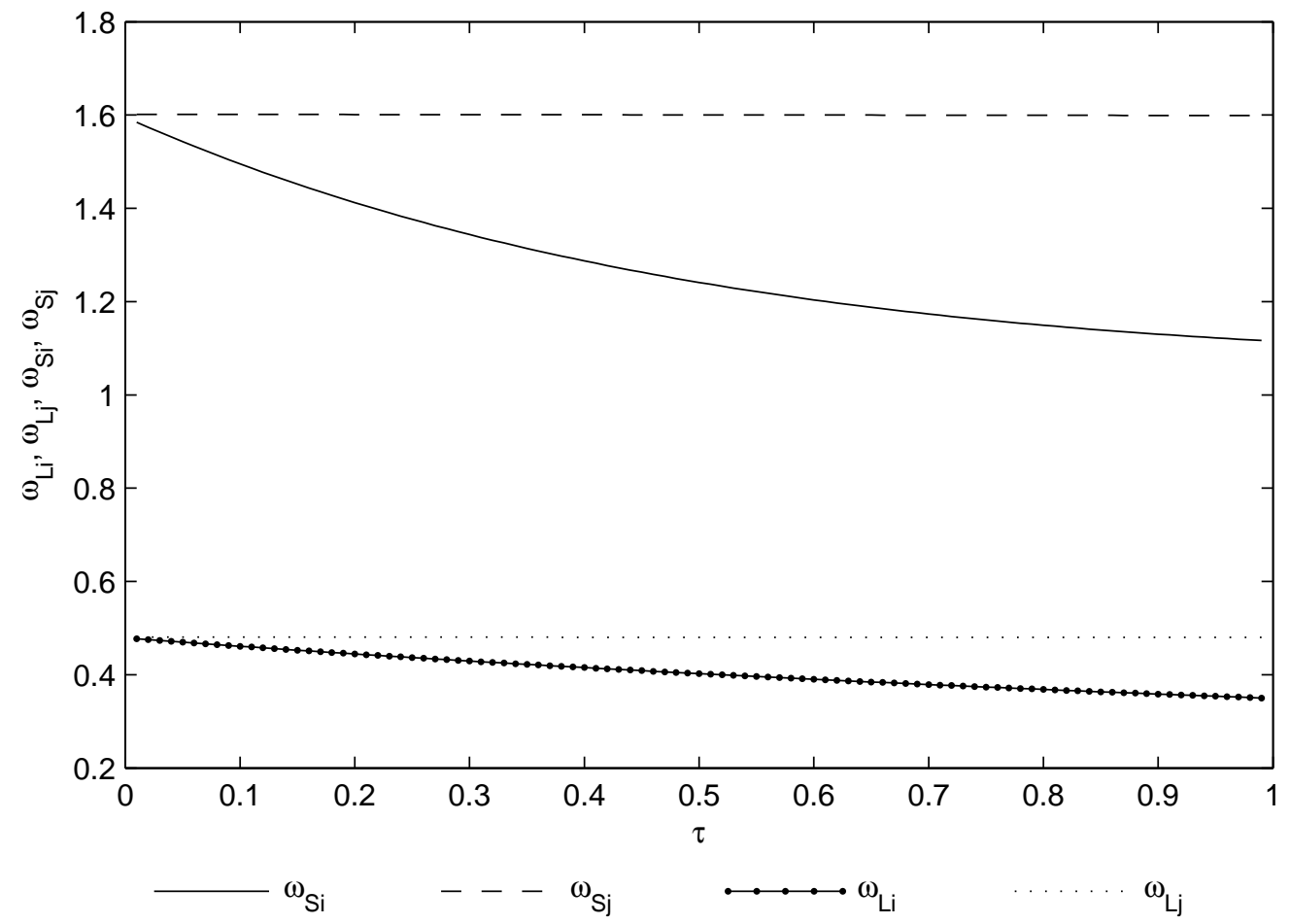

Figure 15: Real factor rewards in stable equilibria of the bifurcation with mobile skilled labor, NEs only, and NEs and vertical MNEs only. 


\section{S2 Existence of Firm-types}

Figures $3(\mathrm{n})-5(\mathrm{v})$ and $(6(\mathrm{n})-6 \mathrm{~b}(\mathrm{v}))$ shed light on the existence, or non-existence,

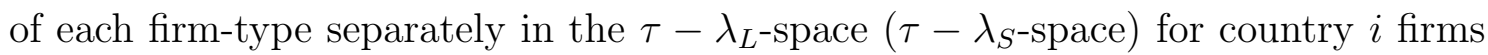
and all four scenarios of firm regimes. Remember that the effects of the existence of firm-types on the core-periphery patterns is discussed in the main text. ${ }^{1}$ Here, we show for which values of transport costs and for which "size" of a country (where size means a country's share of the mobile factor) the different firm-types are present.

\section{S2.1 Unskilled Labor Mobility}

First, we discuss all the scenarios in the case of unskilled labor mobility. Figures $3(\mathrm{n})-3(\mathrm{v})$ show the firm configuration for our standard scenario with all firm-types allowed. In this case, NEs mainly exist at low transport costs (see Figure 3(n)), whereas horizontal MNEs dominate at high values of transport costs (see Figure 3(h)). Vertical MNEs, on the other hand, exist at all levels of transport costs, but only at a very small scale when country $i$ is very well endowed with unskilled labor (see Figure $3(\mathrm{v})$ ). Note that country $i$-based firms become extinct, if a very small share of the mobile factor is located in country $i$.

When only NEs and horizontal MNEs are allowed, NEs dominate at low transport costs and when unskilled labor is very scarce (see Figure 4(n)). Horizontal MNEs are present at high transport costs and for very high unskilled labor endowments (see Figure 4(h)).

If only NEs and vertical MNEs may arise endogenously, NEs dominate almost everywhere (see Figure 5(n)). If a country is well endowed with unskilled labor, vertical MNEs are present at all values of transport costs (see Figure 5(v)). Furthermore, vertical MNEs occur in a lens at higher transport costs with the mobile factor being rather scarce.

\footnotetext{
${ }^{1}$ Note that we omit the scenario of NEs only, since in this case NEs exist throughout, for all values of transport costs and endowments with the mobile factor, and for both modes of factor mobility, respectively.
} 


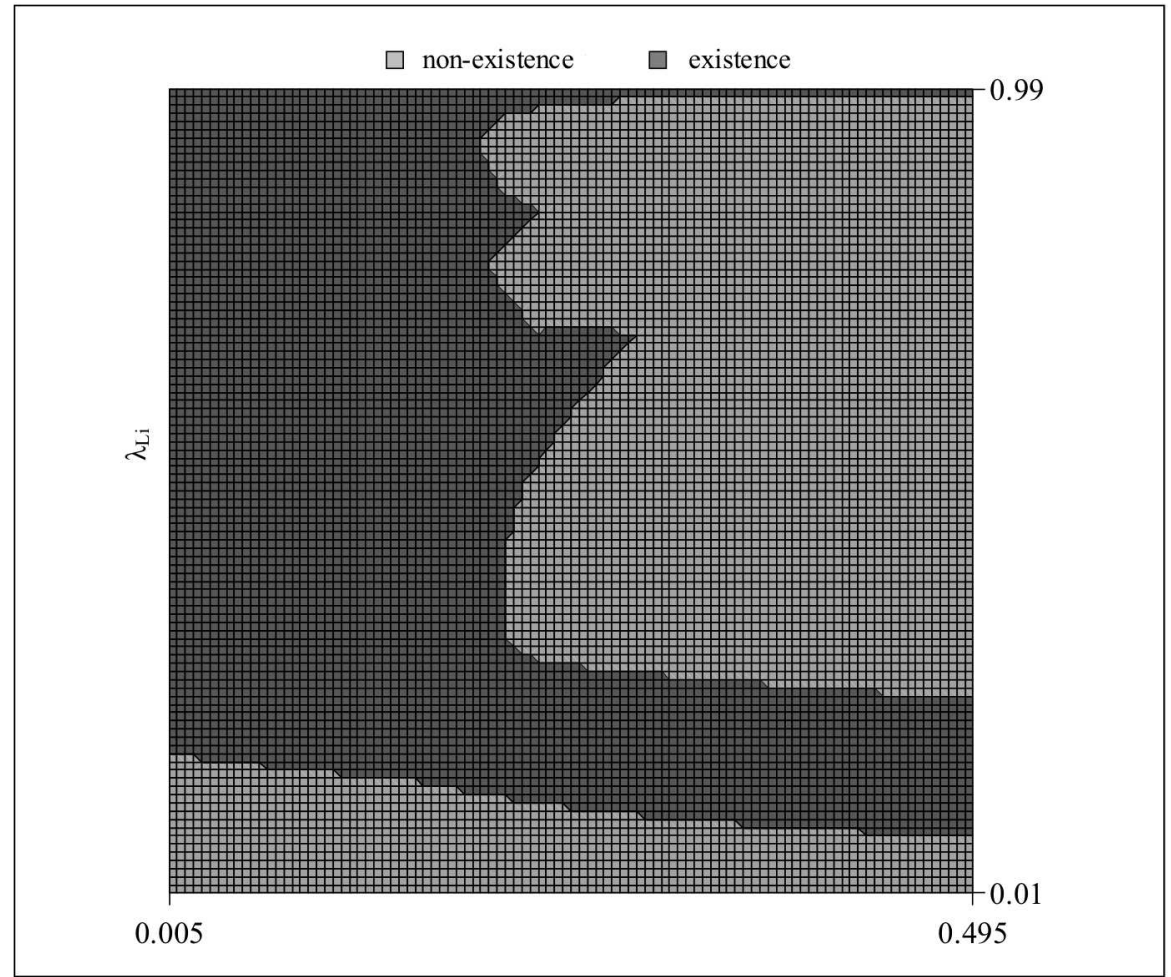

Figure 3(n): Scenario "all firm-types allowed": Existence of NEs

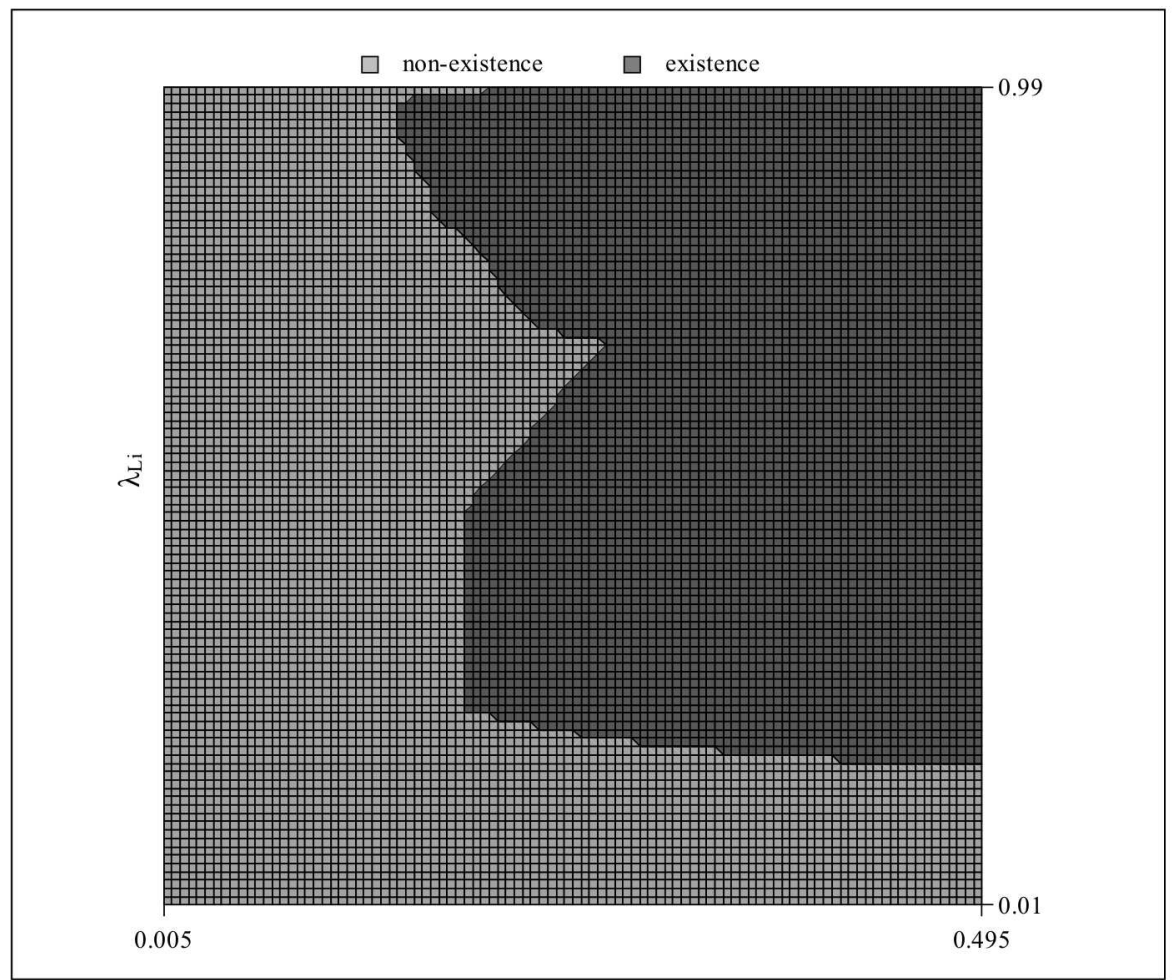

Figure 3(h): Scenario "all firm-types allowed": Existence of horizontal MNEs 


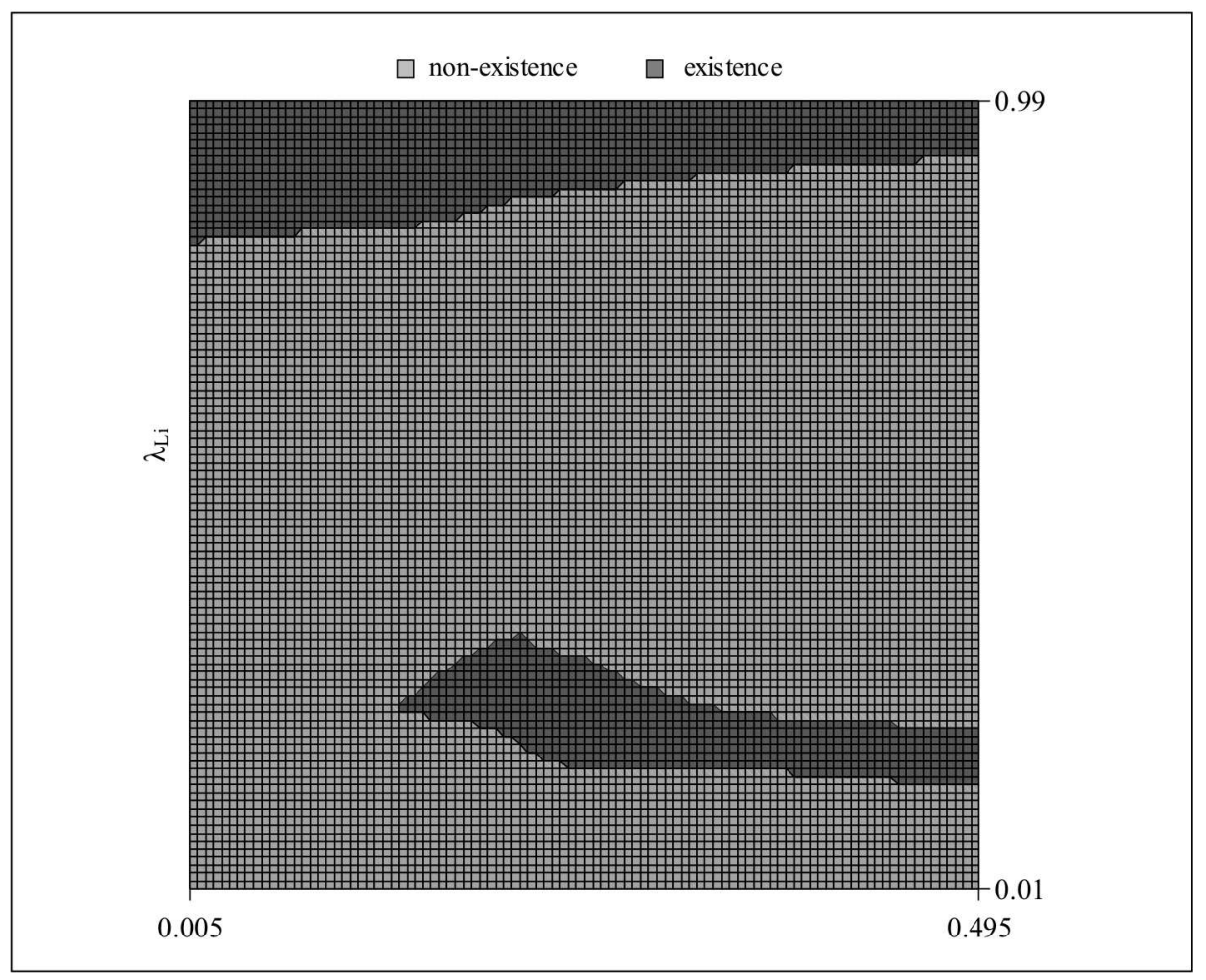

Figure 3(v): Scenario "all firm-types allowed": Existence of vertical MNEs

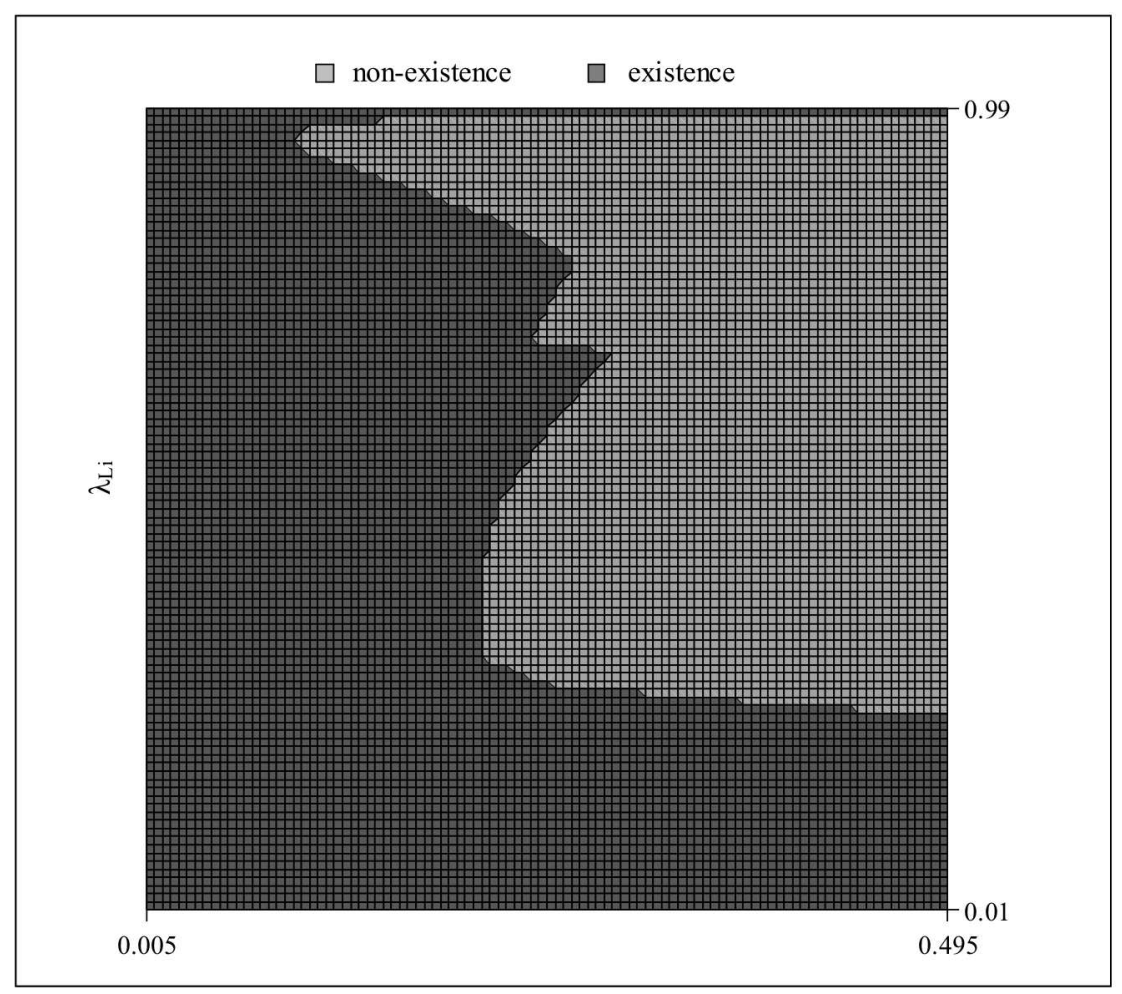

Figure 4(n): Scenario "NEs and horizontal MNEs only": Existence of NEs 


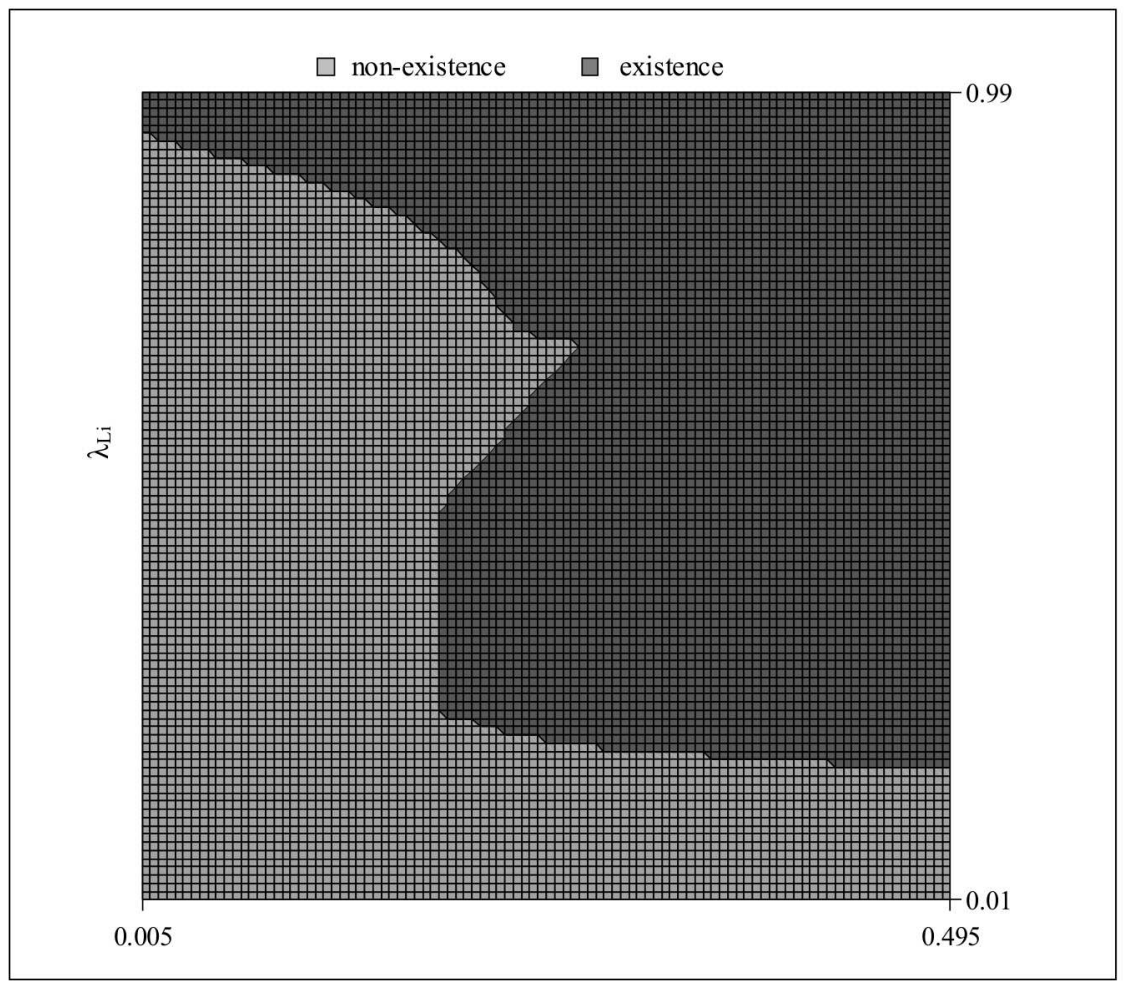

Figure 4(h): Scenario "NEs and horizontal MNEs only": Existence of horizontal MNEs

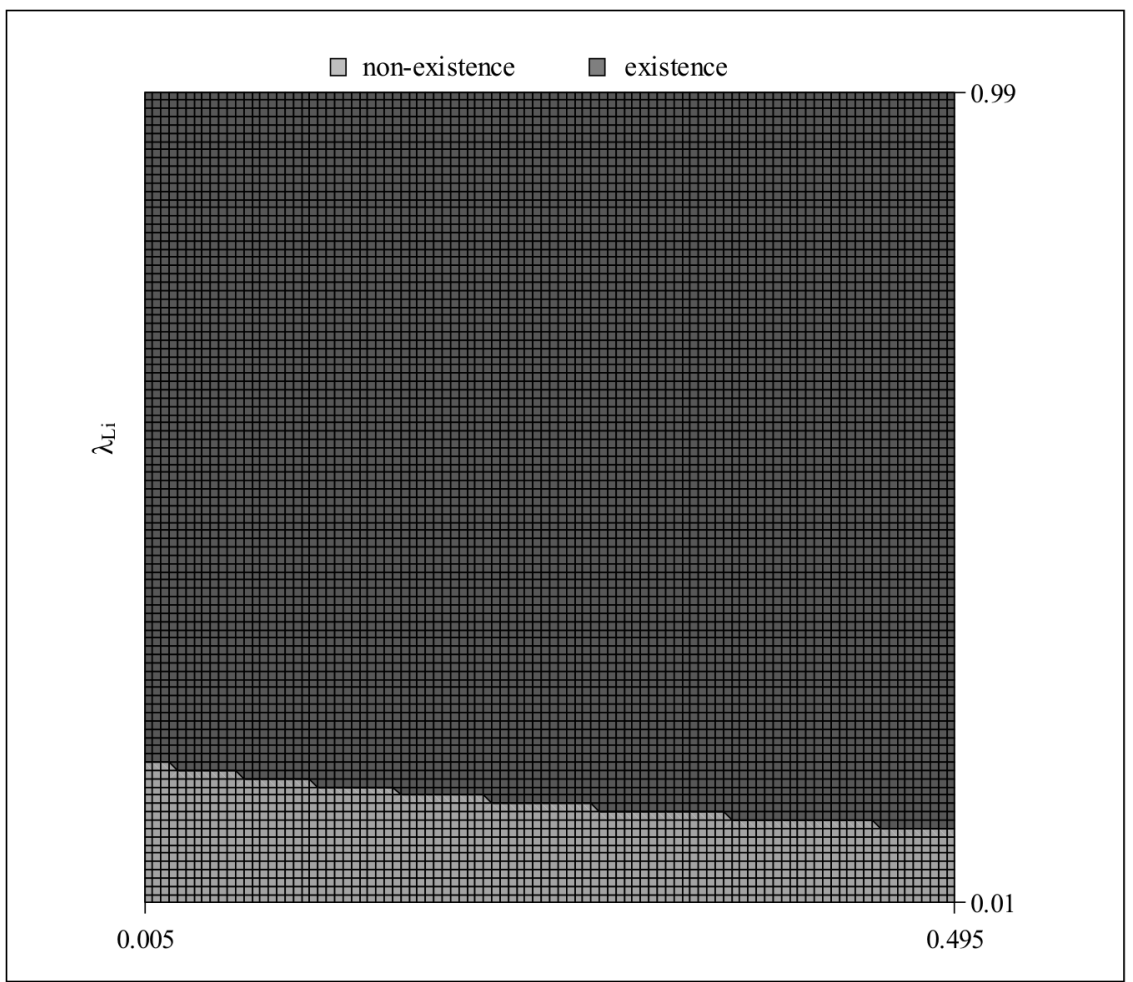

Figure 5(n): Scenario "NEs and vertical MNEs only": Existence of NEs 


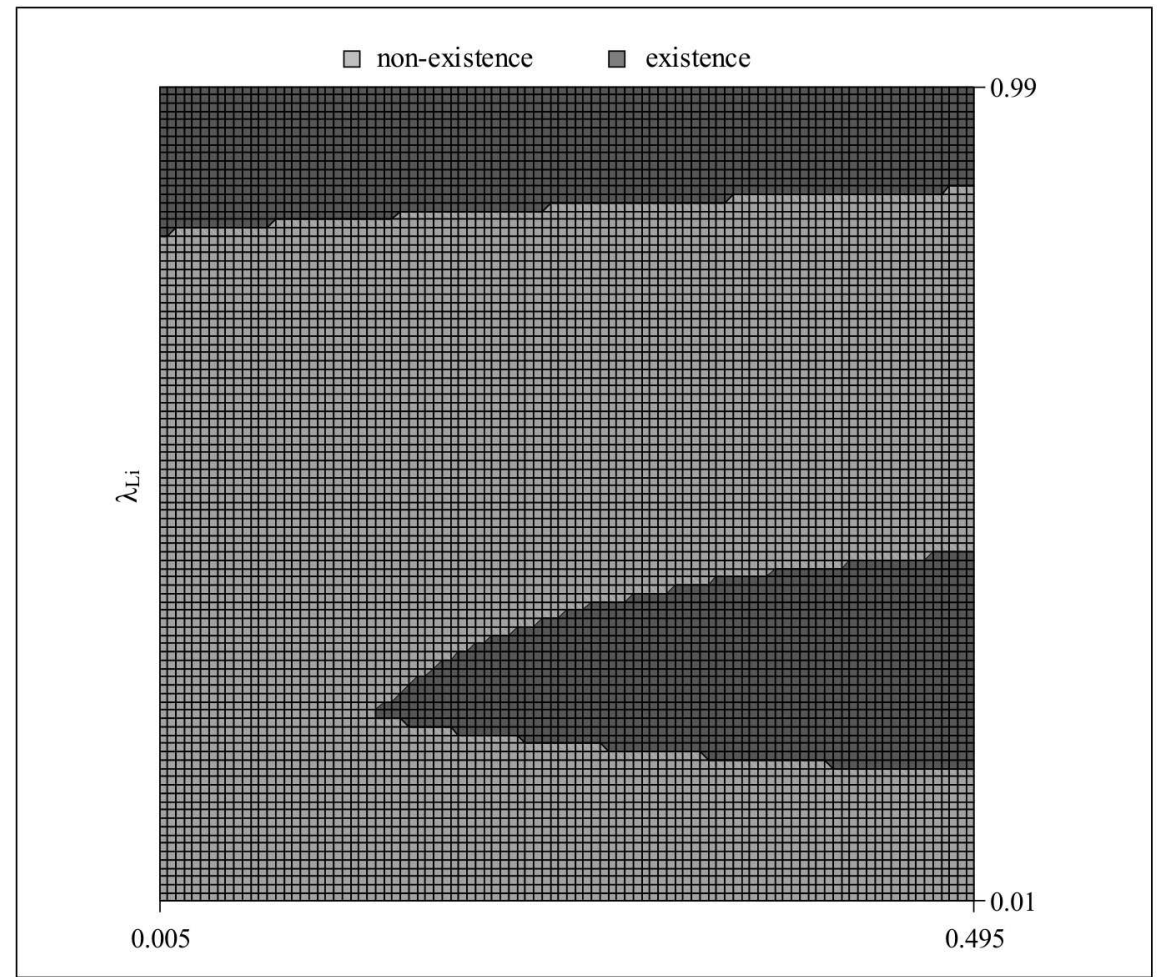

Figure 5(v): Scenario "NEs and vertical MNEs only": Existence of vertical MNEs

\section{S2.2 Skilled Labor Mobility}

Now, we investigate the existence of firm-types for all scenarios of skilled labor mobility. Figures $6(\mathrm{n})-6(\mathrm{v})$ illustrate the firm-configuration in our standard scenario when all types of firms are allowed to coexist. Again, NEs mainly exist at low transport costs, but if skilled labor is abundant, they also come into existence at higher transport costs (see Figure 6(n)). Horizontal MNEs dominate at high transport costs (see Figure 6(h)). Vertical MNEs, however, only play a somewhat minor role in this scenario, since they only exist at low values of transport costs when skilled labor is quite scarce (see Figure 6(v)).

In the scenario with NEs and horizontal MNEs only, both NEs and horizontal MNEs arise in similar configurations as in the scenario with all types of firms (see Figures $6 \mathrm{a}(\mathrm{n})$ and $6 \mathrm{a}(\mathrm{h}))$.

If only NEs and vertical MNEs are allowed, NEs dominate almost everywhere (see Figure 6b(n)). Vertical MNEs occur only at skilled labor abundance, almost regardless of the level of transport costs (see Figure $6 \mathrm{~b}(\mathrm{v})$ ). 


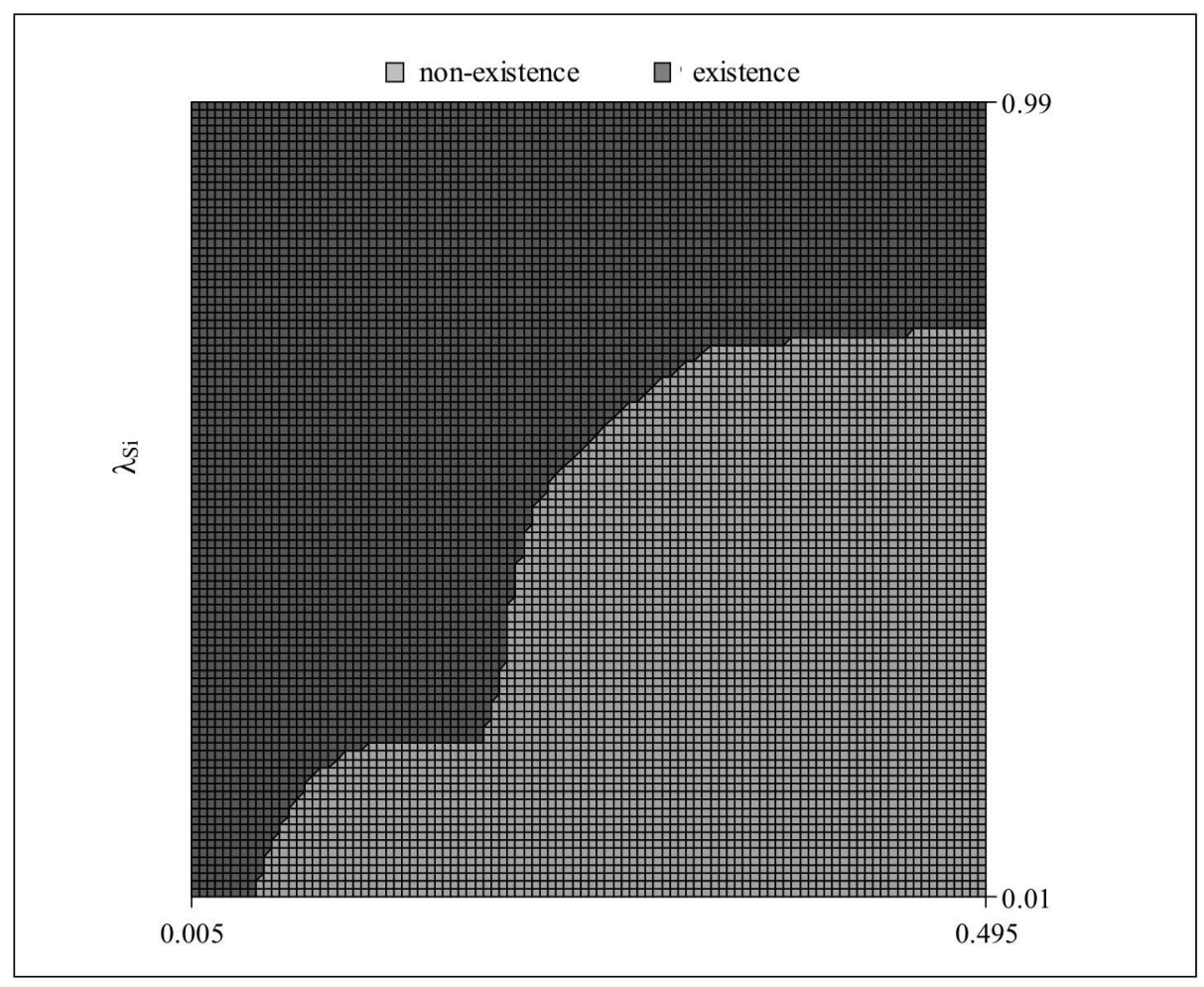

Figure 6(n): Scenario "all firm-types allowed": Existence of NEs

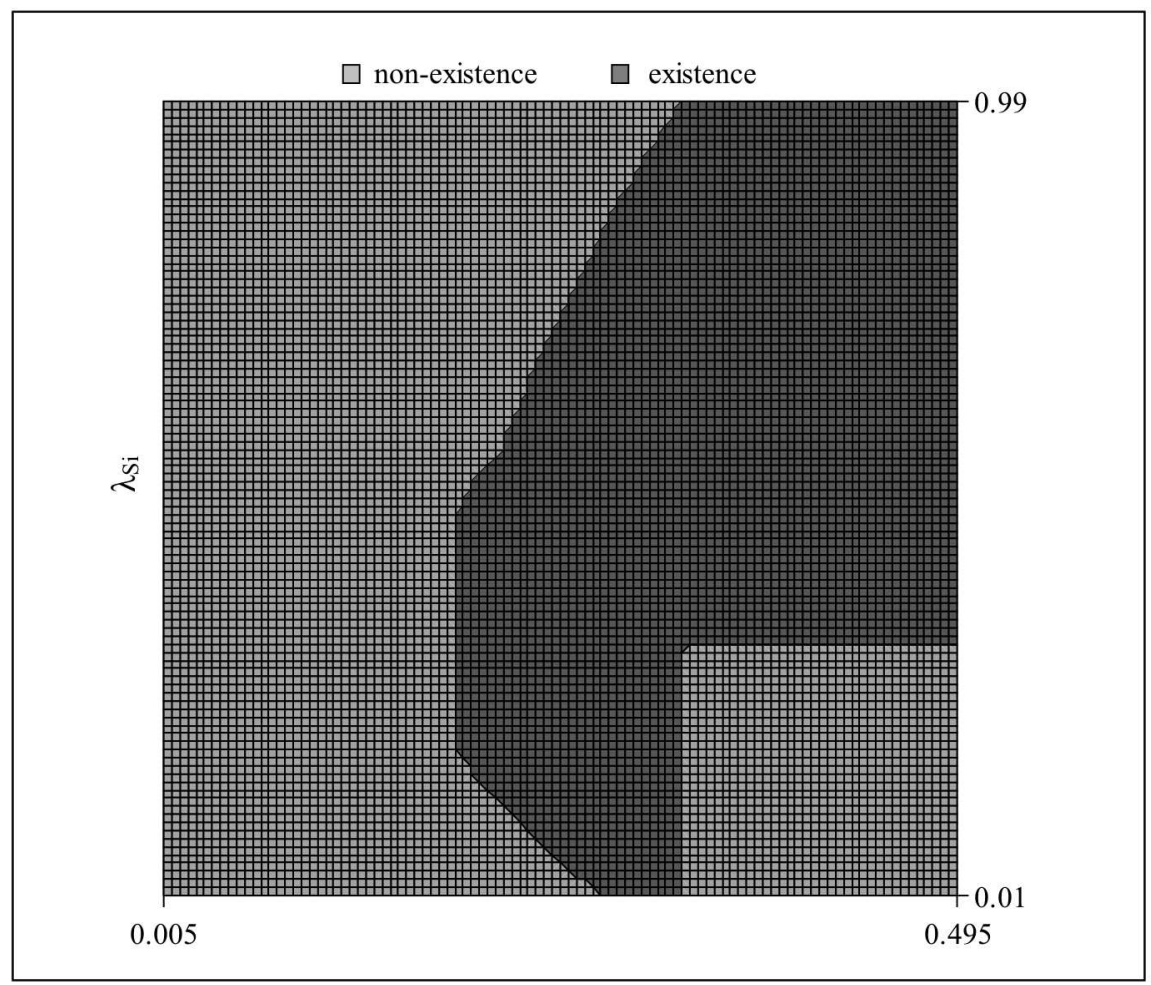

Figure 6(h): Scenario "all firm-types allowed": Existence of horizontal MNEs 


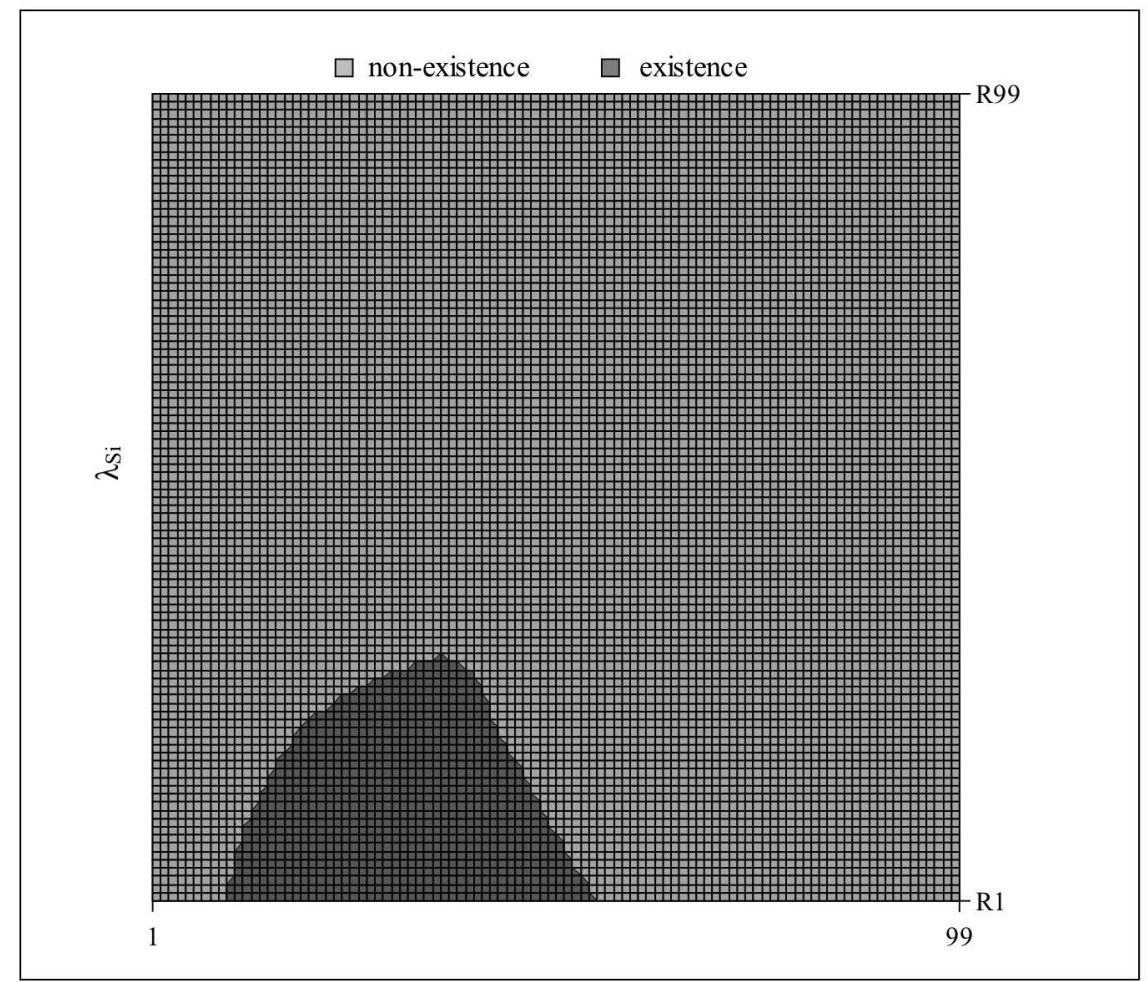

Figure 6(v): Scenario "all firm-types allowed": Existence of vertical MNEs

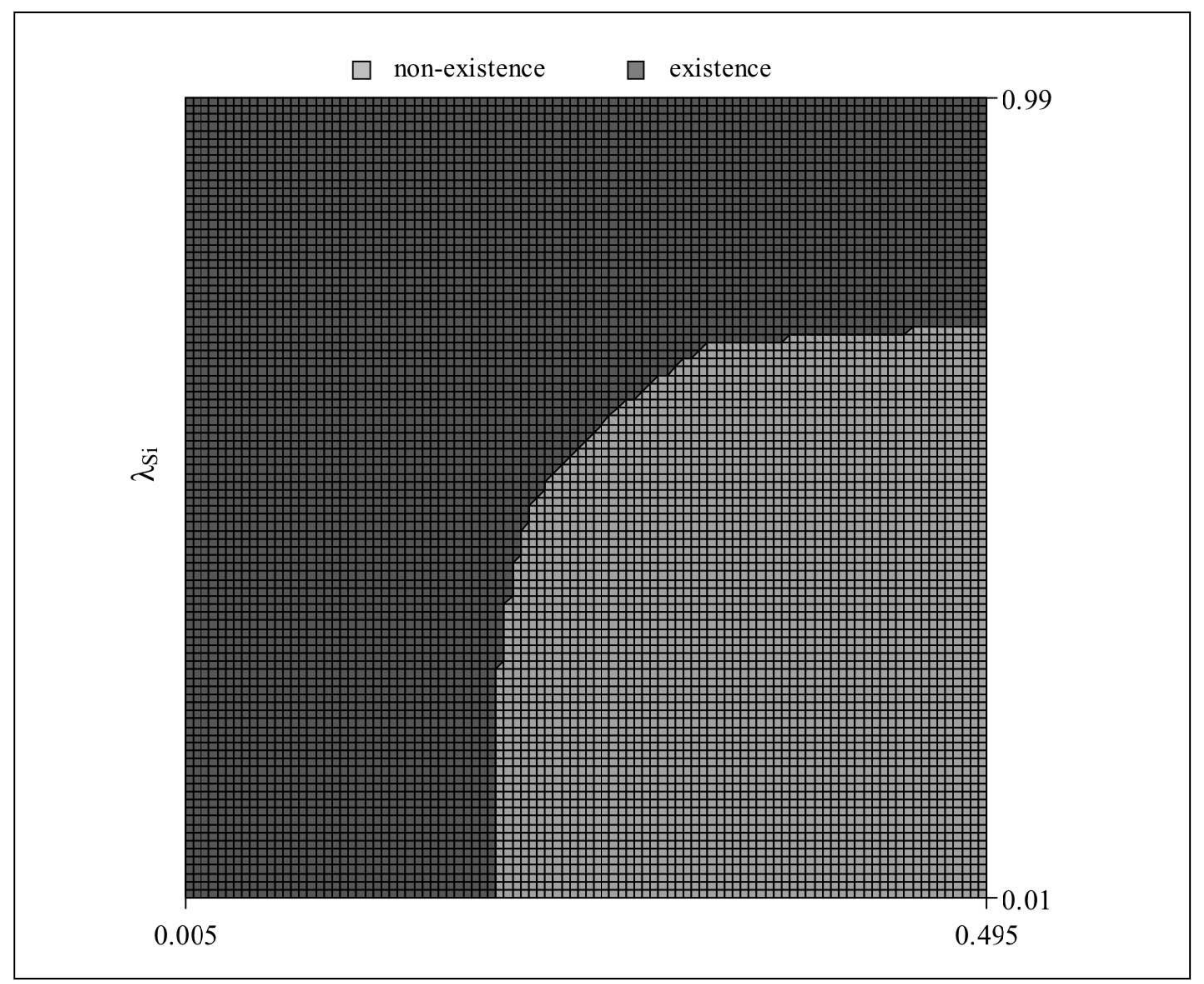

Figure 6a(n): Scenario "NEs and horizontal MNEs only": Existence of NEs 


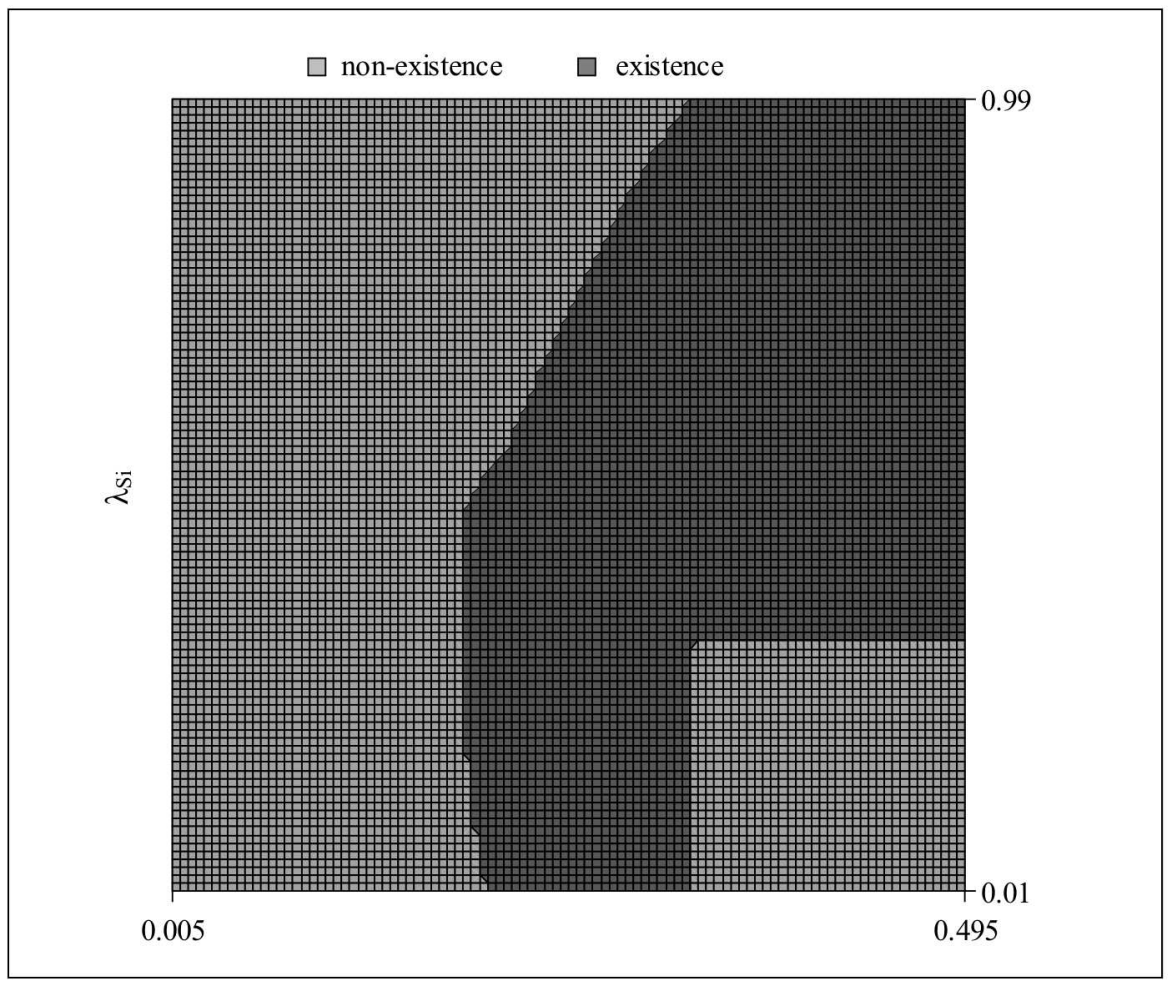

Figure 6a(h): Scenario "NEs and horizontal MNEs only": Existence of horizontal MNEs

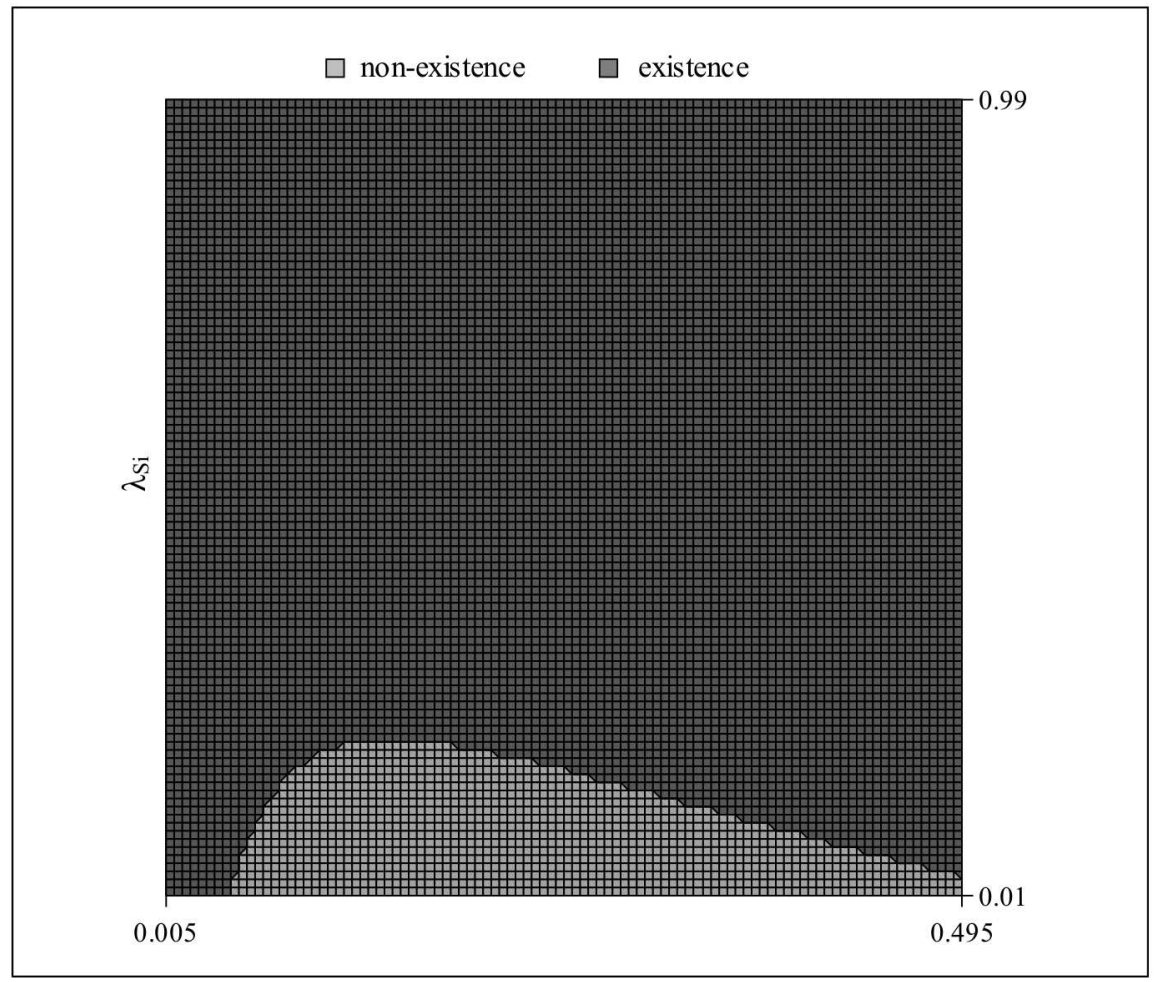

Figure 6b(n): Scenario "NEs and vertical MNEs only": Existence of NEs 


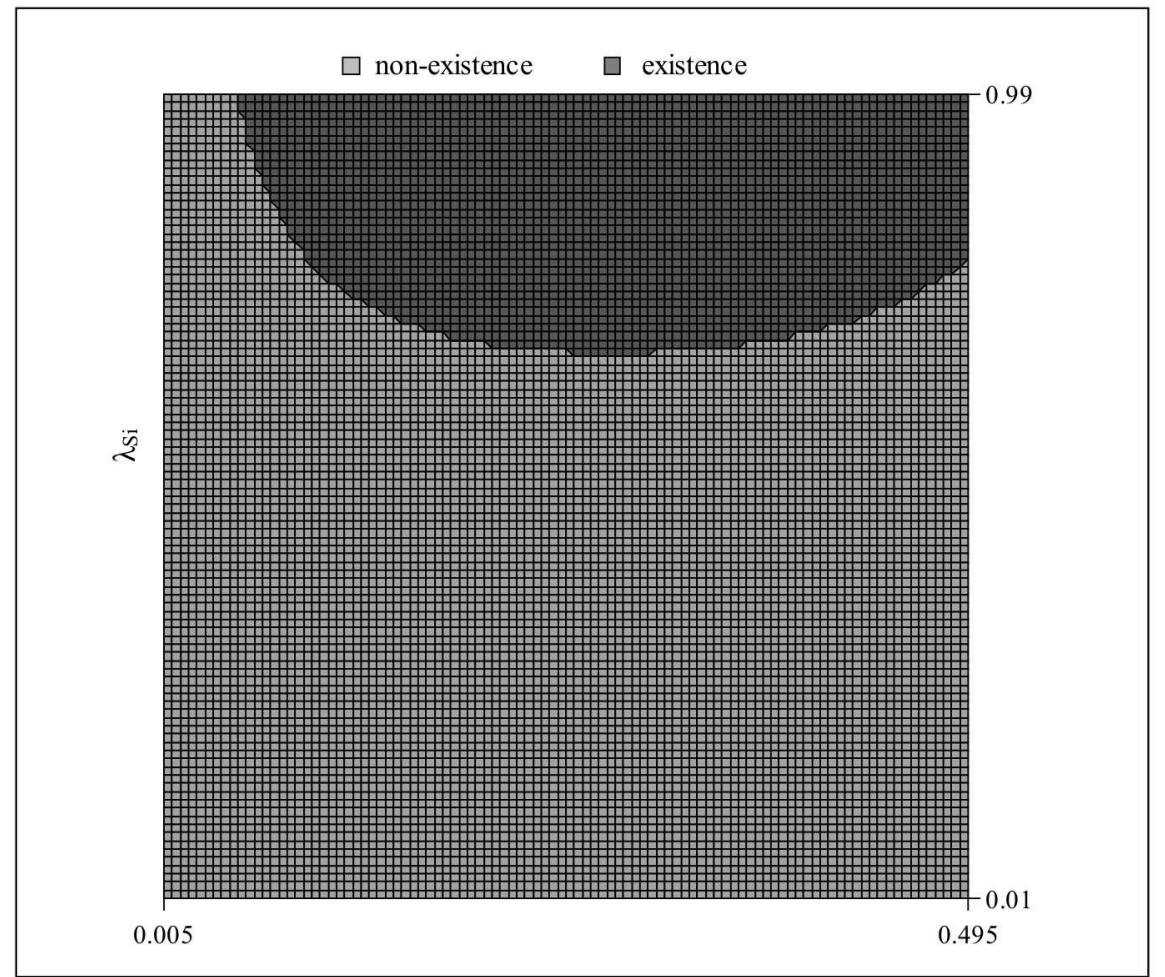

Figure 6b(v): Scenario "NEs and vertical MNEs only": Existence of vertical MNEs

\section{S3 Robustness}

In the following, we investigate the sensitivity of our findings with respect to changes in the parameters $\mu, \rho$ and $\sigma$. For every new parameter value, we analyze the effects with respect to our two reference cases for unskilled as well as skilled labor mobility, where the respective immobile factor is equally allocated between the two countries. These reference cases correspond to Figures 3 and 6 in the paper. Additionally, we run experiments for unequal endowments with the immobile factor for both of our reference scenarios.

\section{S3.1 Alternative Values of $\mu$}

Originally, we let consumers spend $80 \%$ of their income on manufactured goods ( $\mu=0.8$ ). We lower this value to (i) $\mu=0.7$, (ii) $\mu=0.5$ and (iii) $\mu=0.3$, where the latter corresponds to the value frequently used in new economic geography models, for instance in Krugman (1991b) or Ekholm and Forslid (2001).

For both mobile unskilled labor (Figures $3 \mu(0.3), 3 \mu(0.5), 3 \mu(0.7))$ and mobile skilled 
labor (Figures $6 \mu(0.3), 6 \mu(0.5), 6 \mu(0.7))$, we find that for lower values of $\mu$, MNEs become less important, because less income is spent on manufactured goods so that this industry becomes smaller. When gradually lowering $\mu$, the attractiveness of MNEs diminishes, such that the equilibrium area of horizontal MNEs becomes smaller and even vanishes. It is noteworthy that the dominance of horizontal MNEs diminishes in a more pronounced way than that of vertical MNEs, since they face higher fixed costs. Vertical MNEs, on the other hand, exhibit the opportunity to exploit factor price differentials between countries.

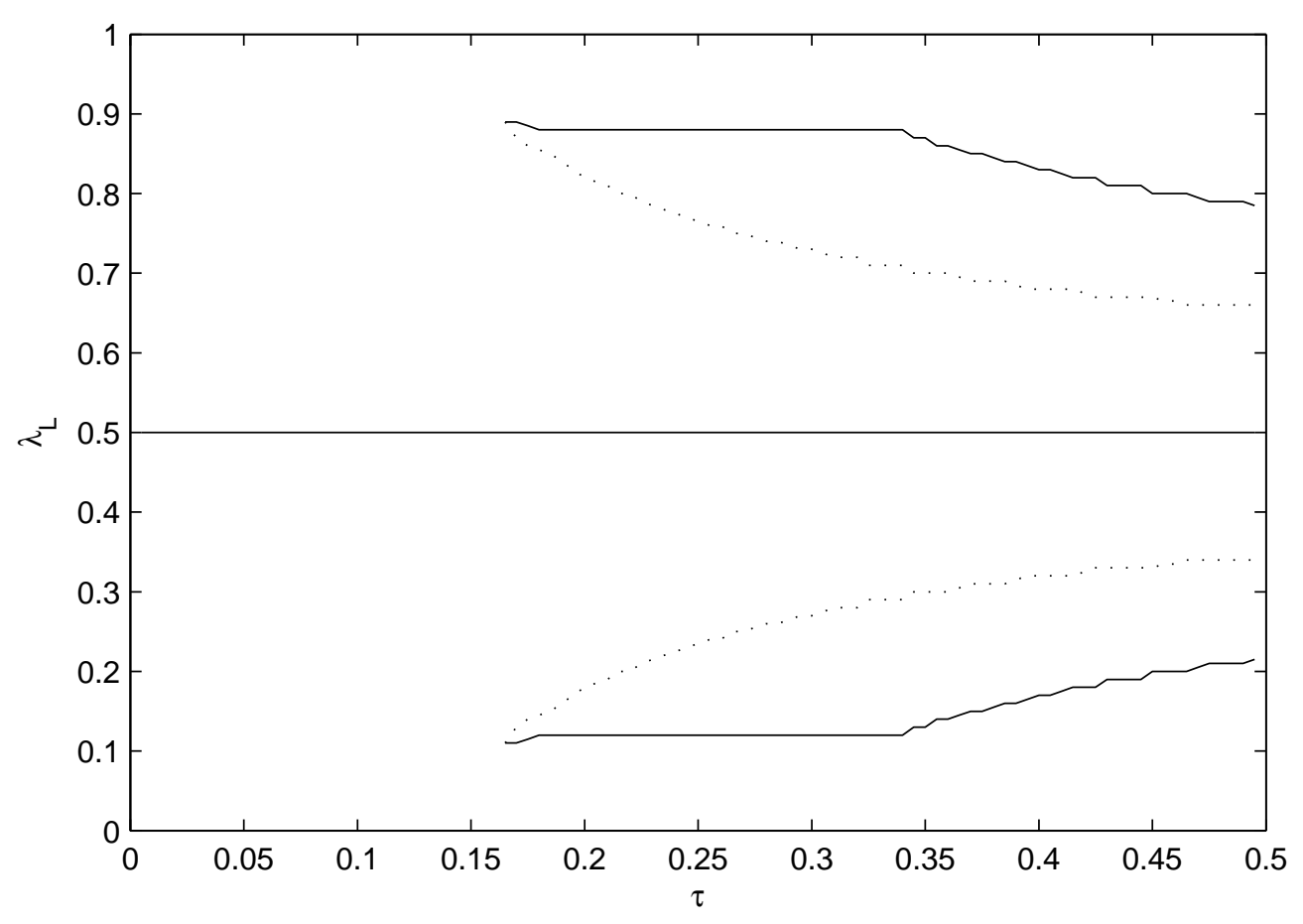

Figure $3 \mu(0.3)$ : Bifurcation with mobile unskilled labor, $\mu=0.3$, and $\lambda_{S}=0.5$. 


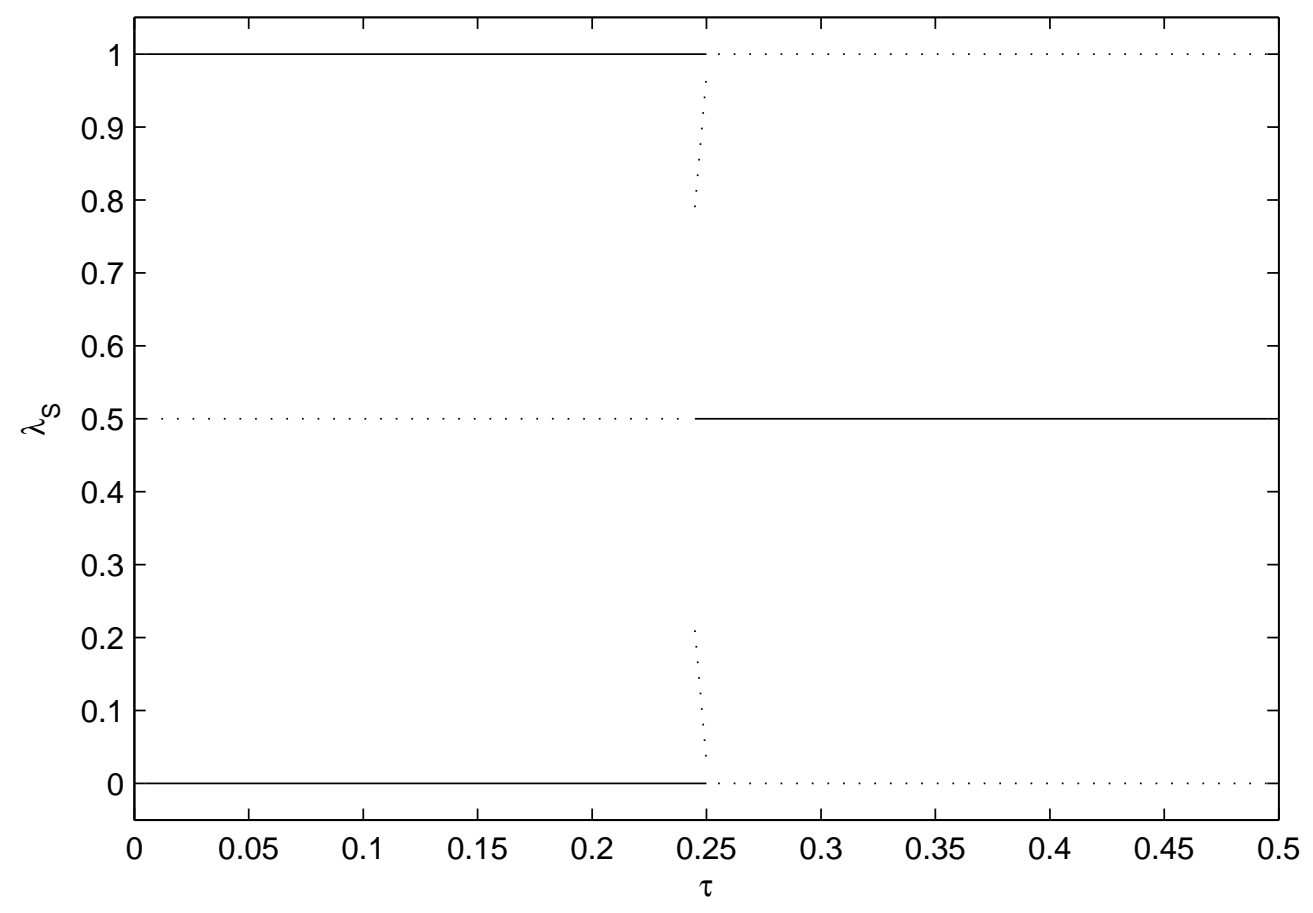

Figure $6 \mu(0.3)$ : Bifurcation with mobile skilled labor, $\mu=0.3$, and $\lambda_{L}=0.5$. 


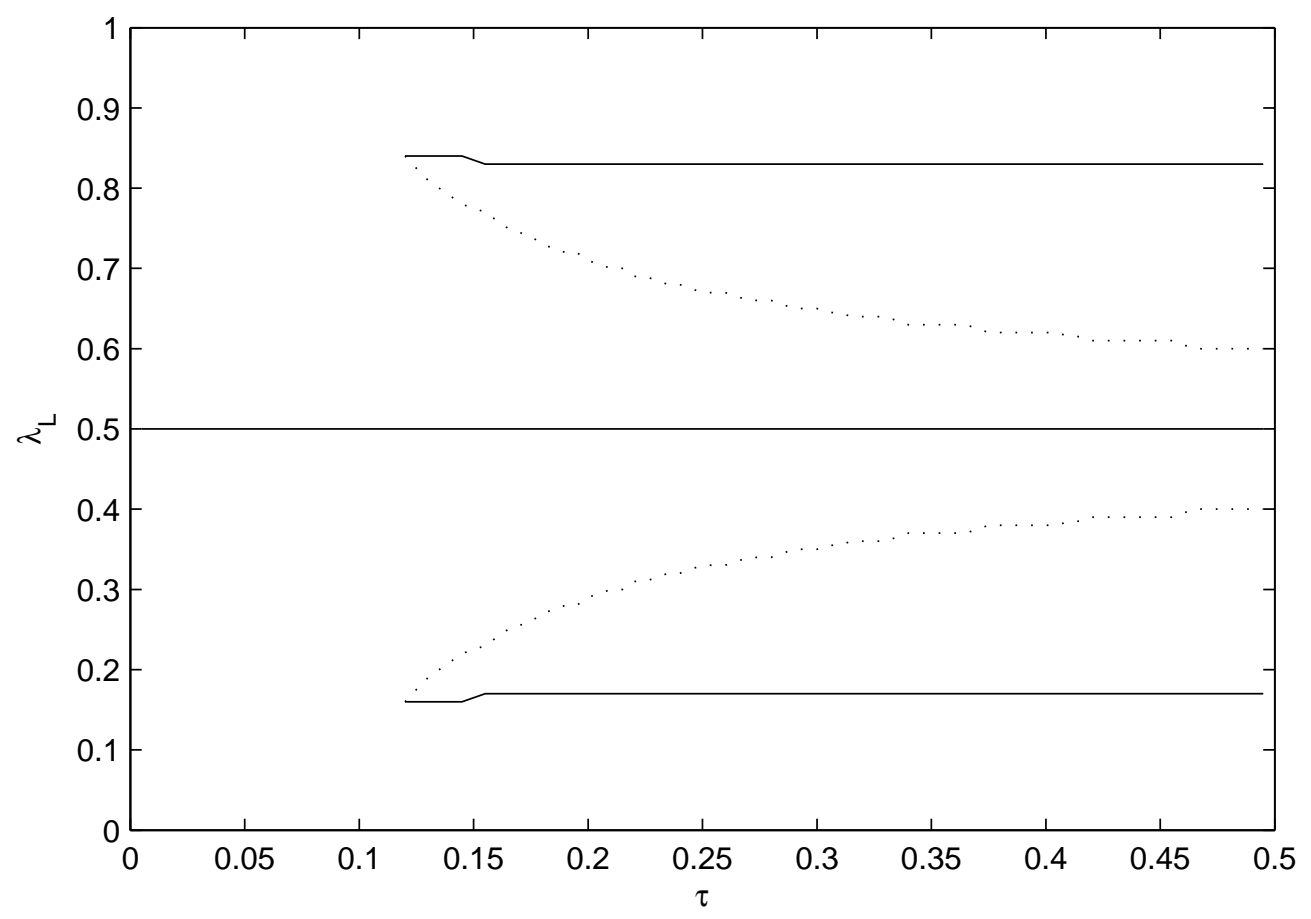

Figure $3 \mu(0.5)$ : Bifurcation with mobile unskilled labor, $\mu=0.5$, and $\lambda_{S}=0.5$.

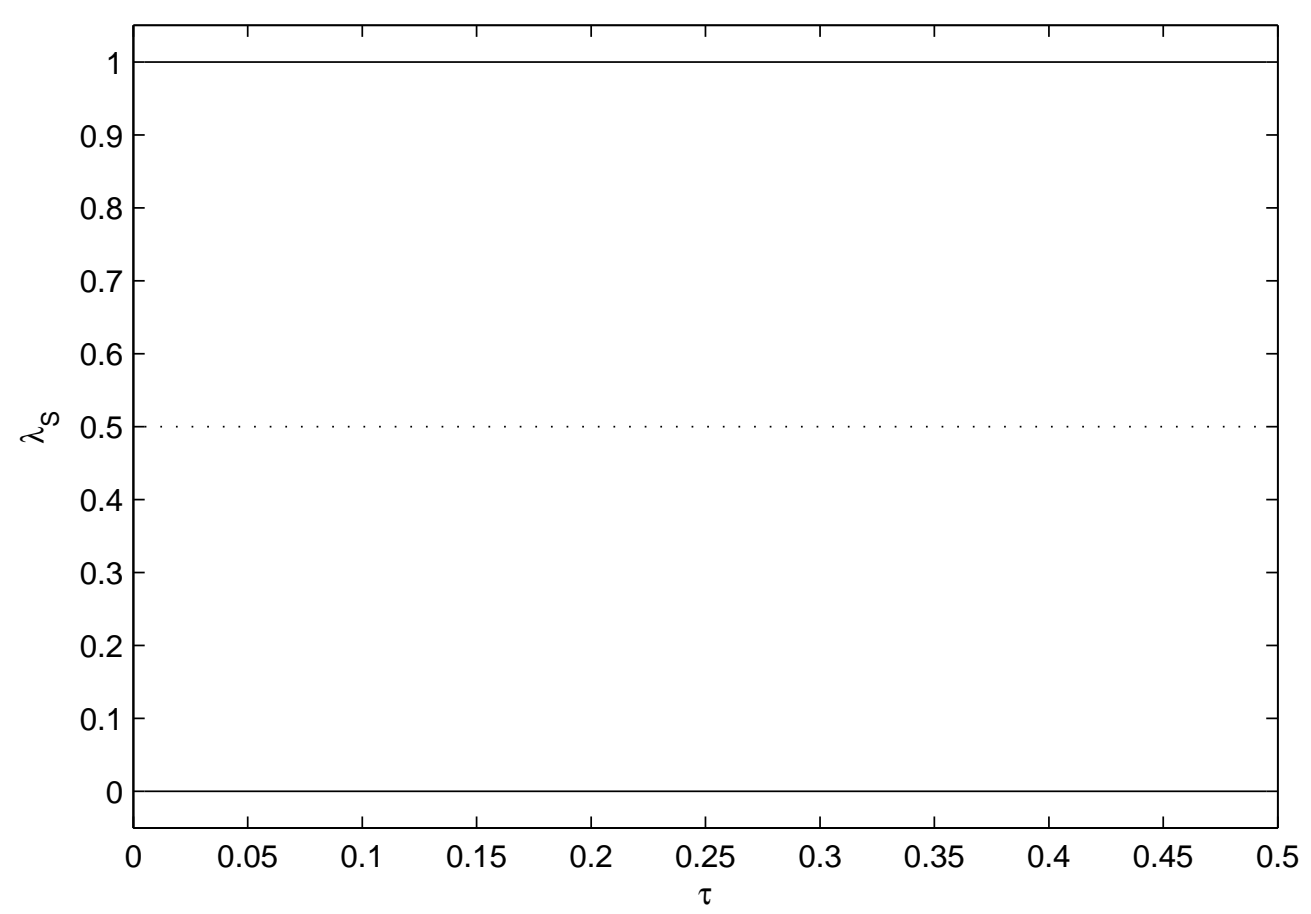

Figure $6 \mu(0.5)$ : Bifurcation with mobile skilled labor, $\mu=0.5$, and $\lambda_{L}=0.5$. 


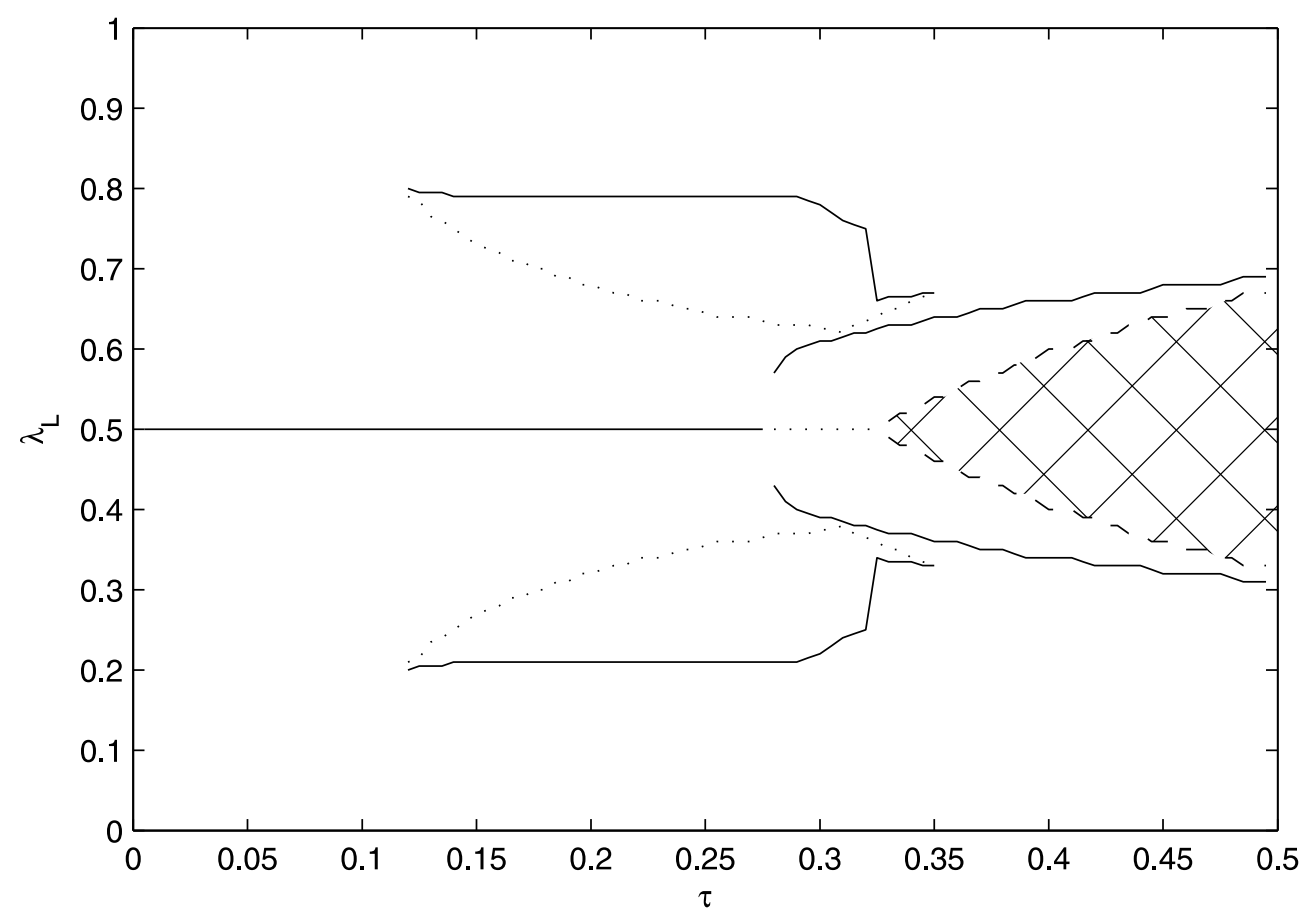

Figure $3 \mu(0.7)$ : Bifurcation with mobile unskilled labor, $\mu=0.7$, and $\lambda_{S}=0.5$.

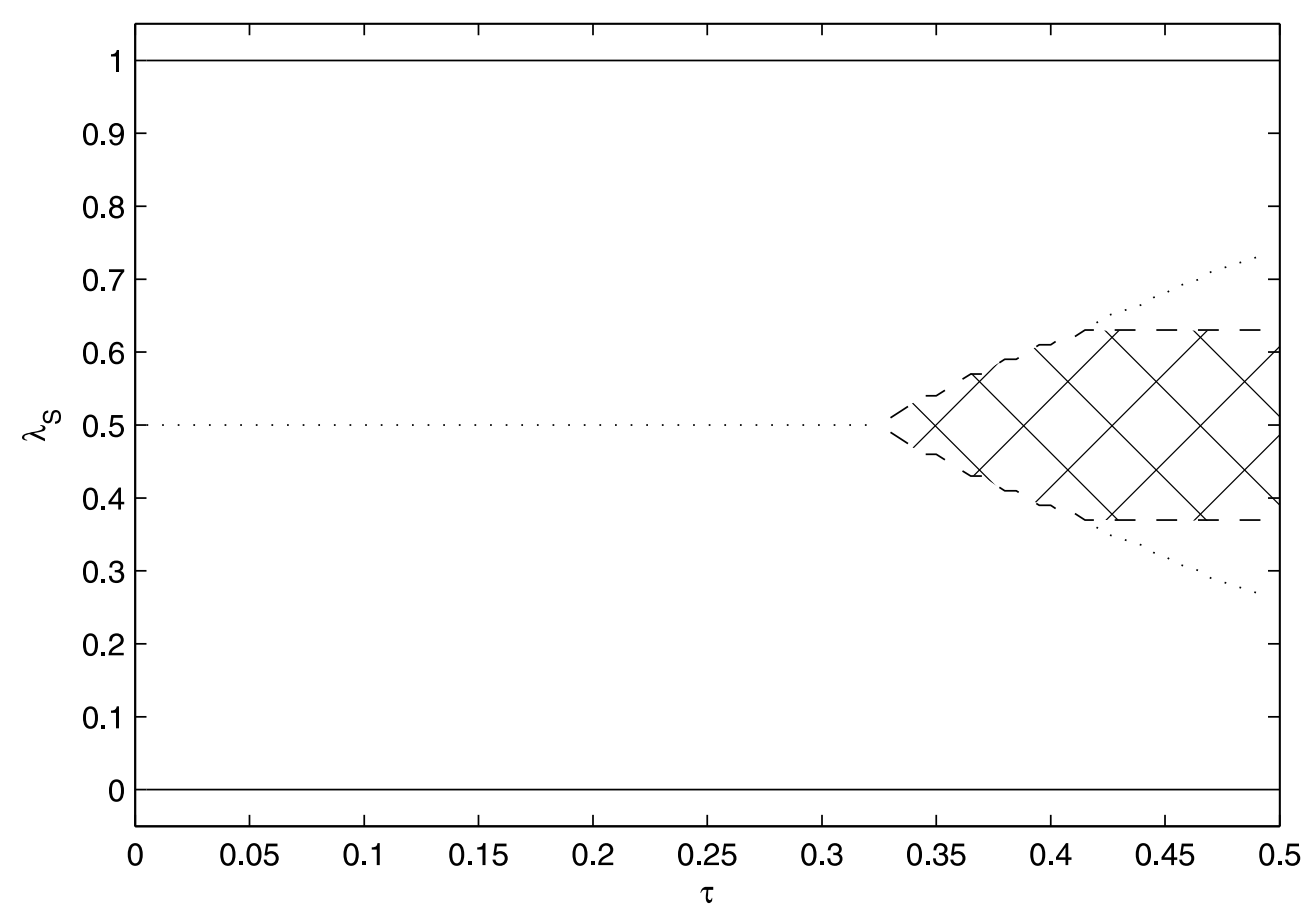

Figure $6 \mu(0.7)$ : Bifurcation with mobile skilled labor, $\mu=0.7$, and $\lambda_{L}=0.5$. 


\section{S3.2 Alternative Values of $\rho$}

We continue by analyzing the effects of a change of $\rho$, the substitutability between the two input factors in the production of manufactures. First, we change $\rho$ from -1 to -5 (i.e., the technical rate of substitution falls from $1 / 2$ to $1 / 6$.). The lower substitutability between skilled and unskilled labor causes skilled labor to become more expensive. Thus, setting up MNEs becomes less attractive and, therefore, the equilibrium area with only horizontal MNEs gets smaller and only exists at higher values of transport costs (see Figures $3 \rho(-5)$ and $6 \rho(-5)$ ). Moreover, the spreading equilibrium remains stable for a relatively wide range of transport costs in case of unskilled labor mobility $(\tau \lesssim 0.19)$. Both partially agglomerated equilibria remain stable for a wide range of transport costs.

Lowering $\rho$ even further to -20 (i.e., changing the technical rate of substitution to $1 / 21$ ), renders it even more difficult to substitute production factors, which intensifies the pattern described above. The equilibrium area with only horizontal MNEs becomes even smaller (both in terms of $\tau$ and $\lambda$ ), and the partially agglomerated equilibria exist for a wider range of transport costs, since especially horizontal MNEs become less attractive. The spreading equilibrium in case of unskilled labor mobility remains stable as long as $\tau \lesssim 0.21$ (see Figures $3 \rho(-20)$ and $6 \rho(-20)$ ).

An increase in the substitutability of production factors in manufacturing (changing $\rho$ from -1 to 0.5 (implying a technical rate of substitution of 2) and 5/6 (which corresponds to a technical rate of substitution of 6 ), respectively, leads to lower factor prices. This makes MNEs ceteris paribus more attractive (see Figures $3 \rho(0.5)$, $3 \rho(5 / 6), 6 \rho(0.5)$ and $6 \rho(5 / 6))$. The higher substitutability increases the equilibrium area with only horizontal MNEs for a larger range of transport costs.

Overall, we can conclude that lower (higher) values of $\rho$ shift the bifurcations to the right (left). 


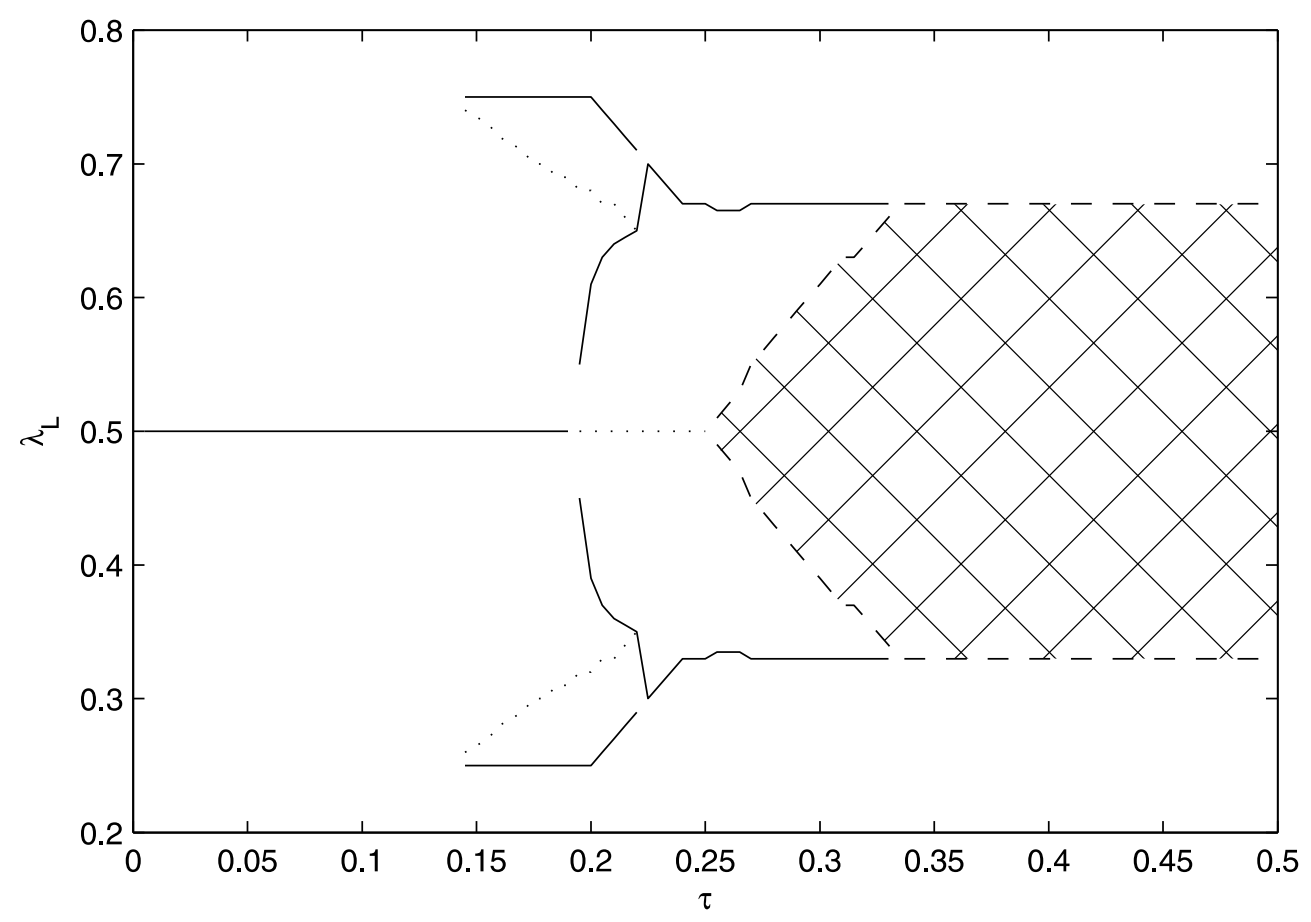

Figure $3 \rho(-5)$ : Bifurcation with mobile unskilled labor, $\rho=-5$, and $\lambda_{S}=0.5$.

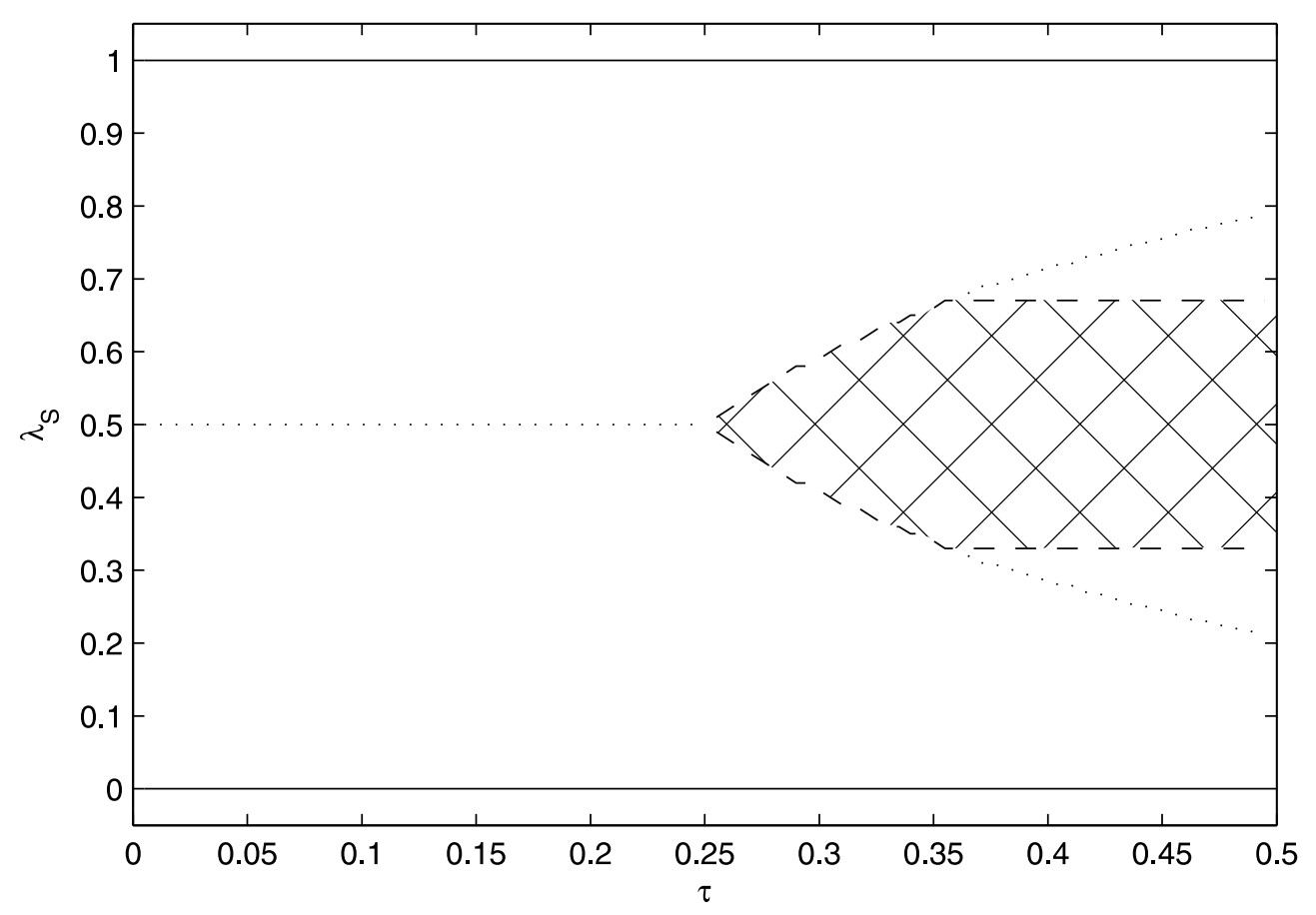

Figure $6 \rho(-5)$ : Bifurcation with mobile skilled labor, $\rho=-5$, and $\lambda_{L}=0.5$. 


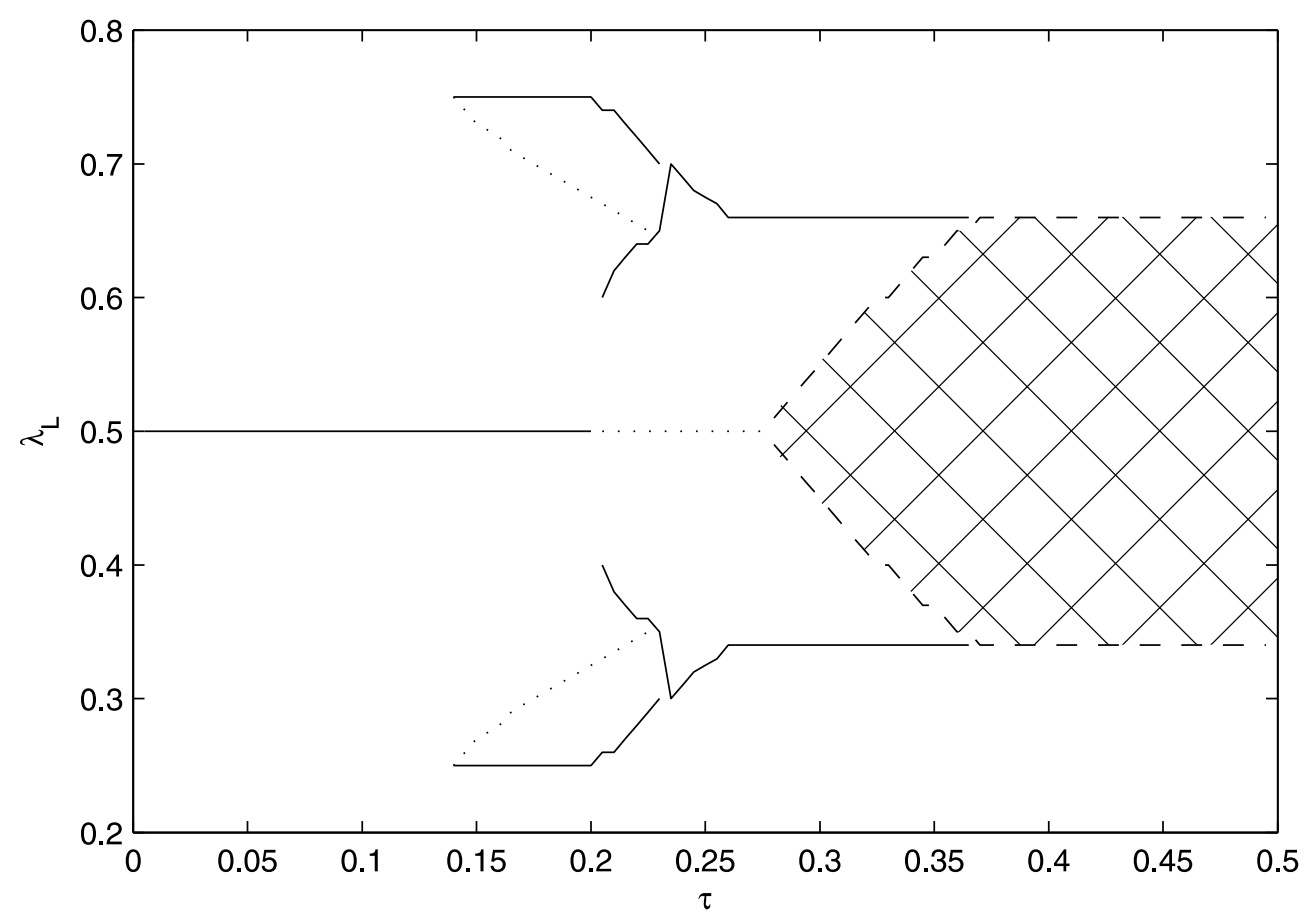

Figure $3 \rho(-20)$ : Bifurcation with mobile unskilled labor, $\rho=-20$, and $\lambda_{S}=0.5$.

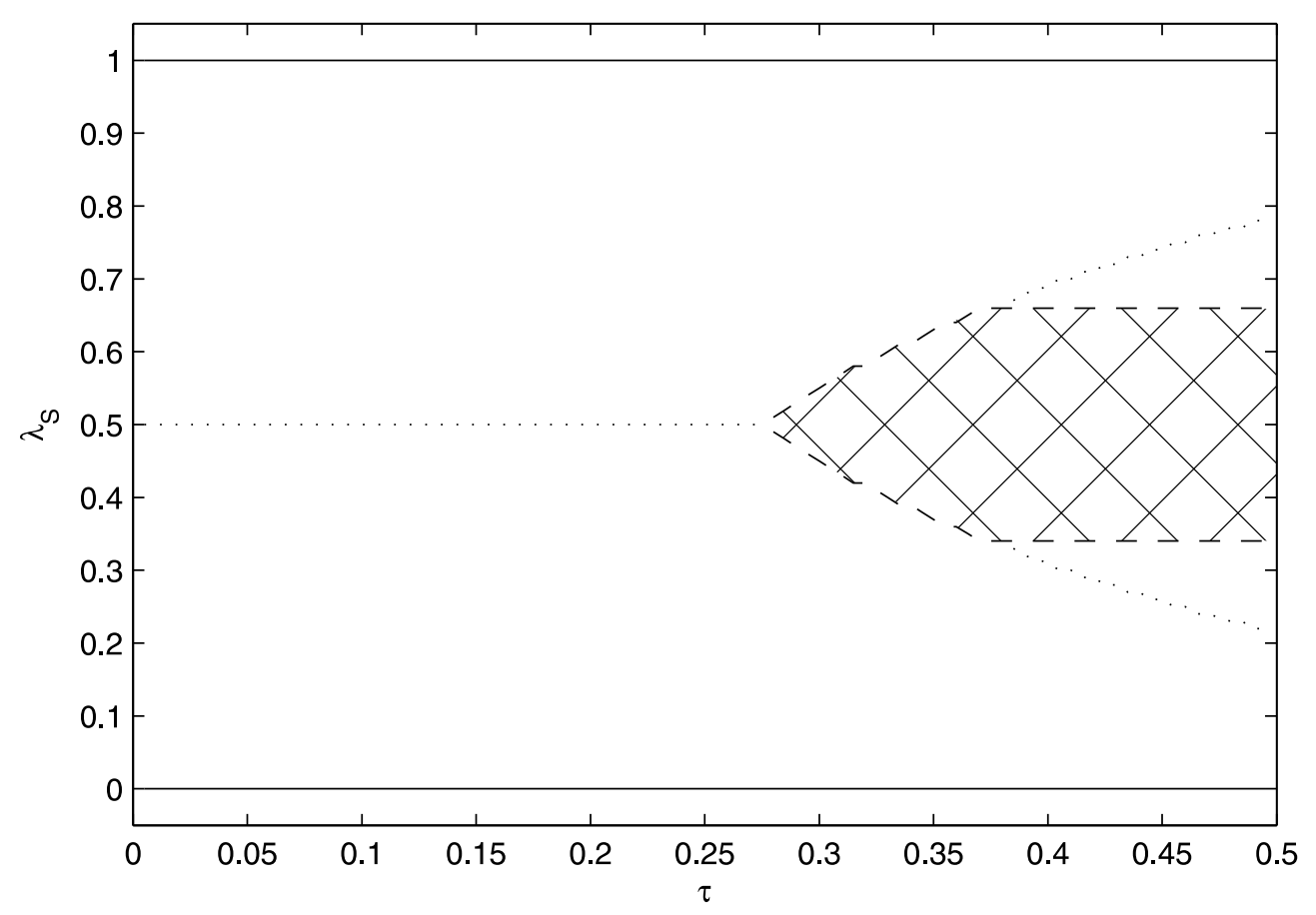

Figure $6 \rho(-20)$ : Bifurcation with mobile skilled labor, $\rho=-20$, and $\lambda_{L}=0.5$. 


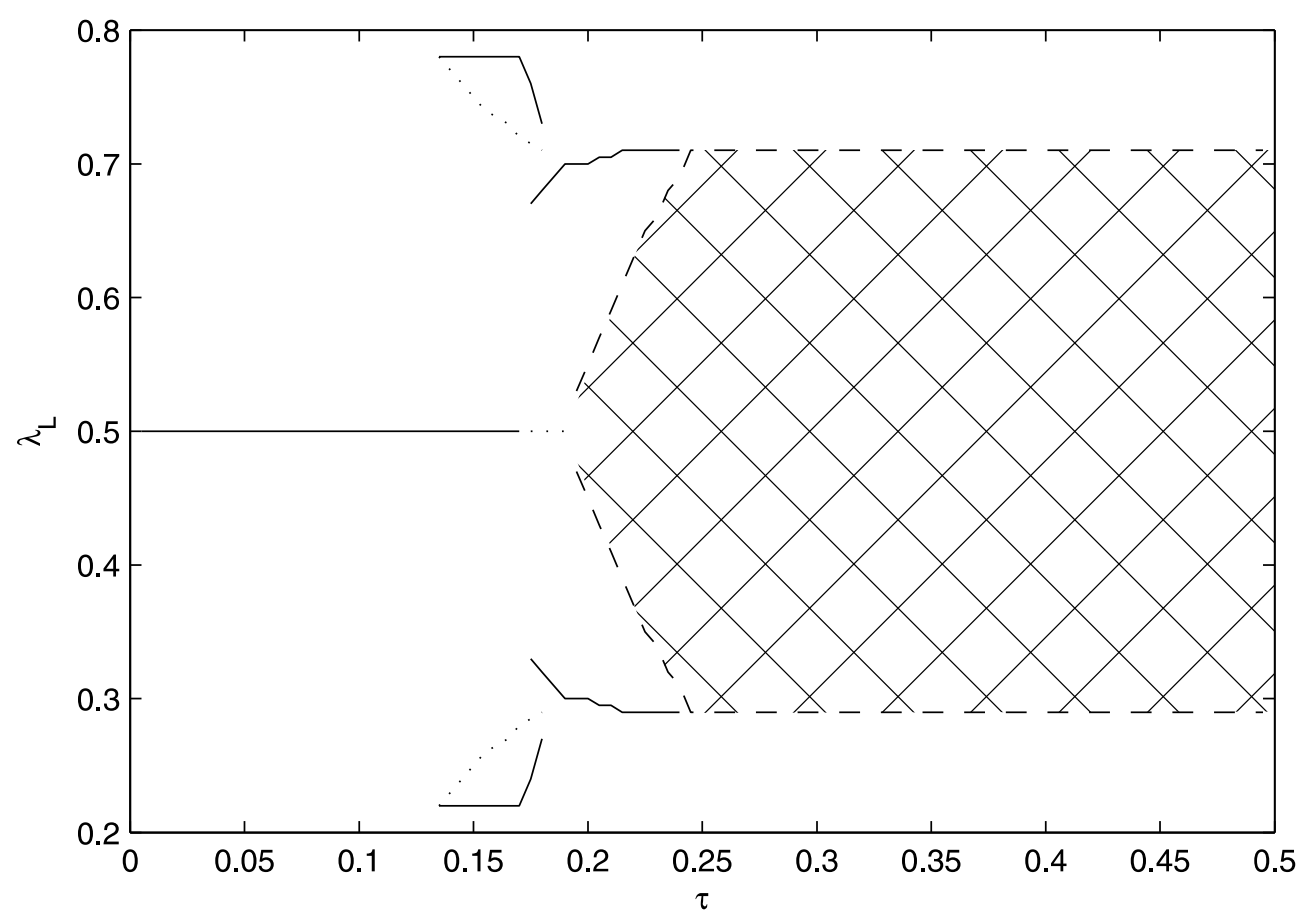

Figure $3 \rho(0.5)$ : Bifurcation with mobile unskilled labor, $\rho=0.5$, and $\lambda_{S}=0.5$.

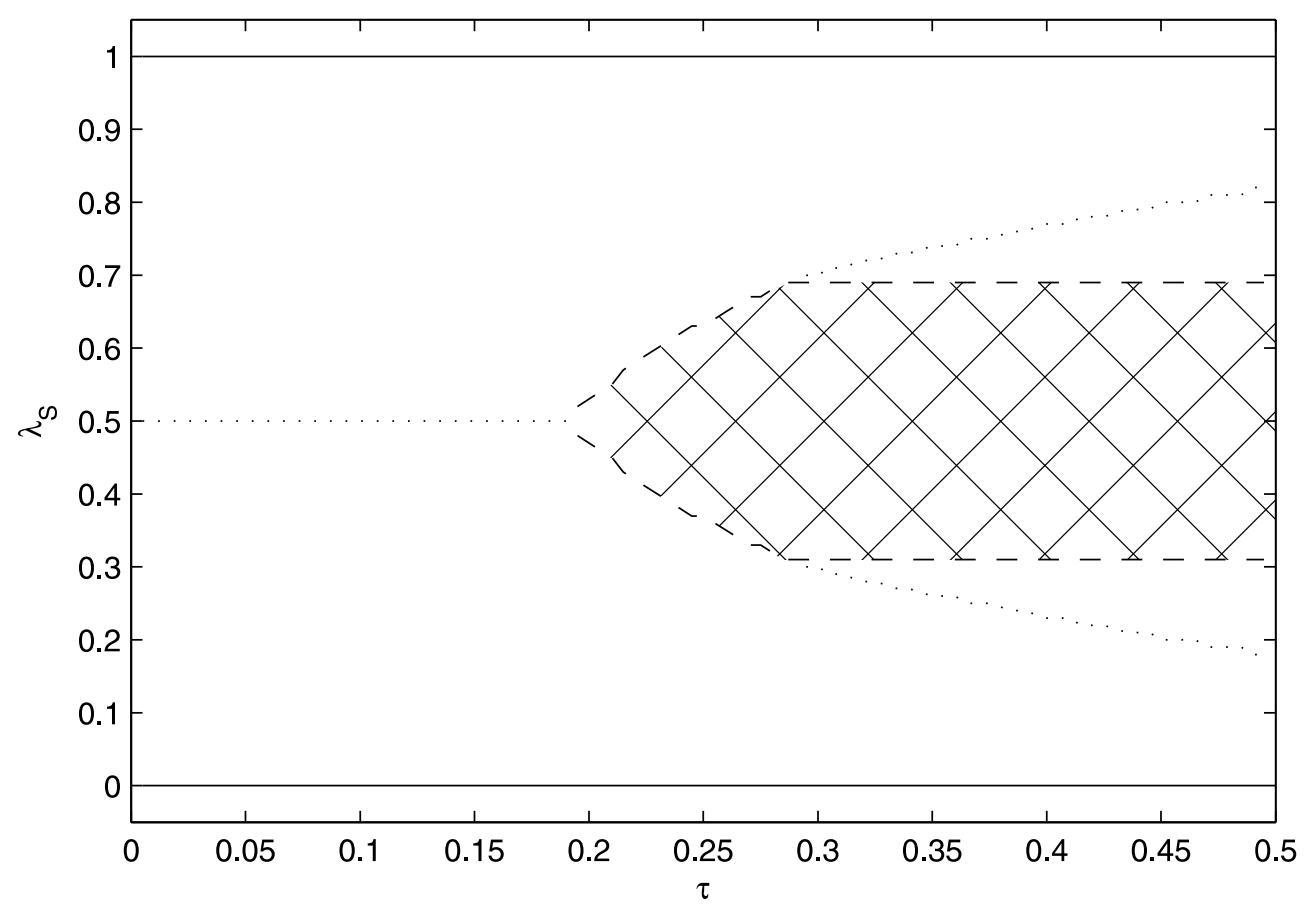

Figure $6 \rho(0.5)$ : Bifurcation with mobile skilled labor, $\rho=0.5$, and $\lambda_{L}=0.5$. 


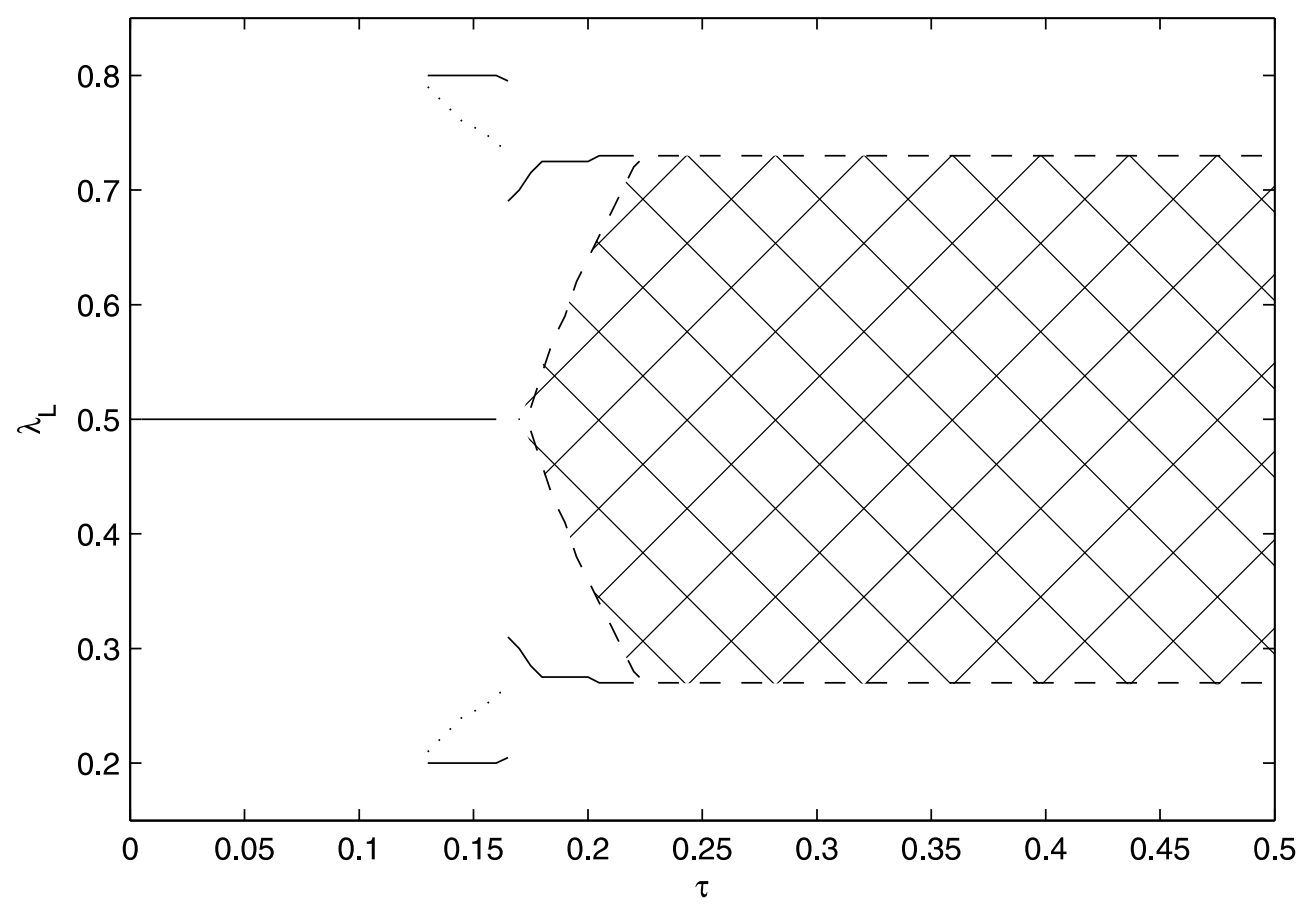

Figure $3 \rho(5 / 6)$ : Bifurcation with mobile unskilled labor, $\rho=5 / 6$, and $\lambda_{S}=0.5$.

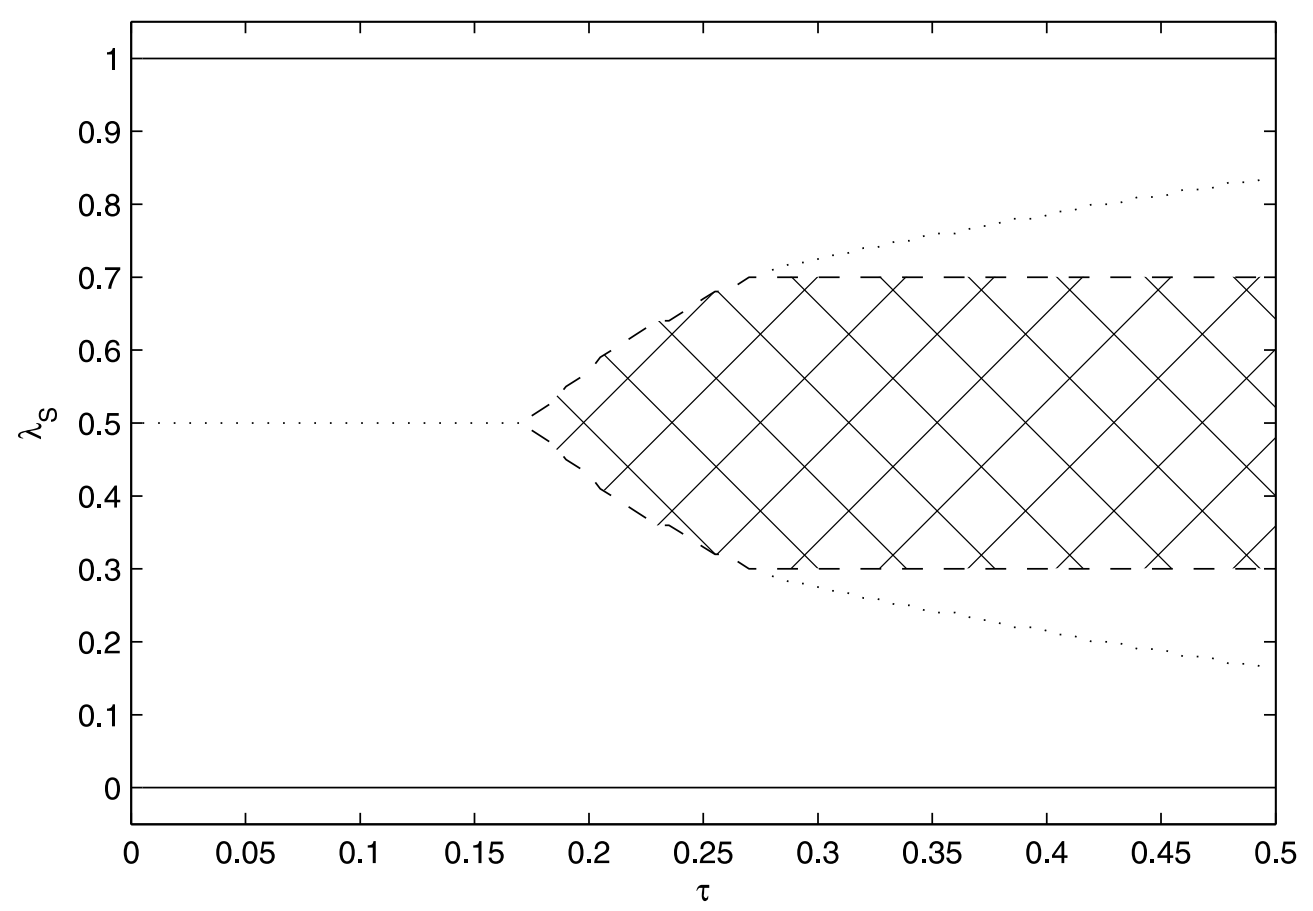

Figure $6 \rho(5 / 6)$ : Bifurcation with mobile skilled labor, $\rho=5 / 6$, and $\lambda_{L}=0.5$. 


\section{S3.3 Alternative Values of $\sigma$}

Lowering the elasticity of substitution between varieties of the manufactured good $(\sigma)$, we find that the equilibrium area with only horizontal MNEs even vanishes (see Figures $3 \sigma(2)-6 \sigma(6))$. This is due to the fact that varieties of the manufactured good are less substitutive. Thus, demand for manufactures is less sensitive to price changes, which renders it less attractive for firms to produce in both countries. This is because the advantage of horizontal MNEs to be able to avoid transport costs diminishes strongly. In other words, transport costs are less important. This is in line with the result of Markusen (2002, p. 116), who finds that the likelihood of horizontal multinational firms rises with the elasticity of substitution.

If unskilled labor is mobile, vertical MNEs become more attractive when gradually lowering $\sigma$. Figure $3 \sigma(6)$ shows a large equilibrium area with horizontal MNEs for a wide range of transport costs, whereas in Figure $3 \sigma(2)$ this area has vanished, and the partially agglomerated equilibria are dominated by vertical MNEs. A long-run stable, symmetric equilibrium persists over the whole range of transport costs, if unskilled labor is mobile and $\sigma$ is sufficiently low (see Figure $3 \sigma(2)$ ).

For skilled labor mobility, we obtain full agglomeration for a all values of transport costs at $\sigma=2$, and the equilibrium area with horizontal MNEs vanishes due to the decline in the advantage of horizontal MNEs to avoid transport costs and the decreased ability of consumers to substitute between varieties of the manufactured good (see Figure $6 \sigma(2)$ ). If the elasticity of substitution between varieties rises (at $\sigma=6$, see Figure $6 \sigma(6))$, the opposite effect occurs and horizontal MNEs are present over a wide range of transport costs (from $\tau \gtrsim 0.12$ ). 


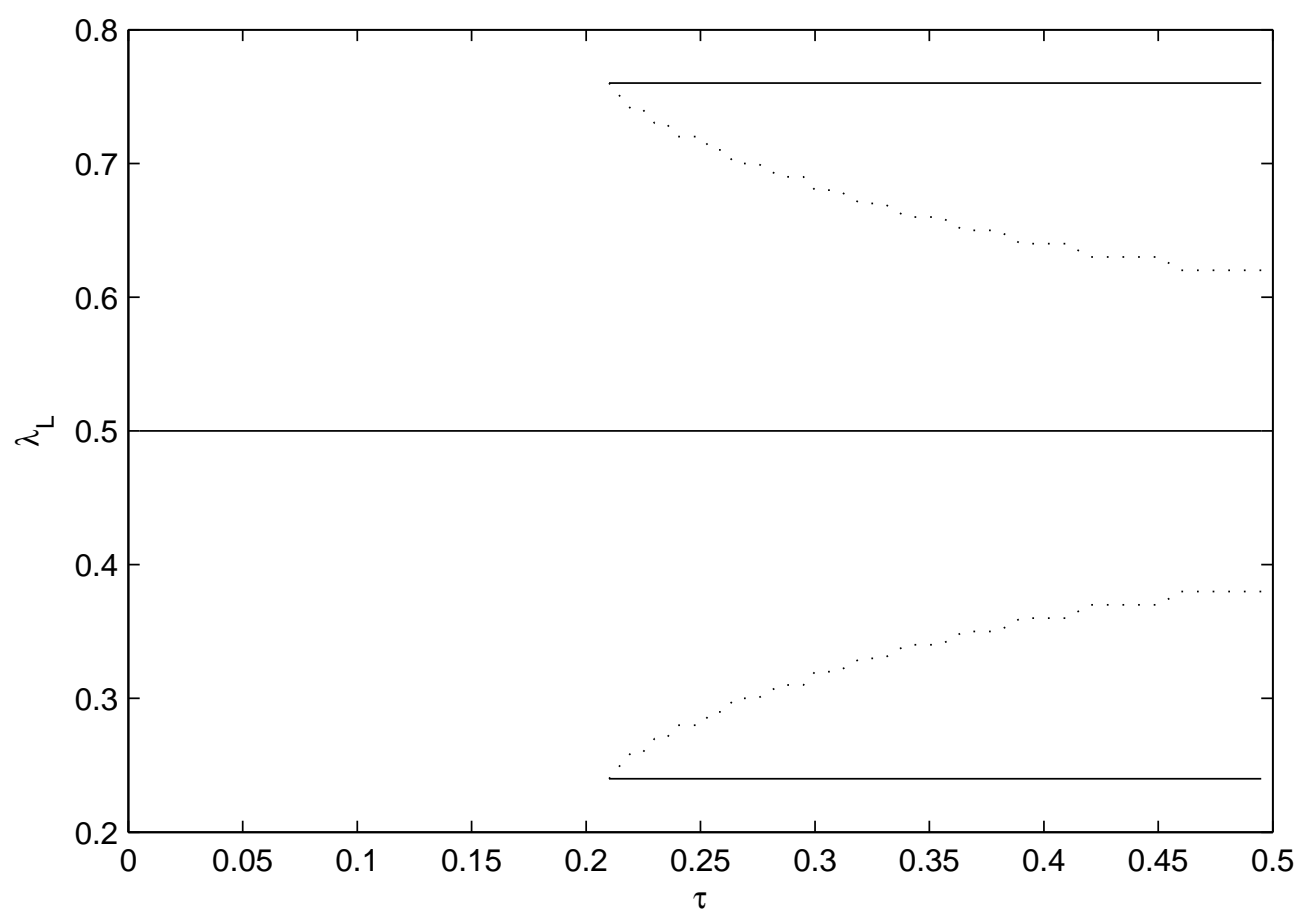

Figure $3 \sigma(2)$ : Bifurcation with mobile unskilled labor, $\sigma=2$, and $\lambda_{S}=0.5$.

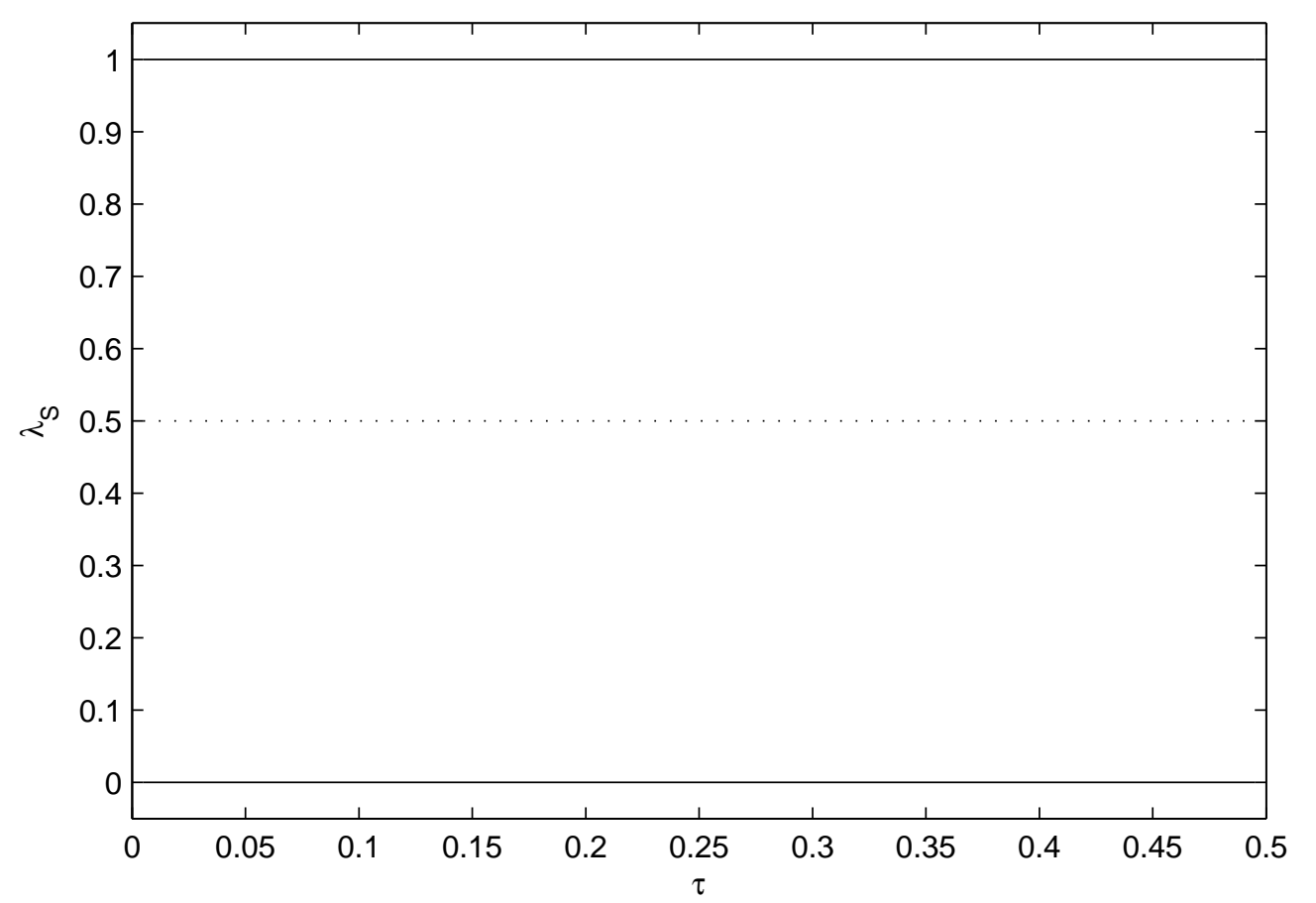

Figure $6 \sigma(2)$ : Bifurcation with mobile skilled labor, $\sigma=2$, and $\lambda_{L}=0.5$. 


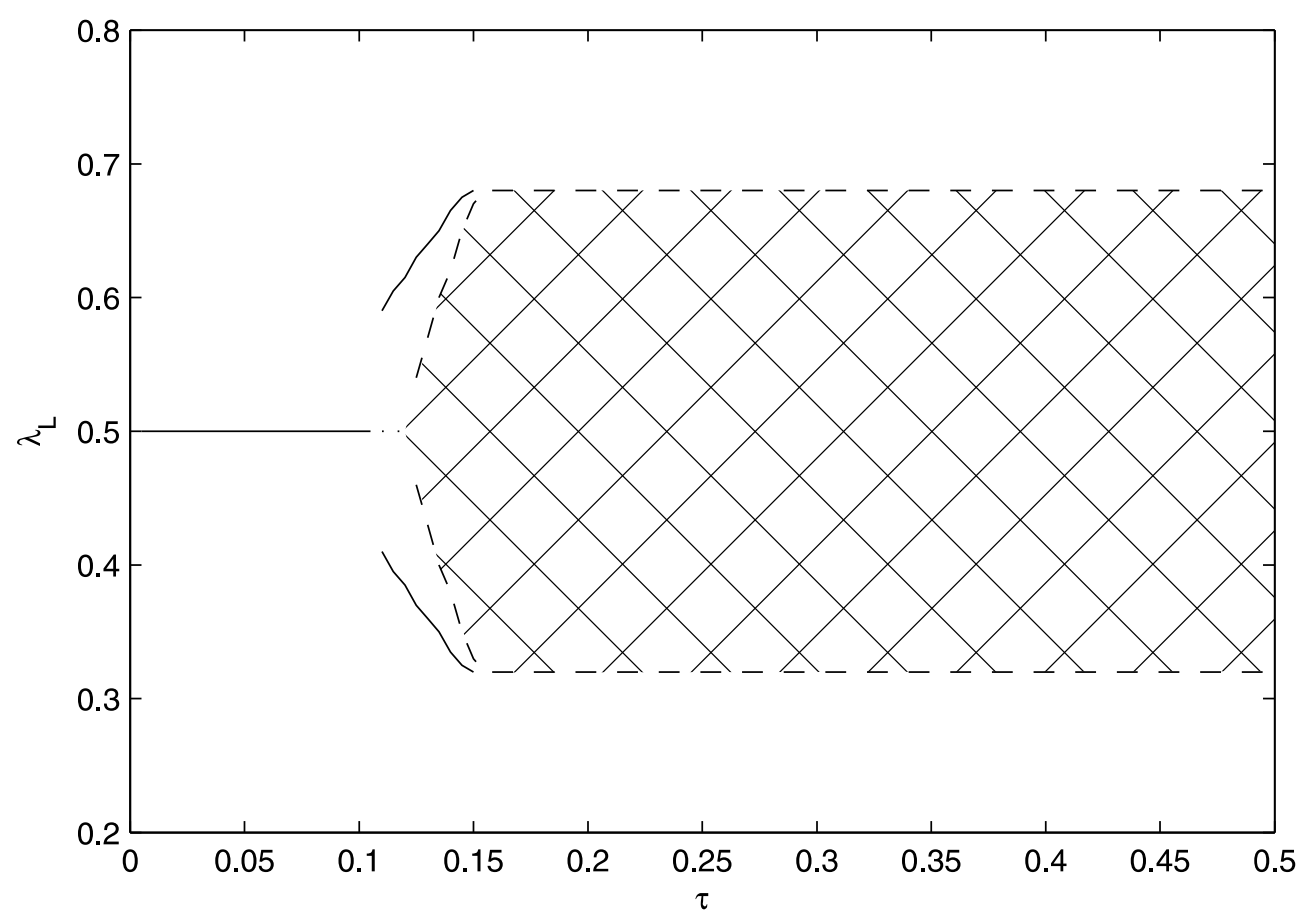

Figure $3 \sigma(6)$ : Bifurcation with mobile unskilled labor, $\sigma=6$, and $\lambda_{S}=0.5$.

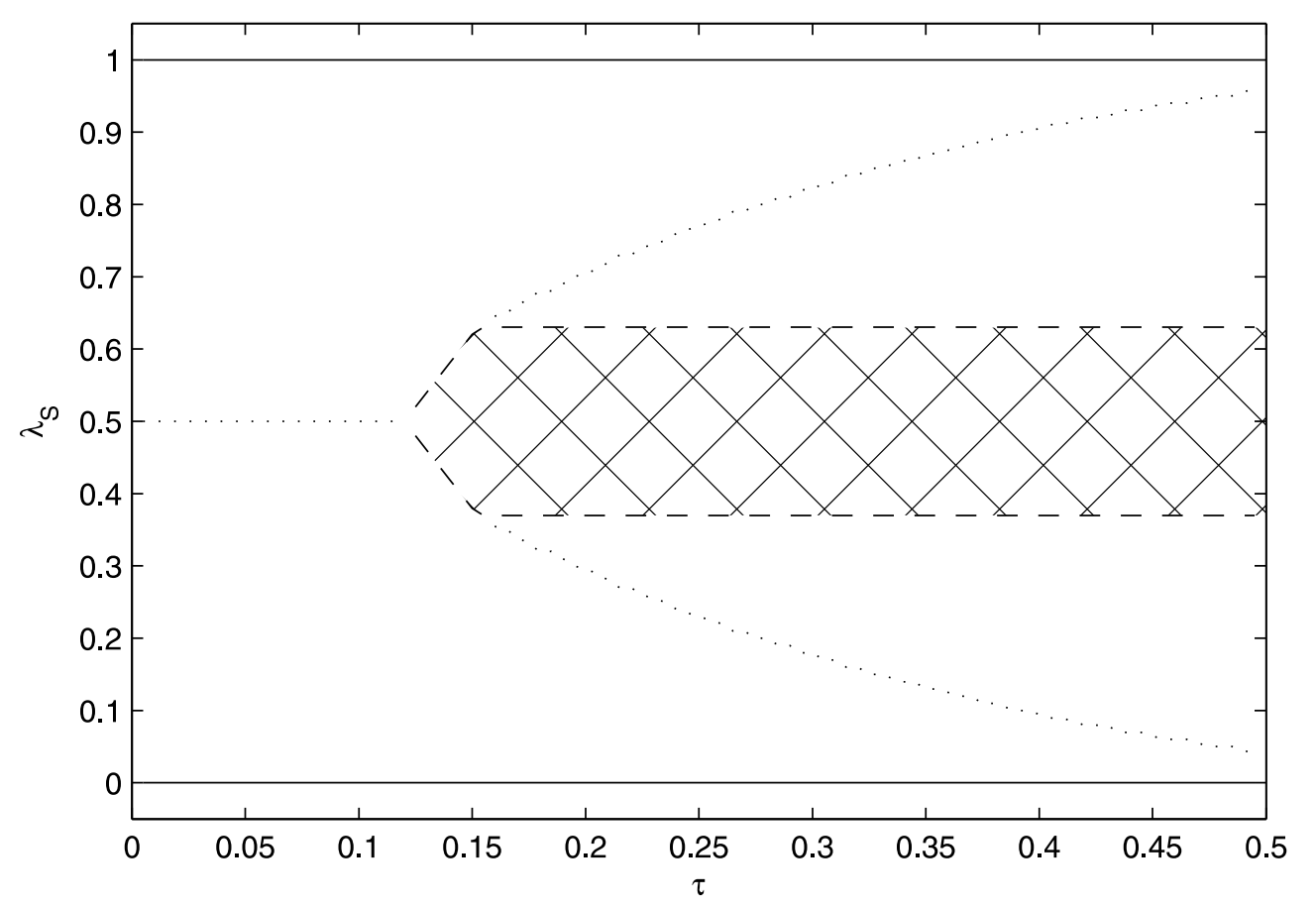

Figure $6 \sigma(6)$ : Bifurcation with mobile skilled labor, $\sigma=6$, and $\lambda_{L}=0.5$. 


\section{S3.4 Asymmetric Endowment with the Immobile Factor}

Finally, we analyze changes in the agglomeration patterns due to asymmetric endowments with the immobile factor across countries. For this, we run experiments for $\lambda_{S}=0.4$ at unskilled labor mobility, and $\lambda_{L}=0.4$ at skilled labor mobility. ${ }^{2}$ The resulting core-periphery patterns are depicted in Figures $3 \lambda_{S}$ and $6 \lambda_{L}$.

In case of unskilled labor mobility (see Figure $3 \lambda_{S}$ ), stable equilibria occur only if country $i$ is rather small in terms of its unskilled labor endowment. We find a partially agglomerated equilibrium for a wide range of transport costs $(0.005 \lesssim \tau \lesssim$ 0.45) where NEs and vertical MNEs dominate. The equilibrium area with horizontal MNEs arises at higher transport costs $(\tau \gtrsim 0.24)$

If skilled labor is mobile (see Figure $6 \lambda_{L}$ ), we find that country $i$ generally ends up as the larger country due to is relative skilled labor abundance in the stable equilibria. This makes it attractive especially for MNEs to set up their headquarters in $i$. Note that the partially agglomerated equilibrium now occurs at high values of $\lambda_{S}$

$\left(0.87 \lesssim \lambda_{S} \lesssim 0.98\right)$ as compared to the case of unskilled labor mobility in Figure $3 \lambda_{S}$, where this equilibrium occurs at $0.19 \lesssim \lambda_{L} \lesssim 0.22$. Again, horizontal MNEs dominate at higher values of transport costs (see the equilibrium area in Figure $6 \lambda_{L}$ ), whereas vertical MNEs are less important, as it is the case in our reference scenario in the paper.

\footnotetext{
${ }^{2}$ Again, we consider country $i$ as the immobile factor scarce one.
} 


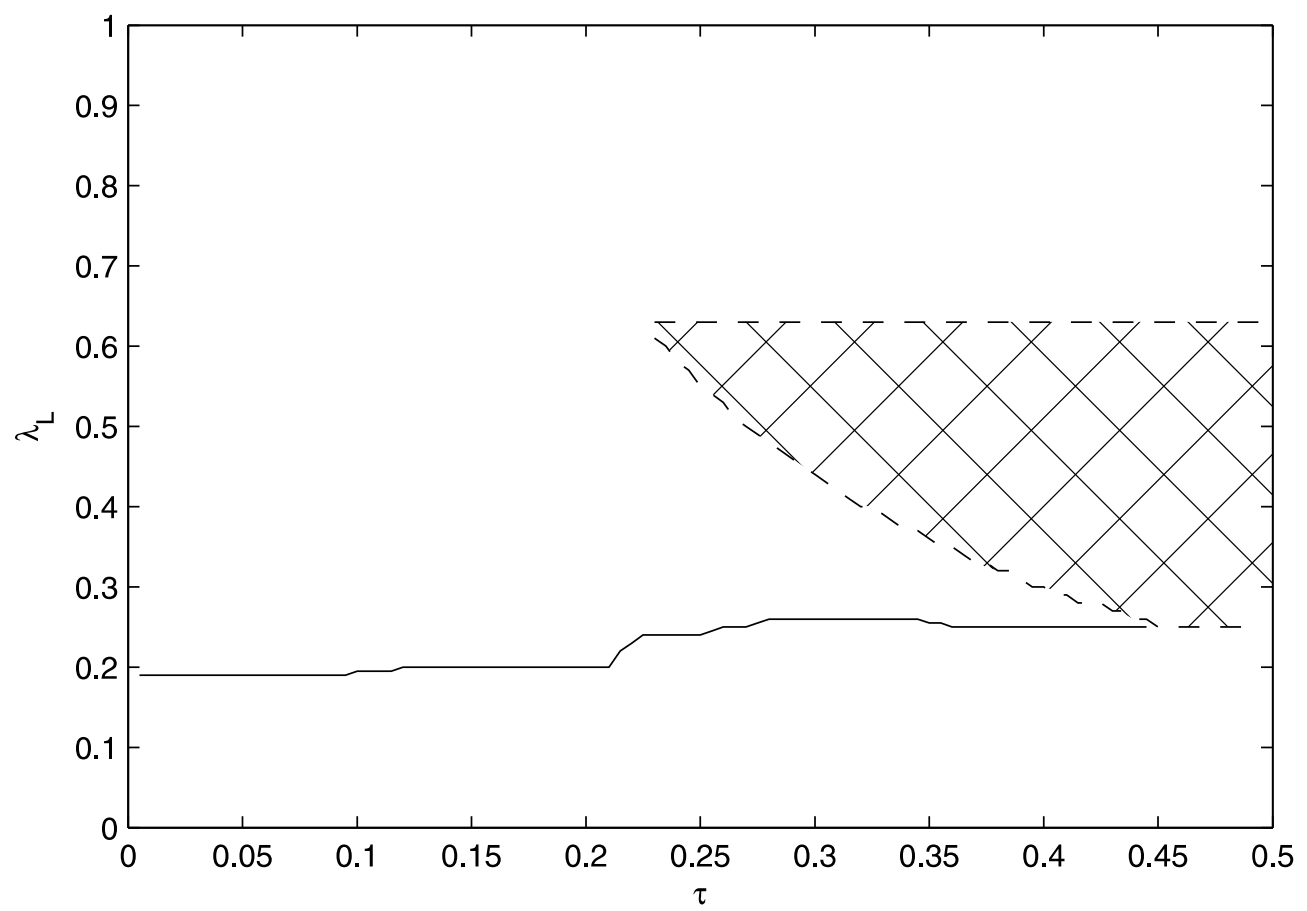

Figure $3 \lambda_{S}$ : Bifurcation with mobile unskilled labor, and $\lambda_{S}=0.4$.

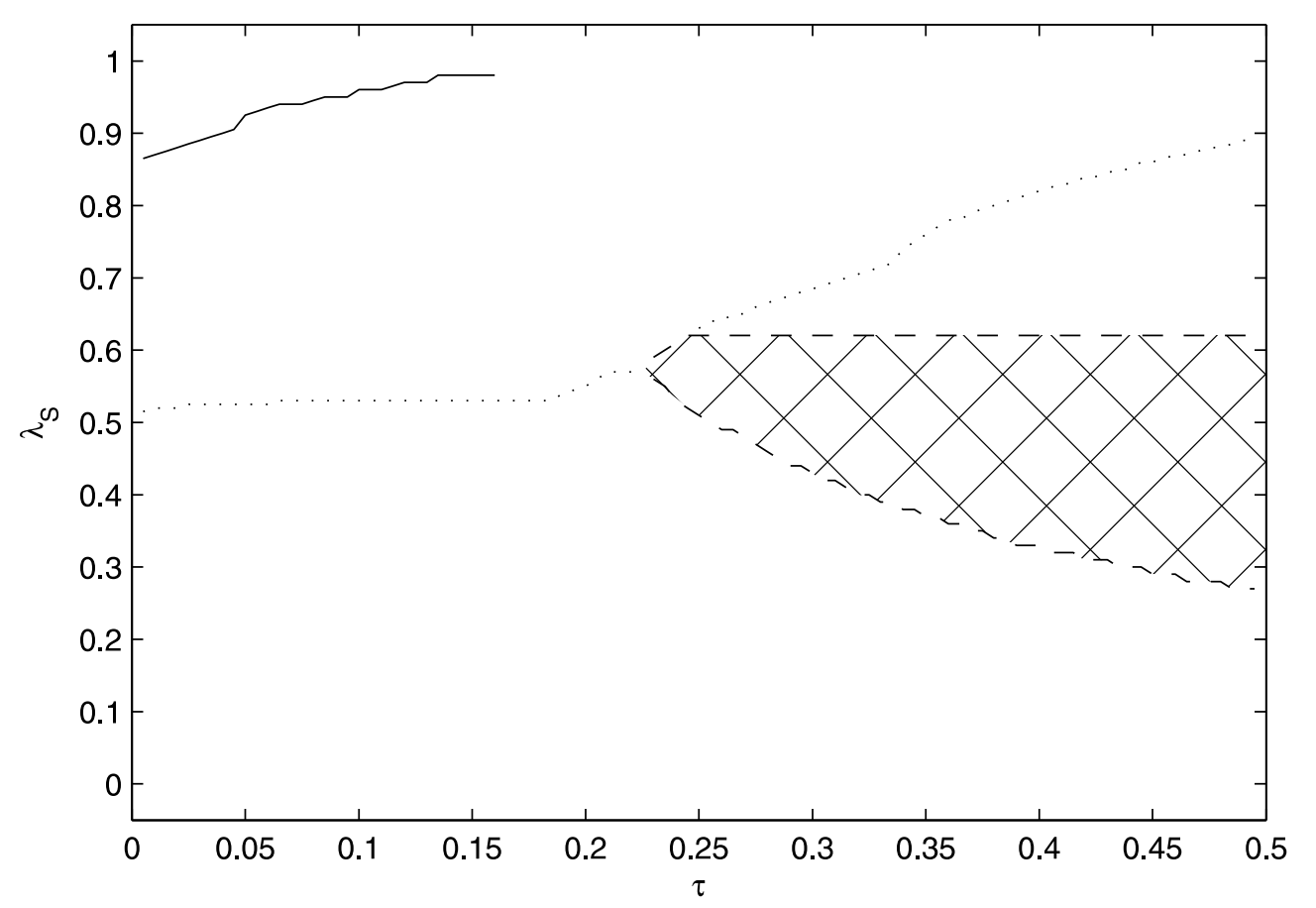

Figure $6 \lambda_{L}$ : Bifurcation with mobile skilled labor, and $\lambda_{L}=0.4$. 


\section{S4 References}

Ekholm, K., Forslid, R. (2001), Trade and Location with Horizontal and Vertical Multi-region-Firms, Scandinavian Journal of Economics 103(1), pp. 101-18.

Krugman, P. (1991b), Increasing Returns and Economic Geography, Journal of Political Economy 99(31), pp. 483-99.

Markusen, J.R. (2002), Multinational Firms and the Theory of International Trade, The MIT Press, Cambridge, Massachusetts.

Raybaudi-Massilia, M. (2000), Economic Geography and Multinational Enterprise, Review of International Economics 8(1), pp. 1-19. 


\title{
CESifo Working Paper Series
}

\author{
(for full list see www.cesifo.de)
}

1370 András Simonovits, Designing Benefit Rules for Flexible Retirement with or without Redistribution, December 2004

1371 Antonis Adam, Macroeconomic Effects of Social Security Privatization in a Small Unionized Economy, December 2004

1372 Andrew Hughes Hallett, Post-Thatcher Fiscal Strategies in the U.K.: An Interpretation, December 2004

1373 Hendrik Hakenes and Martin Peitz, Umbrella Branding and the Provision of Quality, December 2004

1374 Sascha O. Becker, Karolina Ekholm, Robert Jäckle and Marc-Andreas Mündler, Location Choice and Employment Decisions: A Comparison of German and Swedish Multinationals, January 2005

1375 Christian Gollier, The Consumption-Based Determinants of the Term Structure of Discount Rates, January 2005

1376 Giovanni Di Bartolomeo, Jacob Engwerda, Joseph Plasmans, Bas van Aarle and Tomasz Michalak, Macroeconomic Stabilization Policies in the EMU: Spillovers, Asymmetries, and Institutions, January 2005

1377 Luis H. R. Alvarez and Erkki Koskela, Progressive Taxation and Irreversible Investment under Uncertainty, January 2005

1378 Theodore C. Bergstrom and John L. Hartman, Demographics and the Political Sustainability of Pay-as-you-go Social Security, January 2005

1379 Bruno S. Frey and Margit Osterloh, Yes, Managers Should Be Paid Like Bureaucrats, January 2005

1380 Oliver Hülsewig, Eric Mayer and Timo Wollmershäuser, Bank Loan Supply and Monetary Policy Transmission in Germany: An Assessment Based on Matching Impulse Responses, January 2005

1381 Alessandro Balestrino and Umberto Galmarini, On the Redistributive Properties of Presumptive Taxation, January 2005

1382 Christian Gollier, Optimal Illusions and Decisions under Risk, January 2005

1383 Daniel Mejía and Marc St-Pierre, Unequal Opportunities and Human Capital Formation, January 2005 
1384 Luis H. R. Alvarez and Erkki Koskela, Optimal Harvesting under Resource Stock and Price Uncertainty, January 2005

1385 Ruslan Lukach, Peter M. Kort and Joseph Plasmans, Optimal R\&D Investment Strategies with Quantity Competition under the Threat of Superior Entry, January 2005

1386 Alfred Greiner, Uwe Koeller and Willi Semmler, Testing Sustainability of German Fiscal Policy. Evidence for the Period 1960 - 2003, January 2005

1387 Gebhard Kirchgässner and Tobias Schulz, Expected Closeness or Mobilisation: Why Do Voters Go to the Polls? Empirical Results for Switzerland, 1981 - 1999, January 2005

1388 Emanuele Bacchiocchi and Alessandro Missale, Managing Debt Stability, January 2005

1389 Assar Lindbeck and Dirk Niepelt, Improving the SGP: Taxes and Delegation rather than Fines, January 2005

1390 James J. Heckman and Dimitriy V. Masterov, Skill Policies for Scotland, January 2005

1391 Emma Galli \& Fabio Padovano, Sustainability and Determinants of Italian Public Deficits before and after Maastricht, January 2005

1392 Angel de la Fuente and Juan Francisco Jimeno, The Private and Fiscal Returns to Schooling and the Effect of Public Policies on Private Incentives to Invest in Education: A General Framework and Some Results for the EU, January 2005

1393 Juan C. Conesa and Carlos Garriga, Optimal Response to a Demographic Shock, January 2005

1394 Christian Gollier, Optimal Portfolio Management for Individual Pension Plans, February 2005

1395 Ruslan Lukach, Joseph Plasmans and Peter M. Kort, Innovation Strategies in a Competitive Dynamic Setting, February 2005

1396 Gebhard Kirchgässner, (Why) Are Economists Different?, February 2005

1397 Marko Köthenbürger, Panu Poutvaara and Paola Profeta, Why are More Redistributive Social Security Systems Smaller? A Median Voter Approach, February 2005

1398 Gabrielle Demange, Free Choice of Unfunded Systems: A First Assessment, February 2005

1399 Carlos Fonseca Marinheiro, Sustainability of Portuguese Fiscal Policy in Historical Perspective, February 2005

1400 Roel M. W. J. Beetsma and Koen Vermeylen, The Effect of Monetary Unification on Public Debt and its Real Return, February 2005 
1401 Frank Asche, Petter Osmundsen and Maria Sandsmark, Is It All Oil?, February 2005

1402 Giacomo Corneo, Media Capture in a Democracy: The Role of Wealth Concentration, February 2005

1403 A. Lans Bovenberg and Thijs Knaap, Ageing, Funded Pensions and the Dutch Economy, February 2005

1404 Thiess Büttner, The Incentive Effect of Fiscal Equalization Transfers on Tax Policy, February 2005

1405 Luisa Fuster, Ayşe İmrohoroğlu and Selahattin İmrohoroğlu, Personal Security Accounts and Mandatory Annuitization in a Dynastic Framework, February 2005

1406 Peter Claeys, Policy Mix and Debt Sustainability: Evidence from Fiscal Policy Rules, February 2005

1407 James M. Malcomson, Supplier Discretion over Provision: Theory and an Application to Medical Care, February 2005

1408 Thorvaldur Gylfason, Interview with Assar Lindbeck, February 2005

1409 Christian Gollier, Some Aspects of the Economics of Catastrophe Risk Insurance, February 2005

1410 Gebhard Kirchgässner, The Weak Rationality Principle in Economics, February 2005

1411 Carlos José Fonseca Marinheiro, Has the Stability and Growth Pact Stabilised? Evidence from a Panel of 12 European Countries and Some Implications for the Reform of the Pact, February 2005

1412 Petter Osmundsen, Frank Asche, Bård Misund and Klaus Mohn, Valuation of International Oil Companies -The RoACE Era, February 2005

1413 Gil S. Epstein and Shmuel Nitzan, Lobbying and Compromise, February 2005

1414 Marcel F. M. Canoy, Jan C. van Ours and Frederick van der Ploeg, The Economics of Books, February 2005

1415 Eric A. Hanushek and Ludger Wößmann, Does Educational Tracking Affect Performance and Inequality? Differences-in-Differences Evidence across Countries, February 2005

1416 George Kapetanios and M. Hashem Pesaran, Alternative Approaches to Estimation and Inference in Large Multifactor Panels: Small Sample Results with an Application to Modelling of Asset Returns, February 2005

1417 Samuel Mühlemann, Jürg Schweri, Rainer Winkelmann and Stefan C. Wolter, A Structural Model of Demand for Apprentices. February 2005 
1418 Giorgio Brunello and Lorenzo Rocco, Educational Standards in Private and Public Schools, February 2005

1419 Alex Bryson, Lorenzo Cappellari and Claudio Lucifora, Why so Unhappy? The Effects of Unionisation on Job Satisfaction, March 2005

1420 Annalisa Luporini, Relative Performance Evaluation in a Multi-Plant Firm, March 2005

1421 Giorgio Bellettini and Carlotta Berti Ceroni, When the Union Hurts the Workers: A Positive Analysis of Immigration Policy, March 2005

1422 Pieter Gautier, Michael Svarer and Coen Teulings, Marriage and the City, March 2005

1423 Ingrid Ott and Stephen J. Turnovsky, Excludable and Non-Excludable Public Inputs: Consequences for Economic Growth, March 2005

1424 Frederick van der Ploeg, Back to Keynes?, March 2005

1425 Stephane Dees, Filippo di Mauro, M. Hashem Pesaran and L. Vanessa Smith, Exploring the International Linkages of the Euro Area: a Global VAR Analysis, March 2005

1426 Hans Pitlik, Friedrich Schneider and Harald Strotmann, Legislative Malapportionment and the Politicization of Germany's Intergovernmental Transfer System, March 2005

1427 Konstantinos Angelopoulos and Apostolis Philippopoulos, The Role of Government in Anti-Social Redistributive Activities, March 2005

1428 Ansgar Belke and Daniel Gros, Asymmetries in the Trans-Atlantic Monetary Policy Relationship: Does the ECB follow the Fed?, March 2005

1429 Sören Blomquist and Luca Micheletto, Optimal Redistributive Taxation when Government's and Agents' Preferences Differ, March 2005

1430 Olof Åslund and Peter Fredriksson, Ethnic Enclaves and Welfare Cultures - QuasiExperimental Evidence, March 2005

1431 Paul De Grauwe, Roberto Dieci and Marianna Grimaldi, Fundamental and NonFundamental Equilibria in the Foreign Exchange Market. A Behavioural Finance Framework, March 2005

1432 Peter Egger, Stefan Gruber, Mario Larch and Michael Pfaffermayr, Knowledge-Capital Meets New Economic Geography, March 2005 